Um problema de corte de peças integrado à programação da produção - uma abordagem por relaxação lagrangiana

Scheila Valechenski Biehl 


\title{
Um problema de corte de peças integrado à programação da produção - uma abordagem por relaxação lagrangiana
}

\author{
Scheila Valechenski Biehl \\ Orientador: Prof. Dr. Marcos Nereu Arenales \\ Dissertação apresentada ao Instituto de Ciências Matemáticas e \\ de Computação - ICMC-USP, como parte dos requisitos para \\ obtenção do título de Mestre em Ciências de Computação e \\ Matemática Computacional.
}

USP - São Carlos

Fevereiro/2008 
"Aos meus pais e a minha avó..." 


\section{Agradecimentos}

A Deus pela minha vida.

Ao Prof. Marcos Nereu Arenales pela orientação, compreensão e acima de tudo pelo apoio que sempre recebi durante o desenvolvimento deste trabalho.

Aos meus pais, Claudio e Regina, e a minha avó Maria Tereza, por sempre terem me apoiado em momentos difíceis, o meu obrigado e amor eterno. Agradeço também minhas irmãs queridas por darem a meus pais a companhia constante que eu não posso oferecer.

Ao meu namorado Juari Junior pela compreensão, pelo apoio e incentivo nas horas mais difíceis, por sempre estar ao meu lado nas horas tristes e alegres e pelo amor incondicional.

Aos meus amigos do laboratório de otimização, Claudia, Edilaine, Tamara, Carla, Victor, Douglas, Aline, Mariah, Kelly, Adriana, Pedro, Lana, pela amizade e momentos vivenciados nas horas de trabalho e também nas horas de descontração.

Às professoras Maristela e Franklina pela convivência e ensinamentos.

À Dona Hilda por ter me acolhido e me oferecido um segundo lar, em companhia das amigas Claudia, Ester, Gabriela, Hérika e Laís.

A todos os funcionários do ICMC por contribuírem direta ou indiretamente durante o período de desenvolvimento deste trabalho.

Ao $\mathrm{CNPq}$ pelo apoio financeiro. 


\section{Resumo}

O problema de planejamento da produção integrado ao problema de corte de estoque surge em várias indústrias de manufatura, tais como indústria de papel, móveis, aço entre outras, e consiste em um problema de otimização combinatória bastante complexo, devido ao fato de integrar dois problemas conhecidos na literatura de difícil resolução. As aplicações práticas deste problema vêm aumentando em muitas empresas que buscam tornar seus processos produtivos mais eficientes. Neste trabalho, estudamos o problema de otimização integrado que surge em pequenas indústrias de móveis, em que placas de MDF disponíveis em estoque devem ser cortadas em itens menores, de diversos tamanhos e quantidades para comporem os produtos demandados. O modelo matemático de otimização linear inteiro proposto permite que alguns produtos sejam antecipados e estocados. Essa antecipação da produção aumenta os custos de estoque, porém com o aumento da demanda de peças é possível gerar padrões de corte melhores e diminuir os custos com a perda de material. Consideramos no modelo dois tipos de variáveis de antecipação, uma de estoque convencional para atender uma demanda em carteira e outra para aproveitar a produção e atender uma demanda prevista, chamada variável oportunista. A função objetivo consiste em minimizar os custos dos processos de produção e de corte. Para resolver a relaxação linear deste problema, propomos um método lagrangiano e utilizamos a estratégia de horizonte rolante. Alguns testes computacionais são realizados e os resultados apresentados.

Palavras-chave: problema integrado de dimensionamento de lotes e corte de estoque, programação da produção em indústrias de móveis, relaxação lagrangiana. 


\section{Abstract}

The integrated problem of cutting stock and production planning arises in a several manufacturing industries, such as paper, furniture, steel among others, and it is a complex combinatorial optimization problem, due to the fact that it integrates two well-known NP problems of the literature. The real world applications of this problem have increased in many industries that search for more efficient production process. In this work, we studied an integrated optimization problem that arises in small furniture industries, where MDF boards available in inventory must be cut into enough quantities of items to compose demanded finish-goods. The model of integer linear optimization proposed allows anticipating some products and keeping them in inventory. This production anticipation makes increase the inventory costs, although makes it possible to determine better cutting patterns and decreases the costs of the cutting process. We consider in the model two types of anticipation variables, the first one to the ordinary inventory to meet ordered products and an other one, called chance variables, to meet a forecasting demand. The objective function is to minimize the costs of production process and waste of material. To solve a linear relaxation of this problem, we proposed lagrangian approach and used a rolling horizon strategy. Some computational tests are performed and results shown.

Keywords: integrated problem of cutting stock and production planning, production planning in the furniture industries, lagrangian relaxation. 


\section{Conteúdo}

1 Introdução 1

2 Revisão Bibliográfica 5

2.1 Introdução . . . . . . . . . . . . . . . . . . . . 5

2.2 Revisão Bibliográfica . . . . . . . . . . . . . . . . . 5

3 Problemas de Dimensionamento de Lotes e de Corte de Estoque 11

3.1 Introdução . . . . . . . . . . . . . . . . . . . . . . . . . . 11

3.2 Problemas de dimensionamento de lotes . . . . . . . . . . . . . . . . . 11

3.2.1 Problemas de dimensionamento de lotes monoestágio . . . . . . . . 12

3.2.2 Problemas de dimensionamento de lotes multiestágio . . . . . . . . 15

3.3 Problemas de Corte de Estoque . . . . . . . . . . . . . . . . 16

3.3.1 Classificação dos Problemas de Corte quanto à Dimensão . . . . . . . 17

3.3.2 Problema de Corte de Estoque Unidimensional . . . . . . . . . . . . 19

3.3.3 Problema de Corte de Estoque Bidimensional . . . . . . . . . . . . 24

3.3.4 Exemplo Numérico . . . . . . . . . . . . . . . . . . . . . 27

4 O Problema Integrado de Dimensionamento de Lotes e Corte de Estoque Bidimensional 30

4.1 Introdução . . . . . . . . . . . . . . . . . . . . . 30

4.2 Características do Setor Moveleiro no Brasil . . . . . . . . . . . . . 30

4.3 Processo Produtivo da Indústria de Móveis . . . . . . . . . . . . . . . . . . 31

4.4 Definição do Problema . . . . . . . . . . . . . . . . . . . 33

4.5 Modelagem Matemática . . . . . . . . . . . . . . . . 35

5 Relaxação Lagrangiana 42

5.1 Introdução . . . . . . . . . . . . . . . . . . . . . . . . 42

5.2 Relaxação Lagrangiana e o Problema Dual Lagrangiano . . . . . . . . . . . 42 
5.3 Método do Subgradiente . . . . . . . . . . . . . . . . . . . 44

6 Resolução do Modelo Integrado por Relaxação Lagrangiana 46

6.1 Relaxação Lagrangiana do Modelo Integrado . . . . . . . . . . . . . . . . . 46

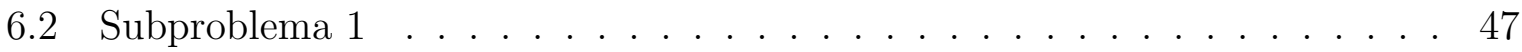

6.3 Subproblema $2 \ldots \ldots \ldots \ldots \ldots \ldots$

7 Testes Computacionais $\quad 73$

7.1 Conjunto de Dados . . . . . . . . . . . . . . . . . . . . . 73

7.2 Resultados da Heurística de Decomposição . . . . . . . . . . . . . . . 76

7.3 Resultados do Modelo Integrado . . . . . . . . . . . . . . . . . . . 82

7.4 Resultados da Relaxação Lagrangiana . . . . . . . . . . . . . . . . . . . . 86

8 Conclusões e Passos Futuros $\quad 90$

A Relações Primais-Duais em Otimização Linear $\quad 93$

Referências Bibliográficas $\quad 94$ 


\section{Lista de Figuras}

1.1 Processo de produção em uma indútria moveleira . . . . . . . . . . . . . 2

1.2 Peças necessárias para compor o produto final "cômoda". . . . . . . . . . 3

3.1 Exemplo de estrutura geral de produtos . . . . . . . . . . . . . . 15

3.2 (a) Barra a ser cortada; (b) Objeto cortado produzindo 4 itens e uma perda. 17

3.3 (a) Placa a ser cortada; (b) Objeto cortado produzindo 8 itens e uma perda. 18

3.4 Caixas empacotadas no contêiner. . . . . . . . . . . . . 18

3.5 Exemplo de padrões de corte unidimensional. . . . . . . . . . . . . . . . 20

3.6 Exemplo de padrão de corte bidimensional guilhotinado. . . . . . . . . . . 25

3.7 Padrão de corte 2-estágios inexato. . . . . . . . . . . . . . . 27

3.8 Problema de corte bidimensional. . . . . . . . . . . . . . . . . . . 28

3.9 Faixas cortadas no padrão de corte bidimensional . . . . . . . . . . . . . 29

4.1 Processo produtivo simplificado . . . . . . . . . . . . . . . . . . . 32

4.2 Horizonte de Planejamento Rolante. . . . . . . . . . . . . . . . . . . . . . 34

6.1 Solução referente ao primeiro período do exemplo $(6.18)$. . . . . . . . . . 64 


\section{Lista de Tabelas}

6.1 Matriz de restrições do problema primal (6.7) . . . . . . . . . . . . . . . . 49

6.2 Matriz de restrições com 2 produtos finais e 3 períodos de tempo . . . . . . 50

6.3 Tabela com dados sobre $c_{i t}, h_{i t}, f_{i t}, d_{i t}$ e $r_{p i} \ldots \ldots \ldots$. . . . 57

6.4 Demanda em carteira $\left(d_{i t}\right)$ e esperada $\left(D_{i}\right)$ do produto $i$ do exemplo (6.18) 64

6.5 Nova demanda em carteira para o exemplo (6.18) . . . . . . . . . . . . . . 64

6.6 Nova demanda em carteira e expectativas de vendas do produto $i$ ao longo do horizonte de planejamento para o exemplo (6.18) . . . . . . . . . 65

6.7 Matriz de restrições do subproblema de corte $(6.26) \ldots \ldots$. . . . . . . 72

7.1 Dimensões das peças . . . . . . . . . . . . . . . . . 74

7.2 Peças necessárias para compor uma unidade de cada produto final . . . . . 74

7.3 Demanda extra do produto $i \ldots \ldots \ldots \ldots$. . . . . . . . . . . . . . . .

7.4 Demanda em carteira do tipo A, B e C do produto $i$ no período $t$. . . . . 75

7.5 Demanda em carteira do tipo D e E do produto $i$ no período $t$. . . . . 76

7.6 Resultados computacionais das heurísticas de decomposição para o modelo integrado $(4.1)-(4.10) . \ldots \ldots \ldots$. . . . . . . . . . . . . 80

7.7 Programação da produção no primeiro período para as heurísticas de decomposição, para os exemplos 1 a 10. . . . . . . . . . . . . . . . 81

7.8 Programação da produção no primeiro período para as heurísticas de decomposição, para os exemplos 11 a 20 . . . . . . . . . . . . . . . 81

7.9 Programação da produção no primeiro período para as heurísticas de decomposição, para os exemplos 21 a $25 . \quad$. . . . . . . . . . . . . . . . . . 82

7.10 Resultados computacionais para o modelo integrado (4.1)-(4.10) . . . . . . 84

7.11 Programação da produção no primeiro período para o modelo integrado (4.1)-(4.10), exemplos 1 a $15 . \ldots \ldots \ldots$. . . . . . . . . . . . 85

7.12 Programação da produção no primeiro período para o modelo integrado (4.1)-(4.10), exemplos 16 a $25 \ldots \ldots \ldots$. . . . . . . . . . . . 85 
7.13 Resultados computacionais para a relaxação lagrangiana (6.1) . . . . . . . . 87

7.14 Programação da produção no primeiro período para a relaxação lagrangiana (6.1), exemplos 1 a $15 \ldots \ldots \ldots$. . . . . . . . . . . . . 88

7.15 Programação da produção no primeiro período para a relaxação lagrangiana

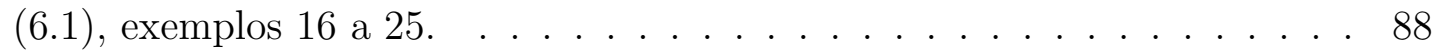




\section{Capítulo 1}

\section{Introdução}

Nas últimas décadas, o avanço tecnológico e computacional tem impulsionado uma grande aplicação de modelos de otimização nas áreas comerciais e industriais, direcionados ao planejamento e controle dos sistemas de produção de uma empresa, visando principalmente maximizar o lucro ou minimizar os custos, a fim de tornar seus processos mais eficientes.

O planejamento e controle de sistemas produtivos dentro de uma empresa coordenam todos os passos do processo de produção, desde a aquisição de matérias-primas até a entrega dos produtos finais. De maneira simplificada, o planejamento e controle dos sistemas de produção de uma empresa (PCP) pode ser dividido em três níveis de planejamento distintos: estratégico, tático e operacional.

O planejamento estratégico está relacionado com as decisões referentes às atividades futuras, como estabelecer o que a empresa deverá produzir, tendo em vista sua capacidade de produção e a previsão de vendas, baseado num quadro da situação esperada a longo prazo.

O planejamento tático cuida da utilização eficiente dos recursos necessários (definidos no nível superior) para satisfazer a demanda, analisando os custos envolvidos e as metas. Nesta etapa devem ser tomadas as decisões a médio prazo.

E o planejamento operacional é responsável pelas decisões decorrentes do dia-a-dia sobre a implementação dos planos táticos, elaborados no segundo nível, procurando obter a máxima eficiência do processo de produção da empresa.

Relacionados ao planejamento tático e operacional surgem problemas de tomada de decisão, como por exemplo, o processo de produção em indústrias de móveis, o qual consiste em cortar peças retangulares de madeira em peças menores de diversos tipos, 
necessárias para compor os produtos finais que são os móveis solicitados pelo cliente, atendendo uma certa demanda, como mostra a Figura 1 (Gramani (2001)).

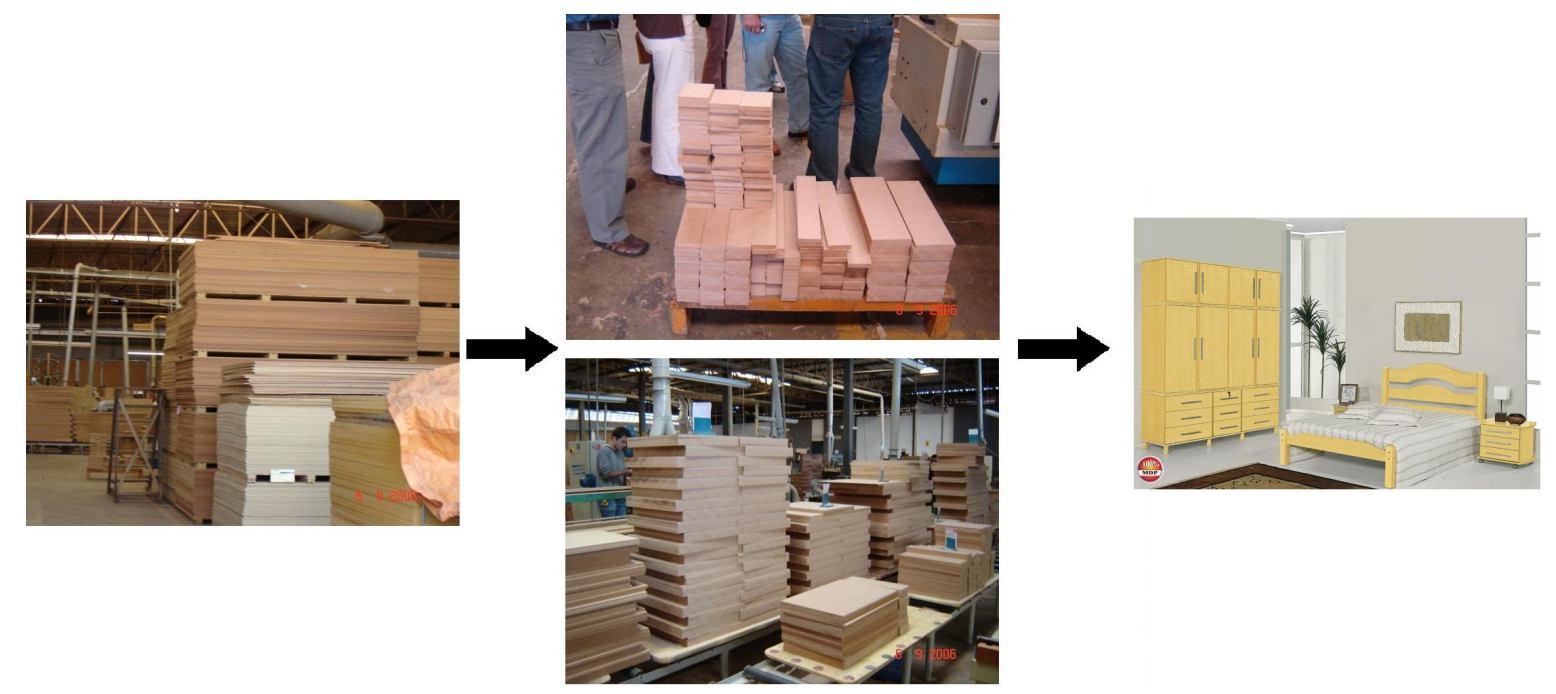

Figura 1.1: Processo de produção em uma indútria moveleira

O processo de programação da produção da indústria de móveis representado de forma simplificada pela Figura 1.1 consiste em três etapas:

1. definir dentro de um horizonte de planejamento finito (por exemplo, uma semana, um mês) as quantidades dos produtos finais a serem produzidos e suas respectivas datas de entrega;

2. converter a demanda de produtos finais em demanda de peças, por exemplo, para uma unidade do produto final "cômoda", são necessárias três peças do tipo 11, duas peças do tipo 12 e quatro peças do tipo 13 (de espessura $3 \mathrm{~mm}$ ), seis peças do tipo 7, três peças do tipo 8 (de espessura $12 \mathrm{~mm}$ ), e, duas peças do tipo 23, três peças do tipo 24 (de espessura 15mm)(ver Figura 1.2). Importante notar que um tipo de peça pode ser utilizada em diferentes tipos de produtos, por exemplo, a peça gaveta pode ser utilizada no produto "guarda-roupa"e no produto "cômoda".

3. decidir a quantidade de produtos finais a serem produzidos em cada período do horizonte de planejamento, tal que minimize os custos de produção e estoque (problema de dimensionamento de lotes - PDL) e os custos de perda no processo de corte (problema de corte de estoque - PCE). Baseado neste compromisso, surge o Problema Integrado de Corte de Estoque e Dimensionamento de Lotes. 


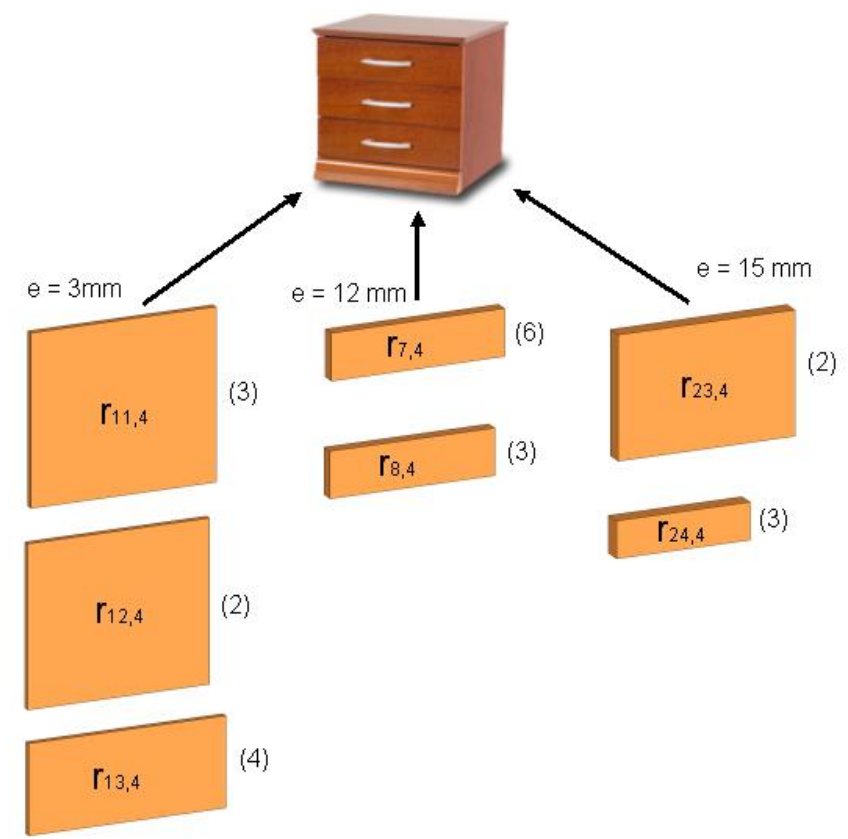

Figura 1.2: Peças necessárias para compor o produto final "cômoda".

Neste trabalho, analisamos a produção de móveis residenciais, principalmente móveis de dormitórios, tendo como matéria-prima placas retangulares de madeira, do tipo MDF (medium density fiberboard), produzidas a partir de fibras de madeiras, aglutinadas com resinas sintéticas, com consistência similar à da madeira. Esses móveis feitos de MDF, geralmente, são classificados como retilíneos, com formatos simples de linhas retas e sem detalhes sofisticados de acabamento. A descrição do processo de produção e da modelagem do problema integrado foram baseados em uma pequena indústria do interior paulista que produz essencialmente móveis de dormitório.

O problema integrado acima que surge em indústrias moveleiras (foco de nosso estudo) é a combinação de dois problemas de otimização bastante conhecidos na literatura: o problema de dimensionamento de lotes e o problema de corte de estoque. Em aplicações práticas, usualmente, estes problemas são tratados separadamente. Mas, ao resolver os modelos separadamente, pode ocorrer que a produção determinada pelo problema de dimensionamento de lotes exceda os limites de capacidade da empresa, como por exemplo, a capacidade da serra. Portanto, estamos motivados a estudar este problema de difícil resolução, ainda pouco abordado na literatura, a fim de encontrar uma solução que minimize dois objetivos conflitantes de forma conjunta.

Segundo Nonas \& Thorstenson (2007) "existem poucos artigos considerando o problema integrado de corte de estoque e de dimensionamento de lotes e geralmente estes 
artigos tratam de problemas específicos".

O trabalho está organizado da seguinte forma:

No capítulo 2 apresentamos uma breve revisão bibliográfica para alguns modelos de problemas integrados encontrados na literatura. Pelo fato do problema integrado envolver os problemas de corte de estoque e de dimensionamento de lotes, que são problemas de otimização bastante conhecidos na literatura, no capítulo 3 faremos uma breve descrição dos mesmos e de algumas abordagens clássicas de resolução que são usualmente utilizadas.

No capítulo 4 fazemos uma descrição das caracteristicas do setor moveleiro e do processo produtivo de uma indústria de móveis residencias. Apresentamos a definição e a modelagem matemática do Problema Integrado.

No capítulo 5 apresentamos uma breve revisão da relaxação lagrangiana, pois uma abordagem de resolução do problema chave deste trabalho é baseada nesta técnica.

No capítulo 6 descrevemos o método de resolução proposto para o modelo integrado que surge em indústrias de móveis e no capítulo 7 apresentamos os testes computacionais realizados.

Por fim, no capítulo 8 apresentamos as conclusões e algumas perspectivas para trabalhos futuros. 


\section{Capítulo 2}

\section{Revisão Bibliográfica}

\subsection{Introdução}

O problema estudado nesta dissertação trata os problemas de corte de estoque e de dimensionamento de lotes de forma integrada, motivado por uma aplicação prática em indústrias moveleiras. Como referências bibliográficas para o Problema Integrado, apresentamos uma breve revisão de alguns trabalhos encontrados na literatura que contém alguns aspectos similares ao problema abordado nesta dissertação. Ressaltamos que ainda são poucos os trabalhos encontrados na literatura, que tratam especificamente do problema que integra o problema de corte de estoque bidimensional e o problema de dimensionamento de lotes.

\subsection{Revisão Bibliográfica}

Reinders (1992) estudou o planejamento da produção para o processo de corte de troncos de árvore em uma companhia na Alemanha. O estudo foi amplamente realizado sobre o aspecto do planejamento tático e operacional, focando em chamados modelos base, que executam as seguintes funções: suporte operacional, em que o $1^{\circ}$ passo é o processo de corte dos troncos das árvores em variedades (esse processo pode ser considerado como um problema da mochila unidimensional), e o $2^{\circ}$ passo é processo de serrar as variedades (toras) em chapas de várias dimensões (esse processo pode ser determinado como um problema da mochila bidimensional); e o suporte tático, em que são elaborados modelos de planejamento da produção. De maneira simplificada, os problemas nesse nível tático foram descritos como: 
- Quantas variedades de quais tipos e de quais troncos de árvores devem ser produzidos e comprados?

- E quantas chapas de quais tipos e de quais variedades devem ser feitas, em qual semana e durante quais dias?

O autor apresenta um modelo matemático integrado, unindo o problema de cortar troncos em variedades e o problema de cortar variedades em chapas. Algumas das restrições consideradas são: disponibilidade limitada de matéria-prima, restrições de capacidade da serra, restrições de balanço de estoque para semi-produtos (variedades) e produtos finais (chapas), entre outras. O objetivo do modelo é encontrar uma programação da produção de maneira a maximizar a produção dos semi-produtos e dos produtos finais, e minimizar os custos de estoque e de atraso.

Hendry et al. (1996) apresentou um estudo de caso em uma indústria de cobre, de um problema de corte de estoque integrado ao problema de planejamento da produção, em que a operação de fundição básica consiste em três processos: derreter os pedaços de cobre em uma fornalha, produzir barras com comprimento fixo e diâmetros específicos e então cortar essas barras em itens menores de diversos comprimentos. Os problemas de planejamento da produção associados aos três processos de fundição objetivam minimizar o número de vezes que o forno é utilizado, determinar quantas barras de cada diâmetro devem ser produzidas (considerando o tempo de preparação do forno para a produção de barras com diferentes diâmetros) e determinar os padrões de corte a serem usados para atender a demanda dos itens, de modo a minimizar a perda de material e conseqüentemente o número de barras utilizadas. Os autores apresentaram um procedimento de solução em dois-estágios baseado no desacoplamento dos problemas, supondo conhecido o número máximo de barras de qualquer diâmetro que pode ser produzido por período (semana) e levando em consideração a capacidade do forno. Foi considerado um horizonte de planejamento de duas semanas, sendo que a cada início de semana este deve ser refeito para determinar a produção diária das barras (horizonte rolante). No primeiro estágio são usados métodos heurísticos para um problema de corte de estoque unidimensional com restrições de capacidade a fim de encontrar padrões de corte que minimizem a perda de material (estes padrões fornecem o número de barras de cada diâmetro produzidas em cada período). Então no segundo estágio, a solução obtida no primeiro estágio é utilizada como entrada em um método ótimo de solução para um problema de dimensionamento de lotes, determinando a programação da produção diária 
de barras. Os métodos heurísticos estudados mostraram soluções melhores em relação aos critérios analisados, quando comparados com os resultados da indústria. Dois critérios analisados de particular importância, foram a perda de material e número de vezes em que o forno é utilizado.

Baseado em um estudo para uma companhia da Noruega que produz um tipo especial de caminhões, Nonas \& Thorstenson (2000) formularam um problema integrado de corte de estoque e dimensionamento de lotes. A produção dos caminhões inicia no departamento de aço da companhia, que produz a maioria das partes de aço para os caminhões, onde grandes placas de aço devem ser cortadas em peças de diferentes formas e tamanhos. Este é um problema integrado de dimensionamento de lotes e corte de estoque bidimensional irregular que consiste em determinar uma programação da produção que minimize os custos da perda ocorrida no processo de corte, os custos de estoque e os custos de preparação para o corte dos diferentes padrões de corte. Porém, para este problema o autor considerou placas de aço com somente uma dimensão padrão e os padrões de corte conhecidos antecipadamente. As restrições de capacidade e as demandas de peças de reposição e de equipamento extra foram ignoradas. Em seguida os custos de preparação associados à troca de padrões de corte foram desconsiderados, resultando em um problema simplificado da primeira formulação, caracterizado como um problema de minimização côncavo com restrições lineares. Foram sugeridas algumas heurísticas para resolução do problema, que em geral apresentaram bons resultados.

Os mesmos autores (Nonas \& Thorstenson (2007)) apresentaram uma versão melhorada do procedimento de solução por geração de colunas para o problema integrado de corte de estoque e de dimensionamento de lotes sugerido anteriormente, o qual se aplicava somente para problemas pequenos. Essa melhoria incluiu características da heurística de busca em árvore sugerida em Nonas \& Thorstenson (2000) e da heurística sequencial proposta em Haessler (1971). Os resultados numéricos mostraram que essa versão melhorou as soluções obtidas para o modelo integrado comparando com os dois procedimentos anteriores. A principal característica dessa melhoria foi resolver grandes e pequenos exemplares do problema integrado, com tempo de solução aceitável.

Gramani (2001) apresenta um estudo do modelo matemático do problema integrado que surge em indústrias moveleiras, onde placas de dimensões $L \times W$ (comprimento $L$ e largura $W$ ) disponíveis em estoque devem ser cortadas em peças menores de dimensões especificadas que compõem os produtos finais (mesas, guarda-roupas etc.) em cada período. Para este problema a autora considerou uma dimensão padrão $L \times W$ para as placas, 
cada período do horizonte de planejamento como sendo um turno de trabalho e custos de preparação associados à produção. O objetivo do modelo integrado consiste em minimizar os custos de produção, preparação e estocagem e também os custos do processo de corte. Inicialmente é apresentada uma heurística de decomposição que trata separadamente os problemas de corte de estoque (PCE) e dimensionamento de lotes (PDL). Para a resolução do PDL foi utilizado o algoritmo de Wagner \& Whitin (1958) implementado segundo Evans (1985) e para a resolução do PCE foi utilizado a técnica de geração de colunas (Gilmore \& Gomory (1965)). Os resultados do problema integrado foram vantajosos quando comparados com a solução dos problemas separadamente. São propostos ainda três métodos de resolução referentes a três alterações feitas no modelo combinado: o enfoque usando o problema integrado simplificado como uma rede de caminho mínimo, um método exato para o problema integrado sem custos de preparação e a relaxação lagrangiana.

Em Gramani \& França (2006) foi publicado o estudo da alteração feita ao modelo integrado da indústria de móveis, com enfoque ao problema integrado simplificado como uma rede de caminho mínimo. O objetivo do problema é minimizar a perda de material no processo de corte e os custos de estocagem e preparação. O método de solução proposto é baseado na analogia com a rede de caminho mínimo, em que cada arco $(k, l)$ da rede é associado com um problema de corte de estoque capacitado que pode ser resolvido pelo método simplex com geração de colunas, proposto por Gilmore \& Gomory (1965). Após a resolução de todos os arcos, a rede é montada e resta então resolver um simples problema do caminho mínimo. Alguns testes computacionais são apresentados e comparando os resultados do problema integrado (resolvido pelo caminho mínimo) com as soluções dos problemas separados houve um ganho significativo. Também comparou-se a qualidade da solução entre os resultados do problema combinado resolvido pela rede de caminho mínimo com as soluções ótimas obtidas pelo pacote comercial AMPL/CPLEX (para exemplares pequenos), obtendo-se resultados bastante satisfatórios para a abordagem por rede de caminho mínimo.

Recentemente, Poltroniere et al. (2007) propuseram um modelo matemático inteiromisto que surge em indústrias papeleiras, o qual integra o problema de corte de estoque à programação da produção de bobinas de papel. O processo de produção inicia com máquinas disponíveis que produzem bobinas-mestre, chamadas jumbos, que em seguida passam para o setor de rebobinamento onde são feitos cortes longitudinais, obtendo bobinas menores (intermediárias) de larguras dadas. Essas bobinas intermediárias vão para 
o setor de acabamento, onde parte é embalada e despachada e as restantes são cortadas em resmas de vários tamanhos (retângulos de papel), de acordo com a demanda por períodos de um horizonte de planejamento (esse processo torna o problema de corte do tipo 1.5-dimensional). O pedido de itens finais leva em consideração a largura, tipo de papel (gramatura), demanda e data de entrega. Há um custo de preparação das diferentes máquinas associado à mudança de um tipo de papel para outro e além disso as máquinas têm restrições de capacidade e produzem jumbos de diferentes larguras. Devido a isso surgem questões como:

- Em qual máquina os jumbos de cada tipo devem ser produzidos?

- E qual deve ser a quantidade de papel de cada tipo produzida em cada máquina?

Nesse contexto, os autores desenvolveram um modelo matemático para o problema acima, objetivando minimizar a soma dos custos de produção, preparação, estoque de jumbos e itens finais e dos custos associados às perdas de papel durante o processo de corte. Para um subproblema que surge, o problema de corte de estoque multiperíodo, são apresentados o método de solução lote-por-lote utilizado usualmente na prática e uma heurística de antecipação dos itens. A heurística de antecipação dos itens permite uma melhor combinação dos itens em cada período e obteve bons resultados quando comparado com a solução lote-por-lote. Para o problema integrado são apresentadas a Heurística Lote-Corte e a Heurística Corte-Lote, os testes computacionais realizados resolveram em torno de $90 \%$ dos exemplos gerados, apresentando resultados bastante satisfatórios para a resolução do modelo integrado.

É importante ressaltar que a modelagem proposta em Gramani (2001) difere em alguns aspectos do modelo estudado neste trabalho, como por exemplo: consideramos o horizonte de planejamento rolante, que representa um mês, divido em períodos de 4 semanas e a primeira semana dividida em subperíodos de 5 dias. Esta estratégia pode ser utilizada na prática pelo gerente de produção de uma empresa, para trabalhar com a programação da produção mediante alterações nos pedidos dos clientes, como por exemplo, quando um pedido é cancelado. Além disso, o modelo nesta dissertação considera uma fabricação extra dos produtos, baseada na expectativa de vendas ao longo do horizonte de planejamento e que também pode ser controlada pelo gerente. Outro aspecto considerado é a limitação de capacidade de furadeira, além da limitação da capacidade de serra.

Uma das abordagens utilizada em Gramani (2001) para resolução do modelo integrado também é a relaxação lagrangiana, porém são relaxadas dois conjuntos de restrições refe- 
rentes ao balanço de estoque de peças (desconsideradas as variáveis de estoque das peças, assegurando apenas que a demanda de peças seja satisfeita nos períodos determinados) e à capacidade de serra, enquanto que na resolução proposta neste trabalho relaxamos apenas as restrições que integram os problemas de dimensionamento de lotes e corte de estoque. 


\section{Capítulo 3}

\section{Problemas de Dimensionamento de Lotes e de Corte de Estoque}

\subsection{Introdução}

Os problemas de dimensionamento de lotes e de corte de estoque, mesmo tratados separadamente, são problemas de grande complexidade computacional. Neste capítulo, apresentamos de forma breve alguns aspectos destes problemas e alguns algoritmos clássicos de resolução.

\subsection{Problemas de dimensionamento de lotes}

O problema de dimensionamento de lotes tem como objetivo determinar as quantidades de itens a serem produzidos em vários (ou único) estágios, em uma ou mais máquinas, ao longo de um horizonte de planejamento finito, para atender uma certa demanda. $\mathrm{O}$ objetivo deste problema é minimizar os custos de produção, estoque e preparação.

Os problemas de dimensionamento de lotes podem ser divididos em dois grupos básicos: monoestágio e multiestágio. Um problema é dito monoestágio quando os itens a serem produzidos são independentes, ou seja, quando um item não depende da produção de outro item. Um problema é multiestágio quando a produção de um item final depende da produção de um ou mais itens que o precedem. Os itens finais possuem suas próprias demandas, chamadas demandas independentes, e os itens que o precedem podem possuir demanda dependente (demanda interna) e independente.

Karimi et al. (2003) classifica os problemas de dimensionamento de lotes levando em 
consideração várias características que afetam a formulação e a complexidade dos modelos, tais como: tipo de horizonte de planejamento, número de estágios e de itens, restrições de capacidade, deterioração dos itens, tipo de demanda, custos e tempo de preparação e atrasos no atendimento a demanda.

\subsubsection{Problemas de dimensionamento de lotes monoestágio}

O problema mais simples de dimensionamento de lotes é quando se considera o problema de determinar um plano de produção para um único item, demanda fixa, sem limitações de capacidade, ao longo dos períodos de planejamento, a fim de minimizar os custos de estoque dos itens. Aqui o tempo e os custos de preparação são irrelevantes, pois são considerados baixos em relação aos custos de produção e estoque e assim, o problema é linear e pode ser resolvido por alguma técnica padrão de otimização linear.

Quando se considera os custos de preparação e ainda vários itens, o problema torna-se um problema inteiro-misto, que, em geral, pode ser resolvido em tempo polinomial, pelo algoritmo proposto por Wagner \& Whitin (1958) e consiste em decompor o problema em $M$ subproblemas, um para cada item, pois não existem restrições de capacidade, e cada subproblema pode ser resolvido por um algoritmo ótimo de programação dinâmica.

O problema de dimensionamento de lotes com múltiplos itens e sem limitações de capacidade pode ser formulado como:

$$
\operatorname{Min} \sum_{\text {sujeito a: }} \begin{cases}\sum_{t=1}^{T} \sum_{i=1}^{M}\left(c_{i t} x_{i t}+h_{i t} I_{i t}+s_{i t} z_{i t}\right) \\
\left\{\begin{array}{lll}
x_{i t}+I_{i(t-1)}-I_{i t} & =d_{i t} & i=1, \ldots, M \quad t=1, \ldots, T \\
x_{i t} & \leq Q . z_{i t} & i=1, \ldots, M \quad t=1, \ldots, T \\
x_{i t}, I_{i t} & \geq 0\left(I_{i o}=0\right) & i=1, \ldots, M \quad t=1, \ldots, T \\
z_{i t} \in\{0,1\} & & i=1, \ldots, M \quad t=1, \ldots, T
\end{array}\right.\end{cases}
$$

Índices:

$t=1, \ldots, T: \quad$ períodos de tempo;

$i=1, \ldots, M:$ itens (produtos finais).

Dados do problema: 
$c_{i t}$ : custo unitário de produção do item $i$ no período $t$;

$s_{i t}$ : custo de preparação para a produção do item $i$ no período $t$;

$h_{i t}$ : custo unitário de estocagem do item $i$ no período $t$;

$d_{i t}$ : demanda do item $i$ no período $t$;

$Q$ : número grande.

Variáveis do problema:

$x_{\mathrm{it}}$ : quantidade a ser produzida do item $i$ no período $t$;

$I_{\text {it }}$ : estoque do item $i$ no fim do período $t$;

$z_{\text {it }}$ : variável binária que indica se há ou não produção do item $i$ no período $t$.

No modelo (3.1), a função objetivo representa a minimização da soma dos custos de estoque, produção e preparação dos $M$ itens ao longo dos $T$ períodos. A primeira restrição representa o balanceamento de estoque de cada item no final de cada período. A segunda restrição assegura que ocorrerá produção somente se ocorrer a preparação, a terceira restrição é de não-negatividade das variáveis e a quarta restrição indica se há produção no período $\left(z_{i t}=1\right)$ ou não $\left(z_{i t}=0\right)$.

Atualmente, os modelos mais utilizados em aplicações industriais consideram a demanda dinâmica, múltiplos itens e restrições de capacidade. Quando se considera o tempo de preparação (setup time), o problema é NP-completo (Maes et al. (1991)).

Enfatizaremos aqui o modelo de dimensionamento de lotes com múltiplos itens e restrições de capacidade (Trigeiro et al. (1989)), o qual considera tempo e custo de preparação de máquina e demanda conhecida em cada período do horizonte de planejamento. O objetivo do modelo é determinar um planejamento da produção tal que minimize os custos, satisfazendo a demanda pré-estabelecida e a capacidade disponível para produção e preparação. Este problema é formulado como:

$$
\begin{aligned}
& \operatorname{Min} \quad \sum_{t=1}^{T} \sum_{i=1}^{M}\left(c_{i t} x_{i t}+h_{i t} I_{i t}+s_{i t} z_{i t}\right) \\
& \text { sujeito a: }\left\{\begin{array}{lll}
x_{i t}+I_{i(t-1)}-I_{i t} & =d_{i t} & i=1, \ldots, M \quad t=1, \ldots, T \\
\sum_{i=1}^{M}\left(v_{i} x_{i t}+f_{i t} z_{i t}\right) & \leq C_{t} & t=1, \ldots, T \\
x_{i t} & \leq Q . z_{i t} & i=1, \ldots, M \quad t=1, \ldots, T \\
x_{i t}, I_{i t} & \geq 0\left(I_{i 0}=0\right) & i=1, \ldots, M \quad t=1, \ldots, T \\
z_{i t} \in\{0,1\} & & i=1, \ldots, M \quad t=1, \ldots, T
\end{array}\right.
\end{aligned}
$$


sendo que os seguintes dados são adicionais ao modelo (3.1):

$v_{i}$ : tempo necessário para produzir uma unidade do item $i$;

$f_{i t}$ : tempos de preparação para a produção do item $i$ no período $t$;

$C_{t}:$ limite de capacidade (em unidades de tempo) para cada período $t$;

Os modelos (3.1) e (3.2) diferem apenas pela segunda restrição do modelo (3.2), que representa a limitação de capacidade, na qual se leva em consideração o tempo gasto para a produção dos itens e preparação das máquinas.

Para o modelo (3.2), uma abordagem de resolução é apresentada em Trigeiro et al. (1989) que desenvolveu um método heurístico baseado na relaxação lagrangiana. Esse método consiste em dualizar a segunda restrição do modelo (3.2), que representa as restrições de capacidade e ligam os itens, reduzindo o modelo a um problema monoestágio sem restrições de capacidade, apresentado em (3.1). Desta maneira, são obtidos $M$ subproblemas sem restrições de capacidade que podem ser resolvidos por um algoritmo ótimo, como em Wagner \& Whitin (1958). O valor da função objetivo do problema relaxado fornece um limitante inferior para o problema original (3.2). Em seguida, se a solução do problema relaxado for infactível, violando as restrições de capacidade, é aplicada uma heurística de factibilização para tornar a solução factível, transferindo a produção de lotes entre períodos, de acordo com a capacidade disponível em cada período e buscando uma propriedade de otimalidade quando não há restrições de capacidade. E, por fim, atualiza os multiplicadores duais utilizando o método do subgradiente.

No modelo proposto por Trigeiro et al. (1989) os custos são considerados variáveis no tempo, mas sua implementação considera todos os custos constante no tempo. Araujo \& Arenales (2000) revisam o método desenvolvido por Trigeiro et al. (1989), mais precisamente, o procedimento de factibilização, alterando a forma de transferência de produção entre os períodos, buscando propriedades de otimalidade do problema com limitações de capacidade.

Uma revisão mais completa de dimensionamento de lotes monoestágio pode ser encontrada em Bahl et al. (1987), Karimi et al. (2003) e Brahimi et al. (2006). 


\subsubsection{Problemas de dimensionamento de lotes multiestágio}

No caso de problemas de dimensionamento de lotes multiestágio, a produção de um item final depende da produção de um ou mais itens que o precedem. Devido às restrições de balanceamento de estoque deste modelo, que considera a demanda dependente, não é possível decompor o modelo por itens, impedindo utilizar as técnicas de resolução empregadas ao problema monoestágio anterior.

Para exemplificar essa situação, considere a Figura 3.1, que representa uma estrutura geral de produtos (Araujo (1999)), isto é, um sistema de produção com múltiplos estágios e com uma especificação da sequência de itens necessários para formar os produtos finais. A enumeração dos itens é feita da seguinte maneira, $i \geq j$ significa que o item $i$ não é sucessor do item $j$, por exemplo, $a_{31}=3$ significa que para fabricar uma unidade do item 1 serão necessárias 3 unidades do item 3, ou seja, o item 3 é antecessor do item 1 . O item 1 é considerado como item final (podem haver diferentes produtos finais).

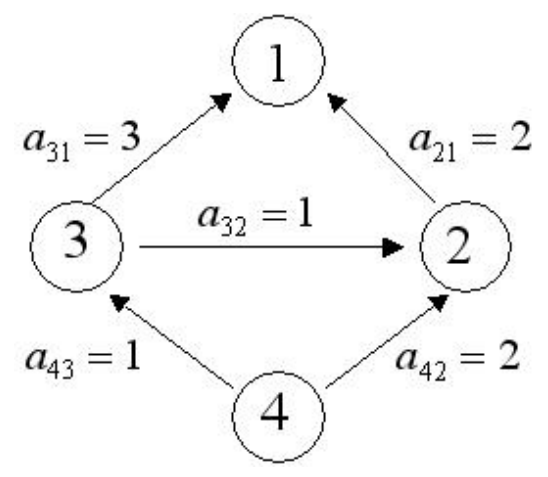

Figura 3.1: Exemplo de estrutura geral de produtos

Seja $a_{i j}$ a quantia do item $i$ necessária para compor uma unidade do item $j$, por exemplo, para um determinado período que requer 5 unidades do item final 1 (sem estoque de qualquer item e sem demanda independente dos itens 2,3 e 4) são necessárias pelo menos 10 unidades do item $2\left(a_{21} x_{1}=2 * 5\right), 25$ unidades do item $3\left(a_{31} x_{1}+a_{32} x_{2}=3 * 5+1 * 10\right) \mathrm{e}$ 45 unidades do item $4\left(a_{42} x_{2}+a_{43} x_{3}=2 * 10+1 * 25\right)$. Assim, as restrições de balanceamento de estoque devem determinar que $x_{i t}$ e $I_{i, t-1}$ devem satisfazer $d_{i t}$ mais $\sum_{j \in S(i)} a_{i j} x_{j t}$, em que $S(i)$ é o conjunto dos itens sucessores imediatos do item $i$.

A seguir apresentamos o modelo de dimensionamento de lotes multiestágio com restrições de capacidade (Billington et al. (1983)). 


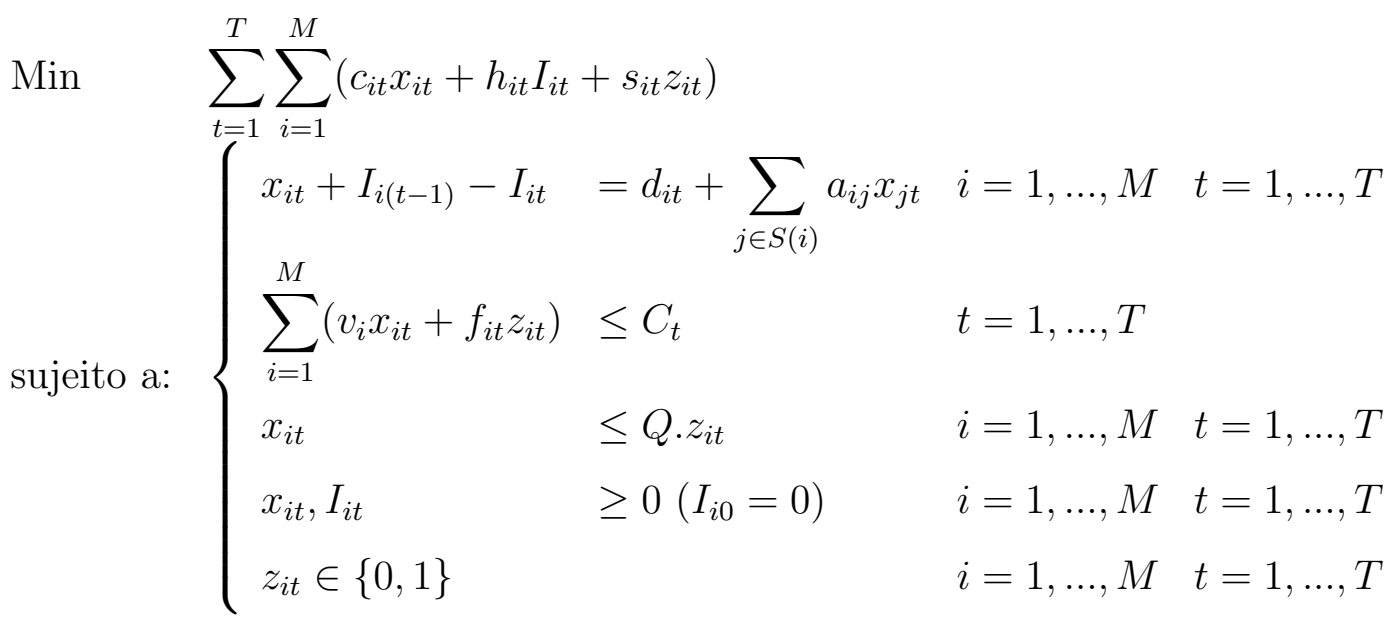

O modelo (3.3) difere do modelo monoestágio (3.2) apenas pelas restrições de balanceamento de estoque, sendo que a primeira restrição do modelo acima considera a demanda dependente, o que torna o modelo não decomponível por item quando as restrições de capacidade são relaxadas, impossibilitando o uso das técnicas de resolução aplicadas a problemas monoestágio.

Uma heurística para resolver o problema multiestágio com restrições de capacidade, é desenvolvida em Maes et al. (1991), com as variáveis inteiras relaxadas o problema linear é resolvido, e três heurísticas de arredondamento são testadas para obtenção das variáveis inteiras.

Uma revisão mais completa de dimensionamento de lotes multiestágio pode ser encontrada por exemplo, em Billington et al. (1983), Maes et al. (1991) e Santos (2000).

\subsection{Problemas de Corte de Estoque}

O processo de corte é uma etapa fundamental no planejamento da produção em várias indústrias de manufatura, como indústrias de móveis, papel, têxtil etc. O problema de corte consiste na otimização do processo de corte de peças grandes (objetos), disponíveis em estoque, para a produção de peças menores (itens), em quantidades especificadas, objetivando por exemplo, minimizar o custo total dos objetos cortados ou a perda de material gerada pelo corte. Por exemplo, na indústria de móveis é necessário cortar a matéria prima principal (por exemplo, madeira, metal e plástico, sendo que a parcela predominante para produção dos móveis consiste da madeira) em peças menores de diversos tamanhos e espessuras, para a produção dos móveis demandados.

Estes problemas têm sido objeto de estudo intenso nas últimas décadas, desde os trabalhos pioneiros de Gilmore \& Gomory $(1961,1963,1965)$, que apresentaram métodos 
de resolução de grande repercussão na literatura. Em Gilmore \& Gomory (1961) foi apresentado o método simplex com geração de colunas, que permitiu encontrar uma boa aproximação para a solução de problemas de corte de estoque de grande porte, a qual deve ser inteira. Gilmore \& Gomory (1963) apresentaram uma variação do método desenvolvido em 1961, para aplicação em um problema específico de corte de papel e um novo método para o problema da mochila. Mais tarde em 1965, os autores desenvolveram um estudo sobre os problemas de corte de estoque bidimensional e multidimensional, apresentando algumas características como o corte guilhotinado, irrestrito e estagiado.

O problema de corte de estoque pode apresentar algumas características, como por exemplo, grande repetição dos itens, ou seja, poucos tipos de itens devem ser produzidos em grande quantidade, as peças maiores (objetos) podem ser de um ou vários tipos e ainda pode haver ou não restrições de capacidade sobre o estoque. As peças menores a serem cortadas dos objetos devem ser combinadas da melhor maneira possível, a fim de diminuir a perda de material e essas combinações são denominadas de padrões de corte. Na prática o número de padrões de corte pode ser muito elevado devido à natureza combinatória do problema, tornando esses problemas improváveis de serem resolvidos em tempo polinomial (NP-difícil).

\subsubsection{Classificação dos Problemas de Corte quanto à Dimensão}

Nesta seção apresentamos a classificação dos problemas de corte de estoque de acordo com as dimensões que são relevantes do objeto a ser cortado.

\section{- Unidimensional}

Quando apenas uma dimensão é relevante no processo de corte, como exemplo podemos citar o corte de barras de aço e bobinas de papel (Ver Figura 3.2).

(a)

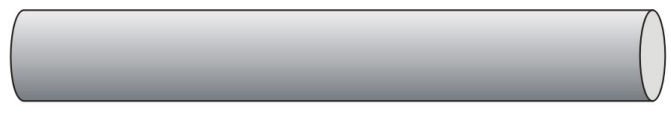

(b)

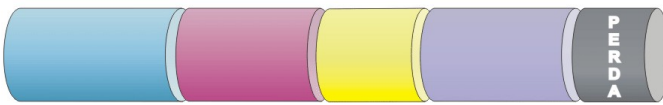

Figura 3.2: (a) Barra a ser cortada; (b) Objeto cortado produzindo 4 itens e uma perda.

\section{- Bidimensional}

Quando duas dimensões (comprimento e largura) são relevantes no processo de corte, 
uma vez que as peças cortadas têm a mesma espessura, como exemplo podemos citar o corte de placas de madeira na indústria de móveis e chapas de aço na indústria metalúrgica. É comum que os cortes sejam do tipo guilhotinados, isto é, cada corte gera dois novos retângulos (Ver Figura 3.3)

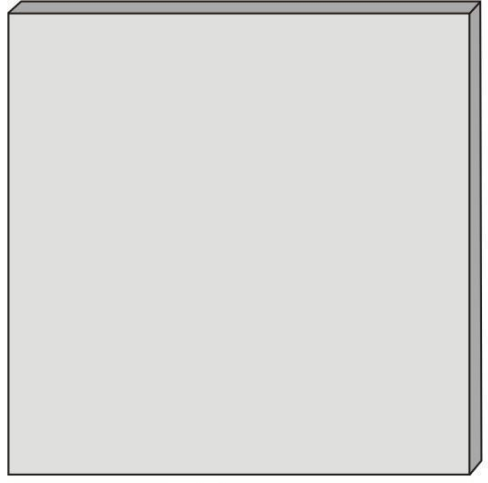

(a)

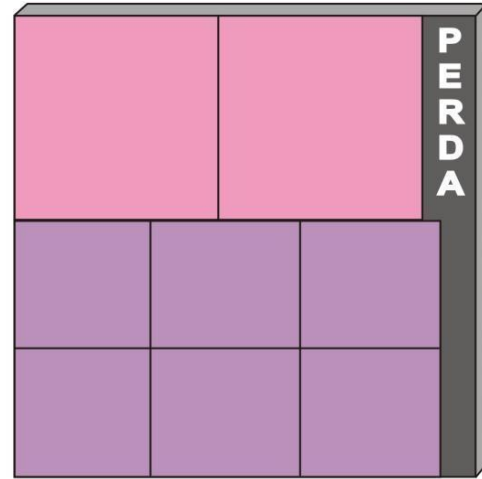

(b)

Figura 3.3: (a) Placa a ser cortada; (b) Objeto cortado produzindo 8 itens e uma perda.

\section{- Tridimensional}

Quando três dimensões (comprimento, largura e espessura) são relevantes no processo de corte. Como exemplo podemos citar o corte de matéria-prima para a produção de colchões. Porém, as aplicações mais interessantes deste tipo de problema surgem no problema inverso do corte, o chamado problema de empacotamento, que consiste em empacotar unidades pequenas dentro de uma unidade grande, mais especificamente trata do carregamento de caixas dentro de contêineres ou caminhões (Morabito (1992)). Veja a Figura 3.4.
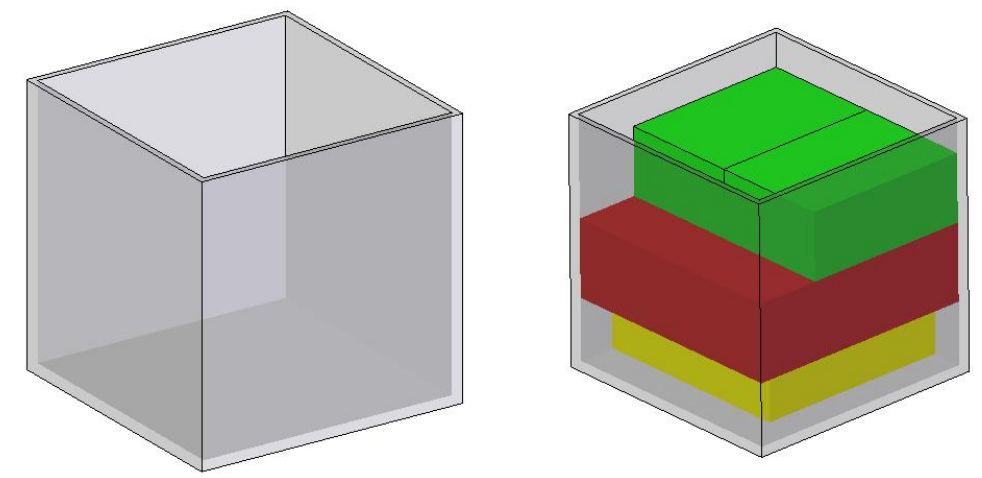

Figura 3.4: Caixas empacotadas no contêiner. 
Problemas do tipo 1.5-dimensional são essencialmente problemas bidimensionais, porém uma das dimensões relevantes no processo de corte é variável, como ocorre por exemplo, no corte de retângulos de uma bobina que é desenrolada, tem largura fixa e comprimento suficientemente longo para a produção dos itens.

Problemas do tipo 2.5-dimensional são essencialmente problemas tridimensionais, porém uma das três dimensões relevantes no processo de corte é variável, como ocorre por exemplo, no carregamento de um contêiner com largura e comprimento fixos e suficientemente alto para acomodar toda a carga.

\section{- Multidimensional}

Quando mais de três dimensões são relevantes para a obtenção da solução, como exemplo podemos citar o problema de alocação de tarefas (Morabito (1992)).

A seguir, apresentamos com mais ênfase o problema de corte unidimensional e o problema de corte bidimensional, sendo que este último está diretamente relacionado com o problema a ser estudado nesta dissertação .

\subsubsection{Problema de Corte de Estoque Unidimensional}

No caso unidimensional, supondo que se tenha um número grande de objetos disponíveis em estoque (objetos podem ser barras de aço, bobinas de papel etc) de um determinado comprimento L, o problema de corte de estoque unidimensional consiste em cortar esses objetos em itens de comprimentos menores $l_{i}, i=1, \ldots, m$ (tais que $l_{i} \leq L$ ), de modo a atender as demandas conhecidas $d_{i}, i=1, \ldots, m$, otimizando uma certa função objetivo, como por exemplo, minimizar a perda de material ou o número de objetos cortados.

Uma das características deste tipo de problema, como já mencionado, é que muitos objetos deverão ser cortados para a produção dos diferentes tipos de itens, tornando necessário o melhor arranjo possível das peças dentro de cada objeto, o que sugere o uso de padrões de corte, dado pela seguinte definição:

Definição 3.3.1 Chamamos de padrão de corte a maneira como um objeto em estoque é cortado para a produção de itens demandados. A um padrão de corte associamos um vetor m-dimensional que contabiliza os itens produzidos:

$$
a=\left(\alpha_{1}, \alpha_{2}, \ldots, \alpha_{m}\right)
$$


em que $\alpha_{i}$ é a quantidade de itens do tipo i no padrão de corte.

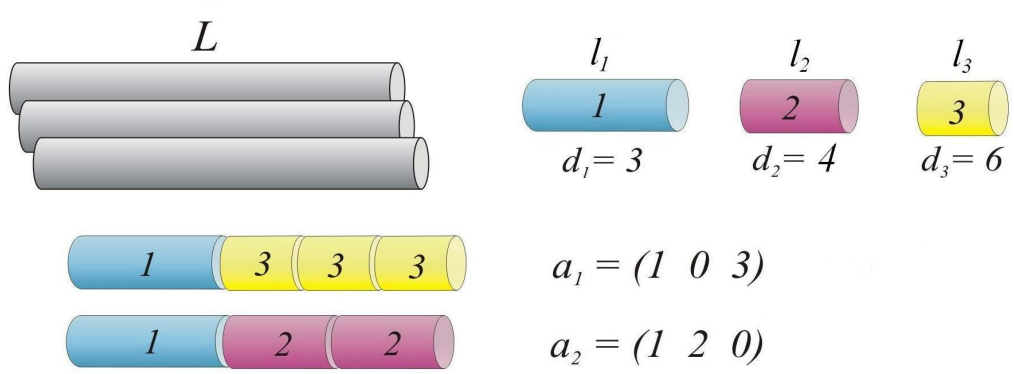

Figura 3.5: Exemplo de padrões de corte unidimensional.

No exemplo da Figura 3.5, um objeto de comprimento $L$, deve ser cortado em itens menores de comprimentos $l_{1}, l_{2}$ e $l_{3}$, com demandas $d_{1}, d_{2}$ e $d_{3}$, respectivamente, e dois possíveis padrões de corte são dados por $a_{1}=(1,0,3)$ e $a_{2}=(1,2,0)$.

Um vetor $a=\left(\alpha_{1}, \alpha_{2}, \ldots, \alpha_{m}\right)$ corresponde a um padrão de corte se, e somente se, satisfazer as restrições físicas do problema (restrições do Problema da Mochila):

$$
\begin{aligned}
& l_{1} \alpha_{1}+l_{2} \alpha_{2}+\ldots+l_{m} \alpha_{m} \leq L \\
& \alpha_{i} \geq 0, i=1, \ldots, m \text { e inteiro. }
\end{aligned}
$$

Definição 3.3.2 Um padrão de corte que produza apenas um tipo de item é chamado padrão de corte homogêneo.

Isto significa que um padrão de corte é homogêneo se o vetor associado tiver apenas uma coordenada não-nula: $a=\left(0, \ldots, \alpha_{i}, \ldots, 0\right), \alpha_{i} \neq 0$. Observe que sempre teremos pelo menos $m$ padrões de corte homogêneos, sendo que os vetores associados a estes padrões definem uma matriz diagonal e a quantidade do item $i$ no padrão homogêneo correspondente é dada por $\left\lfloor\frac{L}{l_{i}}\right\rfloor$.

Após definir os padrões de corte, é necessário determinar o número de vezes que cada padrão de corte $j$ será utilizado para resolver o problema, representado pela variável de decisão $x_{j}$. Desta maneira, a modelagem matemática de um problema de corte unidimensional pode ser feita em duas etapas principais:

1. Definir todos os possíveis padrões de corte, ou seja, todas as soluções possíveis de:

$$
\begin{aligned}
& l_{1} \alpha_{1}+l_{2} \alpha_{2}+\ldots+l_{m} \alpha_{m} \leq L \\
& \alpha_{i} \geq 0, i=1, \ldots, m \text { e inteiro. }
\end{aligned}
$$


Esta primeira etapa da geração de padrões de corte pode ser feita independentemente da demanda dos itens, supondo as $n$ possíveis soluções:

$$
a_{1}=\left(\begin{array}{c}
\alpha_{11} \\
\alpha_{21} \\
\vdots \\
\alpha_{m 1}
\end{array}\right), a_{2}=\left(\begin{array}{c}
\alpha_{12} \\
\alpha_{22} \\
\vdots \\
\alpha_{m 2}
\end{array}\right), \ldots, a_{n}=\left(\begin{array}{c}
\alpha_{1 n} \\
\alpha_{2 n} \\
\vdots \\
\alpha_{m n}
\end{array}\right)
$$

em que $\alpha_{i j}$ é o número de itens do tipo $i$ no padrão de corte $j, i=1, \ldots, m, j=$ $1, \ldots, n$.

2. Definir quantas vezes cada padrão de corte é utilizado para atender a demanda, que deve ser um número inteiro e não-negativo.

$\mathrm{Na}$ segunda etapa, a modelagem matemática deste problema de corte de estoque pode ser formulada como um problema de otimização linear inteiro, com $m$ equações e $n$ variáveis, em que $n$ representa o número de padrões de corte gerados na primeira etapa:

$$
\begin{array}{ll}
\text { Minimizar } & f(x)=x_{1}+x_{2}+\ldots+x_{n} \\
\text { sujeito a: } & \begin{cases}a_{1} x_{1}+a_{2} x_{2}+\ldots+a_{n} x_{n}=d \\
x_{j} \geq 0, \quad j=1, \ldots, n & \text { e inteiro }\end{cases}
\end{array}
$$

Em notação matricial o problema (3.4) é escrito como:

$$
\begin{aligned}
\text { Minimizar } & \sum_{j=1}^{n} x_{j} \\
\text { sujeito a: } & \begin{cases}A x & =d \\
x & \geq 0 \text { e inteiro }\end{cases}
\end{aligned}
$$

em que cada coluna da matriz $A \in R^{m \times n}$ é um vetor associado a um padrão de corte e d é um vetor de demanda.

A função objetivo do modelo (3.5) a ser minimizada representa o número total de objetos em estoque a serem cortados. A primeira restrição garante o atendimento à demanda e a segunda restrição garante que a repetição de cada padrão de corte $j$ seja um número inteiro não-negativo. 
Quando o objetivo do problema é minimizar as perdas ocorridas durante o processo de corte, a função objetivo do modelo (3.5) é substituída pela função perda total, dada a seguir:

$$
\text { Minimizar } f(x)=\sum_{j=1}^{n} c_{j} x_{j}
$$

em que

$$
c_{j}=L-\left(\alpha_{1 j} l_{1}+\alpha_{2 j} l_{2}+\ldots+\alpha_{m j} l_{m}\right)
$$

define a perda no padrão de corte $j, j=1, \ldots, n$.

As funções objetivos em (3.4) e (3.6) são equivalentes, consistindo em minimizar o número total de objetos cortados e em minimizar a perda total, respectivamente, para o caso de apenas um tipo de barra em estoque e restrições de igualdade (Poldi (2003)).

Uma revisão sobre a modelagem de problemas de corte de estoque, considerando algumas variações no estoque de objetos, como por exemplo, diversos tipos de barra em estoque em quantidades ilimitadas e diversos tipos de barra em estoque em quantidades limitadas, pode ser encontrada em Arenales et al. (2004).

Tipicamente, a resolução do problema de corte de estoque em (3.5) é de grande dificuldade computacional, devido a dois fatores: a condição de integralidade sobre as variáveis $x_{j}$, e $n$ (o $\mathrm{n}^{\mathrm{o}}$ de padrões de corte - colunas) pode ser da ordem de centenas de milhares, o que inviabiliza a geração de todos os padrões de corte. Para contornar esses problemas, Gilmore \& Gomory (1961) relaxaram as restrições relativas à condição de integralidade, resolvendo o problema de otimização linear resultante pelo método simplex com geração de colunas, resumido a seguir.

\section{- O Método Simplex com Geração de Colunas}

Durante as iterações do método Simplex (usado na resolução de problemas de corte de estoque), um dos passos consiste em selecionar uma coluna para entrar na base a fim de melhorar a solução. Considerando que cada coluna representa um padrão de corte, essa análise torna-se inviável, pois, como já observamos, em problemas práticos o número de variáveis $n$ (colunas) é muito grande. A modificação proposta em Gilmore \& Gomory (1961), gera uma nova coluna a cada iteração do método simplex, resolvendo um problema auxiliar (geralmente um problema da mochila), que é de programação inteira e pode ser resolvido por métodos como enumeração implícita, programação dinâmica e heurísticas. Esse método fornece uma solução para o problema de corte com a condição 
de integralidade relaxada, a qual geralmente é fracionária e, a partir desta solução relaxada, é possível determinar soluções inteiras, por meio de procedimentos heurísticos de arredondamento, que podem ser encontrados por exemplo, em Wascher \& Gau (1996), Poldi (2003) e Arenales et al. (2004).

A técnica de geração de colunas, embutida no algoritmo simplex, consiste em gerar uma coluna $k$ utilizando o critério de Dantzig, que procura a variável $x_{k}$ com o menor custo relativo. Dada uma base numa iteração qualquer do método simplex (com matriz básica B), a solução básica é calculada por $x_{B}=B^{-1} b$ e o vetor multiplicador simplex é dado por $\pi^{T}=c_{B}^{T} B^{-1}$, em que $c_{B}$ é o vetor dos custos básicos. Tipicamente, padrões de corte homogêneos são usados para a matriz básica inicial e a escolha da coluna a entrar na base é feita pelo critério de Dantzig:

$$
c_{k}-\pi^{T} a_{k}=\min \left\{c_{j}-\pi^{T} a_{j}, j=1,2, \ldots, n\right\}
$$

Se $c_{k}-\pi^{T} a_{k} \geq 0$ então a solução básica $x_{B}=B^{-1} b$ é ótima, caso contrário, a coluna $a_{k}$ entra na base. Como uma coluna $a=\left(\alpha_{1}, \alpha_{2}, \ldots, \alpha_{m}\right)$ corresponde a um padrão de corte, então (3.8) pode ser reescrito como:

$$
\begin{array}{ll}
\text { Minimizar } & c(a)-\sum_{i=1}^{m} \pi_{i} \alpha_{i} \\
\text { sujeito a: } & \begin{cases}\sum_{i=1}^{m} l_{i} \alpha_{i} & \leq L \\
\alpha_{i} & \geq 0 \text { e inteiro } i=1, \ldots, m\end{cases}
\end{array}
$$

em que $c(a)$ é o custo desta coluna, que pode ser $c(a)=1$ no caso do problema (3.4), ou $c(a)=L-\sum_{i=1}^{m} \alpha_{i} l_{i}$ no caso de (3.7).

Considerando por exemplo, que a função a ser minimizada seja o total de objetos a serem cortados, isto é, $f(x)=x_{1}+x_{2}+\ldots+x_{n}$, então $c(a)=1$ e o subproblema (3.9) é equivalente ao seguinte problema da mochila:

$$
\begin{gathered}
g(a)=\text { máximo } \sum_{i=1}^{m} \pi_{i} \alpha_{i} \\
\text { sujeito a: }\left\{\begin{array}{l}
\sum_{i=1}^{m} l_{i} \alpha_{i} \leq L \\
\alpha_{i} \geq 0 \text { e inteiro, } \quad i=1, \ldots, m
\end{array}\right.
\end{gathered}
$$


Neste caso, se o menor dos custos relativos for não-negativo, isto é, $c(a)-g(a) \geq 0$, podemos garantir que a solução do problema (3.5) relaxado é ótima, senão, a solução fornece a nova coluna para entrar na base e atualizar o método.

\subsubsection{Problema de Corte de Estoque Bidimensional}

Nesta seção consideramos o problema de cortar placas retangulares para a produção de itens menores com demandas pré-estabelecidas, o que caracteriza o problema de corte de estoque, no qual deve-se determinar a quantidade de placas a serem cortadas, analogamente ao problema unidimensional, diferenciando-se apenas no fato que as placas e os itens têm duas dimensões relevantes (comprimento $L$ e largura $W$ ) no processo de corte. Consideramos aqui apenas um tipo de placa $L \times W$ disponível em estoque.

As etapas da modelagem matemática descritas na seção anterior para o caso unidimensional, são ainda válidas para os problemas bidimensionais, porém a técnica para a geração dos padrões de corte é outra. O método Simplex com geração de colunas ainda pode ser utilizado, porém o subproblema gerador de colunas em (3.9) não é mais válido, pois suas restrições fornecem um padrão de corte unidimensional.

A seguir apresentamos algumas definições e como o subproblema gerador de colunas pode ser resolvido para problemas de corte bidimensional (Arenales et al. (2004)).

Definição 3.3.3 Um corte sobre uma placa retangular que produza dois novos retângulos é chamado corte guilhotinado ortogonal, ou simplesmente, corte guilhotinado. Uma sequência de cortes guilhotinados, aplicados sobre a placa e sobre os retângulos resultantes produz um padrão de corte guilhotinado.

No exemplo da Figura 3.6, considerando $m=5$ itens, o vetor associado que contabiliza os itens no padrão é dado por $a=(2,2,0,3,2)$, sendo dois itens do tipo 1 , dois itens do tipo 2, nenhum item do tipo 3, três itens do tipo 4 e dois itens do tipo 5 . Note que 8 cortes guilhotinados foram necessários para a produção do padrão de corte. 


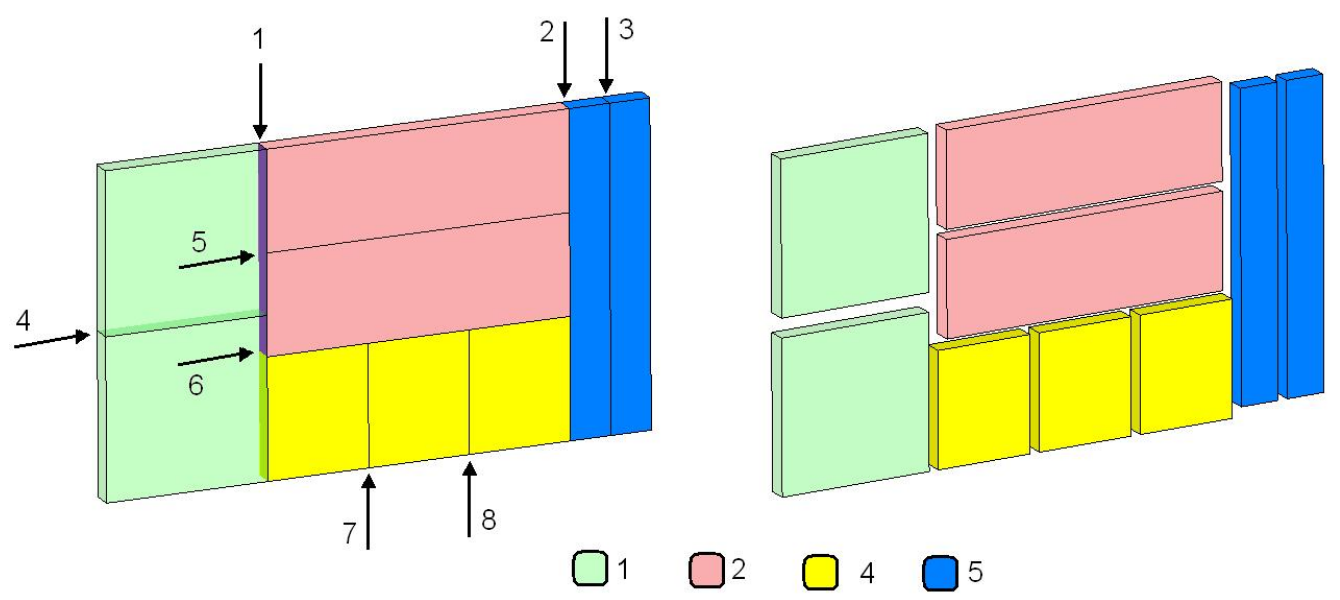

Figura 3.6: Exemplo de padrão de corte bidimensional guilhotinado.

Os estágios de um padrão de corte guilhotinado podem ser organizados da seguinte forma: no primeiro estágio cortes guilhotinados são feitos sobre a placa, paralelos um ao outro, no segundo estágio os retângulos obtidos são cortados perpendicularmente aos cortes do estágio anterior, e assim sucessivamente, definindo os estágios de corte. $\mathrm{Na}$ Figura 3.6 os cortes 1, 2 e 3 são feitos no primeiro estágio, seguidos dos cortes 4,5 e 6 no segundo estágio e por fim os cortes 7 e 8 no terceiro estágio.

Definição 3.3.4 Se o número permitido de estágios é limitado por $k$, dizemos que o padrão de corte resultante é um padrão de corte guilhotinado em k-estágios.

\section{Problema de corte bidimensional guilhotinado em 2-estágios}

Damos ênfase aos padrões de corte em 2-estágios, isto é, quando no máximo dois estágios são permitidos, pois o problema de corte que surge em indústrias moveleiras, tipicamente requer padrões de corte guilhotinados 2-estágios. A seguir mostramos as duas etapas da modelagem para a construção destes padrões.

Considere uma placa de dimensões $L \times W$ (comprimento $L$ e largura $W$ ) que deve ser cortada para a produção de $m$ itens menores de dimensões $l_{i} \times w_{i}, i=1, \ldots, m$. A cada item $i$ está associado um valor de utilidade $v_{i}, i=1, \ldots, m$ e $\left(\alpha_{1}, \alpha_{2}, \ldots, \alpha_{m}\right)$ é o vetor associado a um padrão de corte sobre a placa $L \times W$, isto é, $\alpha_{i}$ é o número de itens do tipo $i$ no padrão. O problema pode então ser modelado da seguinte forma (Gilmore \& Gomory (1965), Morabito \& Arenales (1995), Arenales et al. (2004)):

- Definir as melhores maneiras de se cortar as faixas $L \times w_{1}, L \times w_{2}, \ldots, L \times w_{m}$. 
Os itens que podem ser cortados numa faixa $L \times w_{k}$ são representadas no conjunto por $W_{k}=\left\{i \mid w_{i} \leq w_{k}\right\}$ e as faixas são definidas somente para larguras diferentes, isto é, se $w_{1}=w_{2}$ então apenas a faixa $L \times w_{1}$ é necessária. Supondo então que as $r$ primeiras larguras são diferentes entre si, consideramos apenas as faixas $L \times w_{1}, L \times w_{2}, \ldots, L \times w_{r}$.

Cada faixa deve ser cortada para a produção dos itens demandados de maneira que se obtenha o maior valor de utilidade. Logo, para cada faixa $L \times w_{k}(k=1, \ldots, r)$, segue o problema da mochila:

$$
\begin{array}{ll}
V_{k}=\text { Maximizar } & \sum_{i \in W_{k}} v_{i} \gamma_{i k} \\
\text { sujeito a: } & \left\{\begin{array}{l}
\sum_{i \in W_{k}} l_{i} \gamma_{i k} \leq L \\
\gamma_{i k} \geq 0 \text { e inteiro } i=1, \ldots, m
\end{array}\right.
\end{array}
$$

em que $\gamma_{i k}$ é o número de itens do tipo $i$ na faixa $L \times w_{k}$.

A resolução dos $r$ problemas da mochila em (3.11) fornece os valores de utilidade para cada faixa e quais itens devem ser cortados, ou seja, definem as melhores faixas para comporem o padrão de corte bidimensional.

- Determinar quantas vezes cada faixa deve ser utilizada no padrão bidimensional.

Temos de resolver agora o problema da mochila seguinte, considerando as larguras $w_{k}$ de cada faixa $k$ e a largura $W$ da placa.

$$
\begin{array}{ll}
V=\text { Maximizar } & V_{1} \beta_{1}+V_{2} \beta_{2}+\cdots+V_{r} \beta_{r} \\
\text { sujeito a: } & \left\{\begin{array}{l}
w_{1} \beta_{1}+w_{2} \beta_{2}+\cdots+w_{r} \beta_{r} \leq W \\
\beta_{1} \geq 0, \quad \beta_{2} \geq 0, \cdots, \quad \beta_{r} \geq 0 \text { e inteiros }
\end{array}\right.
\end{array}
$$

O vetor associado ao padrão de corte obtido pelo procedimento acima, que determina o número de itens no padrão é representado por:

$$
a=\left(\begin{array}{c}
\alpha_{1}=\sum_{k=1}^{r} \gamma_{1 k} \beta_{k} \\
\alpha_{2}=\sum_{k=1}^{r} \gamma_{2 k} \beta_{k} \\
\vdots \\
\alpha_{m}=\sum_{k=1}^{r} \gamma_{m k} \beta_{k}
\end{array}\right)
$$

Esse procedimento produz padrões de corte em 2-estágios, sendo que o primeiro é obtido por cortes horizontais, já que são produzidas faixas $L \times w_{k}$. Observe que os 
padrões de corte 2-estágios obtidos pelo procedimento descrito podem ser como ilustrado na Figura 3.7. Tais padrões de corte requerem uma apara final que pode ser vista como um terceiro estágio e são chamados padrões de corte 2-estágios inexatos. Se a apara final não é permitida, então deve-se definir os conjuntos $W_{k}=\left\{i \mid w_{i}=w_{k}\right\}$ e os padrões de corte são chamados 2-estágios exatos.

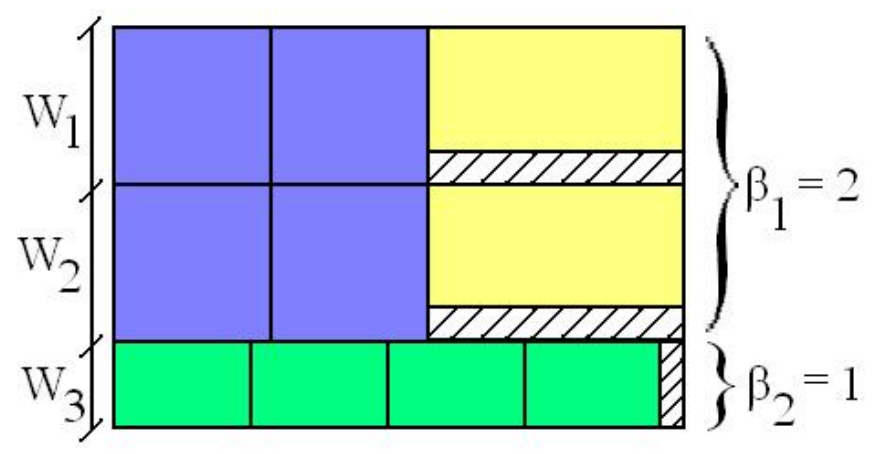

Figura 3.7: Padrão de corte 2-estágios inexato.

Para produzir padrões de corte guilhotinados em 2-estágios, de modo que o primeiro estágio seja formado por cortes verticais, basta produzir faixas $l_{k} \times W$ e redefinir o conjunto de itens que podem ser cortados nessa faixa como $L_{k}=\left\{i \mid l_{i} \leq l_{k}\right\}$, com as substituições coerentes nos problemas (3.11) e (3.12).

Uma revisão de outros modelos para a geração de padrões de corte bidimensionais, tais como padrão bidimensional guilhotinado 1-grupo, padrões guilhotinados k-estágios e padrão bidimensional não-guilhotinado, podem ser encontrados por exemplo, em Gilmore \& Gomory (1965), Morabito \& Arenales (1996) e Vianna (2000).

\subsubsection{Exemplo Numérico}

Apresentamos a seguir um exemplo numérico de um problema de corte bidimensional, o qual está relacionado com o modelo em estudo. Considere a situação em que placas de dimensões $150 \mathrm{~cm}$ x $150 \mathrm{~cm}$ devem ser cortadas para a produção de algumas peças, cujas dimensões e valores de utilidade são dadas na Figura 3.8: 


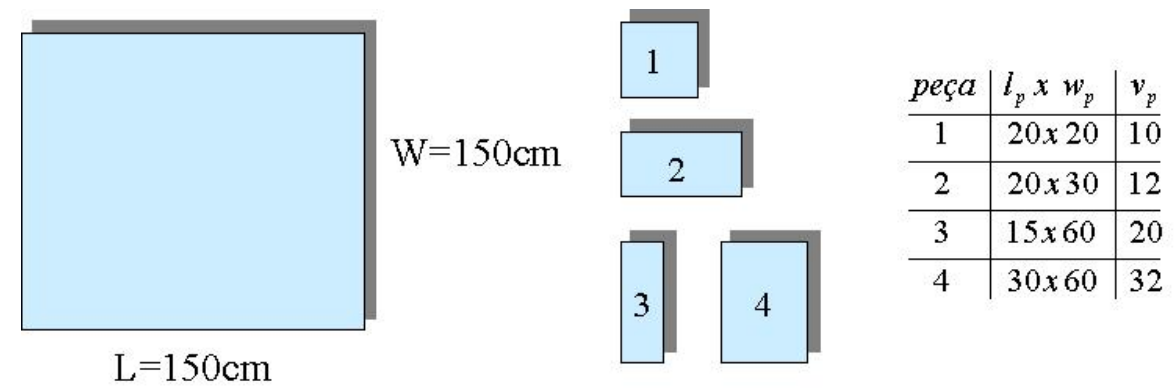

Figura 3.8: Problema de corte bidimensional.

As faixas horizontais $\left(L \times w_{k}, k=1, \ldots, r\right)$ em que as peças podem ser cortadas são:

- Faixa 1: $150 \mathrm{~cm} \times 20 \mathrm{~cm} \rightarrow W_{1}=\{1\}$

- Faixa 2: $150 \mathrm{~cm} \times 30 \mathrm{~cm} \rightarrow W_{2}=\{1,2\}$

- Faixa 3: $150 \mathrm{~cm} \times 60 \mathrm{~cm} \rightarrow W_{3}=\{1,2,3,4\}$

Resolvemos então os problemas da mochila em (3.11) para determinar as melhores maneiras de cortar as faixas, obtendo:

Faixa 1:

$$
\begin{aligned}
& V_{1}=\operatorname{Max} 10 \gamma_{11} \\
& \text { s.a: }\left\{\begin{array}{l}
20 \gamma_{11} \leq 150 \\
\gamma_{11} \geq 0 \text { e inteiro }
\end{array}\right.
\end{aligned}
$$

Solução: $\gamma_{11}=7$ e $V_{1}=70$

\section{Faixa 2:}

$$
\begin{aligned}
& V_{2}=\operatorname{Max} 10 \gamma_{12}+12 \gamma_{22} \\
& \text { s.a: }\left\{\begin{array}{l}
20 \gamma_{12}+20 \gamma_{22} \leq 150 \\
\gamma_{12} \geq 0, \gamma_{22} \geq 0 \text { e inteiros }
\end{array}\right.
\end{aligned}
$$

Solução: $\gamma_{12}=0, \gamma_{22}=7$ e $V_{2}=84$

\section{Faixa 3:}

$$
\begin{aligned}
& V_{3}=\operatorname{Max} 10 \gamma_{13}+12 \gamma_{23}+20 \gamma_{33}+32 \gamma_{43} \\
& \text { s.a: }\left\{\begin{array}{l}
20 \gamma_{13}+20 \gamma_{23}+15 \gamma_{33}+30 \gamma_{43} \leq 150 \\
\gamma_{13} \geq 0, \gamma_{23} \geq 0, \gamma_{33} \geq 0, \gamma_{43} \geq 0 \text { e inteiros }
\end{array}\right.
\end{aligned}
$$

Solução: $\gamma_{13}=0, \gamma_{23}=0, \gamma_{33}=10, \gamma_{43}=0$ e $V_{3}=200$ 
Para determinar quantas vezes cada faixa deve ser cortada na placa, resolvemos o problema da mochila (3.12).

$$
\begin{array}{ll}
V=\operatorname{Max} & 70 \beta_{1}+84 \beta_{2}+200 \beta_{3} \\
\text { sujeito a: } & \left\{\begin{array}{l}
20 \beta_{1}+30 \beta_{2}+60 \beta_{3} \leq 150 \\
\beta_{1} \geq 0, \beta_{2} \geq 0, \beta_{3} \geq 0 \text { e inteiros }
\end{array}\right.
\end{array}
$$

Cuja solução é $\beta_{1}=6, \beta_{2}=1, \beta_{3}=0$ e $V=504$. Isto significa que o melhor padrão de corte bidimensional terá que ser cortado com seis faixas do tipo 1 e uma faixa do tipo 2. Veja Figura 3.9.

$\left.\begin{array}{|l|l|l|l|l|l|l|}\hline 1 & 1 & 1 & 1 & 1 & 1 & 1 \\ \hline 1 & 1 & 1 & 1 & 1 & 1 & 1 \\ \hline 1 & 1 & 1 & 1 & 1 & 1 & 1 \\ \hline 1 & 1 & 1 & 1 & 1 & 1 & 1 \\ \hline 1 & 1 & 1 & 1 & 1 & 1 & 1 \\ \hline 1 & 1 & 1 & 1 & 1 & 1 & 1 \\ \hline 2 & 2 & 2 & 2 & 2 & 2 & 2\end{array}\right] \longrightarrow$ perda

Figura 3.9: Faixas cortadas no padrão de corte bidimensional

Assim, o vetor associado ao padrão de corte bidimensional, que contabiliza o número de itens (neste caso, peças) no padrão é dado por:

$$
a=\left(\begin{array}{c}
\alpha_{1} \\
\alpha_{2} \\
\alpha_{3} \\
\alpha_{4}
\end{array}\right)=\left(\begin{array}{c}
42 \\
7 \\
0 \\
0
\end{array}\right)
$$




\section{Capítulo 4}

\section{O Problema Integrado de}

\section{Dimensionamento de Lotes e Corte de Estoque Bidimensional}

\subsection{Introdução}

Neste capítulo apresentamos algumas características do setor moveleiro no Brasil, os aspectos gerais do processo produtivo de uma indústria de móveis de pequeno porte, situada no pólo moveleiro de Votuporanga, no noroeste do Estado de São Paulo. Na prática, as indústrias de móveis, bem como outras indústrias de manufatura, realizam o planejamento da produção resolvendo os problemas de corte de estoque (PCE) e de dimensionamento de lotes (PDL) separadamente, devido à grande dificuldade de resolução do modelo integrado. O enfoque de nosso estudo foi o problema de otimização integrado, com o propósito de analisar a resolução dos problemas de PCE e PDL de forma conjunta.

\subsection{Características do Setor Moveleiro no Brasil}

A indústria de móveis no Brasil é caracterizada pelo uso de várias matérias-primas, pela manufatura de grande diversidade de produtos e pelas diferentes tecnologias empregadas. Em Justina (2004) são citados quatros critérios para se classificar um móvel, os quais são brevemente comentados a seguir:

- $O$ uso a que são destinados

A produção nacional dos móveis é segmentada de acordo com os produtos manufa- 
turados e seus respectivos mercados como: móveis residenciais, móveis de escritório e móveis institucionais (aqueles destinados a escolas, consultórios, hospitais e outros), com $60 \%, 25 \%$ e $15 \%$ da produção nacional, respectivamente.

\section{- A matéria-prima predominante utilizada na produção}

As matérias-primas predominantes são madeira, metal e plástico, sendo que a madeira possui a parcela mais significativa da produção nacional de móveis. A madeira pode ser ainda classificada como: madeira maciça, painel de compensado, painel de aglomerado e painel de medium-density fiberboard (MDF), este último é produzido a partir de fibras de madeira, aglutinadas com resinas sintéticas, possuindo consistência similar à da madeira e é a matéria-prima utilizada pela indústria de móveis em estudo.

\section{- O tipo de produto demandado}

Os móveis de madeira podem ser classificados em dois tipos básicos: retilíneos (lisos, com formas retas e simples, cuja matéria-prima principal são os três tipos de painéis citados acima) e torneados (possuem detalhes de acabamento mais sofisticados, com formas retas e curvilíneas).

- Forma de produção

A forma de produção pode ser seriada quando para distribuição comercial via varejistas e comerciantes, e sob encomenda quando direto para o cliente.

Outra característica marcante do setor moveleiro no Brasil é a sua concentração em pólos regionais, apesar da grande dispersão geográfica que apresenta. Estes pólos estão localizados na região Sul, com $46 \%$ da produção nacional, na região sudeste com 40\%, e nas demais regiões com baixos índices, cerca de 3 a 7\%. Entre os principais pólos estão: Bento Gonçalves (RS), São Bento do Sul (SC), Arapongas (PR), Mirassol (SP), Votuporanga (SP) e Grande São Paulo (SP).

\subsection{Processo Produtivo da Indústria de Móveis}

O processo de programação da produção de uma indústria de móveis, como já apresentado anteriormente, consiste em duas etapas fundamentais: a primeira etapa é definir as quantidades e as datas de entrega dos produtos finais demandados e sua estrutura (componentes necessários) para um horizonte de planejamento finito. A segunda etapa consiste 
em decidir a quantidade de produtos finais que devem ser produzidos em cada período do horizonte de planejamento, minimizando os custos totais de produção e estoque e a perda ocorrida no processo de corte das placas em peças, respeitando-se as limitações de capacidade da empresa.

Neste trabalho, analisamos o processo produtivo de uma fábrica de móveis de pequeno porte para a produção de móveis de dormitório, como armários (de 4 e 5 portas), cômodas e criados. A matéria-prima utilizada para confecção destes móveis são painéis do tipo MDF e as formas dos móveis demandados são do tipo retilíneas. Apresentamos a seguir, a descrição do processo produtivo simplificado destes móveis, que envolve algumas etapas e equipamentos (Figura 4.1).
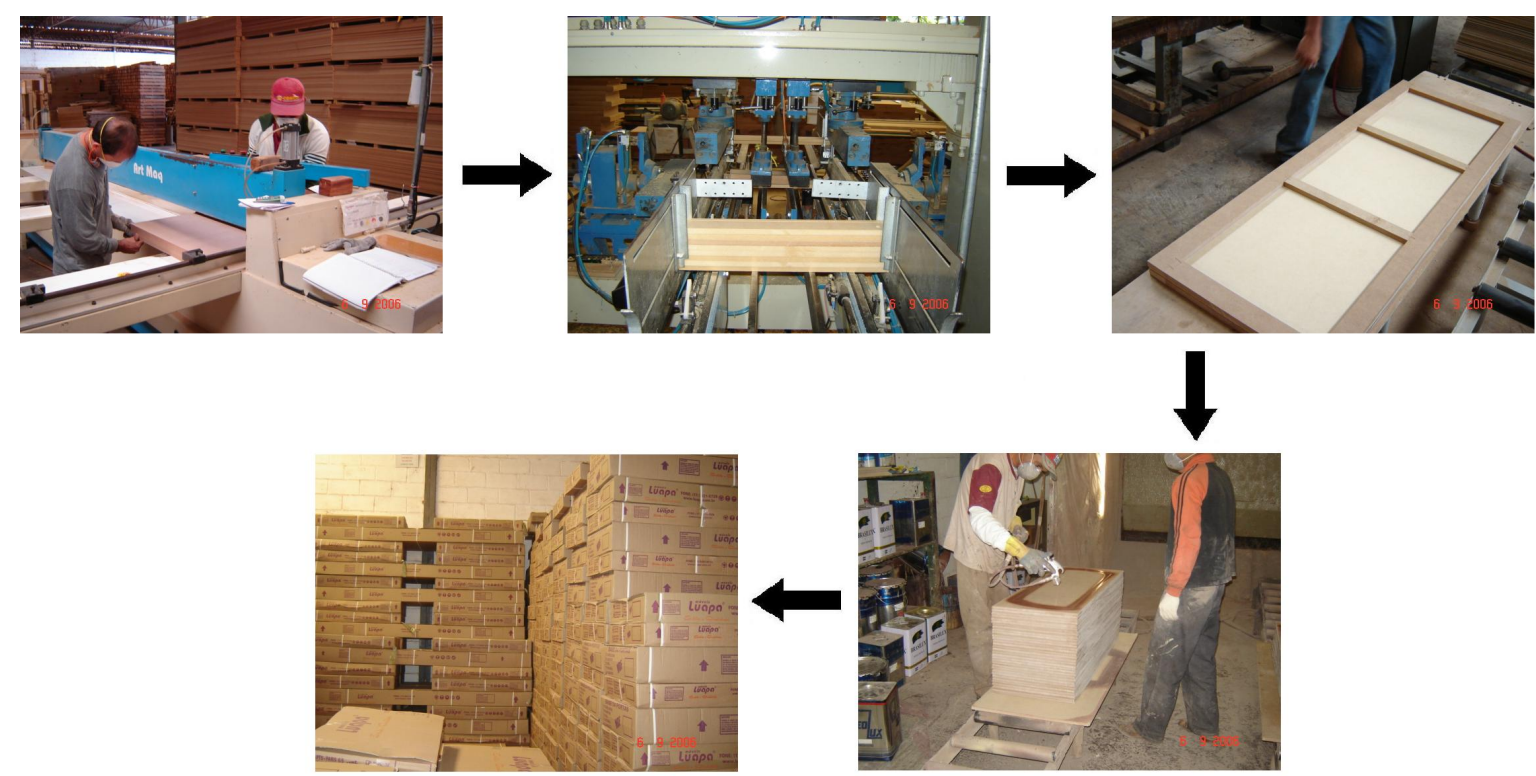

Figura 4.1: Processo produtivo simplificado

- Setor de Corte: A primeira etapa do processo de produção consiste em resolver um problema de corte de estoque bidimensional, em que os objetos em estoque (neste caso placas retangulares de MDF com dimensões e espessura fixos) devem ser cortados em peças menores, utilizando os melhores padrões de corte possíveis. A resolução deste problema de corte deve ser feita de modo que uma quantidade de produtos finais seja satisfeita. Esta etapa é realizada por uma seccionadora, operada manualmente por dois funcionários, podendo cortar simultaneamente vários painéis (a espessura máxima que a máquina permite cortar é $60 \mathrm{~mm}$ ), realizando apenas cortes guilhotinados ortogonais.

- Setor de Furação: Após cortadas, as peças são enviadas para o setor de furação, 
operado por até duas máquinas, que furam uma peça por vez para o encaixe de outras peças e montagem dos móveis.

- Setor de Montagem: O setor de montagem, composto por diversas máquinas, tais como lixadora, prensa, entre outras, recebe as peças furadas, para serem lixadas, para colagem ou colocação de bordas etc. Depois de preparadas, são então levadas para a pintura.

- Setor de Pintura: No setor de pintura um conjunto de máquinas operam interligadas. Inicialmente as peças recebem uma cor de fundo, depois são secas nas estufas e recebem a cor definitiva.

- Embalagem e Estocagem: Na última etapa do processo de produção, as peças que compõem os móveis recebem uma vistoria final e são embaladas juntamente com os acessórios (parafusos, puxadores das portas e gavetas, por exemplo). Depois disso, estes produtos são estocados em caixas específicas (tipicamente desmontados) até a data de entrega.

Os setores de corte e furação são os principais gargalos do processo de produção da indústria.

\subsection{Definição do Problema}

Neste trabalho, consideramos a estratégia de horizonte de planejamento rolante, ou seja, o primeiro período tem as decisões detalhadas e os demais agregadas. O horizonte de planejamento representa um mês, os períodos quatro semanas $(t=1, \ldots, 4)$ e os subperíodos cinco dias da primeira semana $(\tau=1, \ldots, 5)$. Resolvemos o problema e somente a solução relativa ao primeiro período é implementada. Os dados são atualizados (na prática essa técnica de horizonte rolante é interessante, pois a demanda de produtos tem uma componente estocástica podendo sofrer alterações, por exemplo, novos pedidos são feitos ou mesmo cancelados) e resolvemos o modelo novamente a partir do segundo período, agora considerado como o primeiro e detalhado e assim sucessivamente. De maneira simplificada, a divisão do horizonte de planejamento é feita conforme a Figura 4.1: 


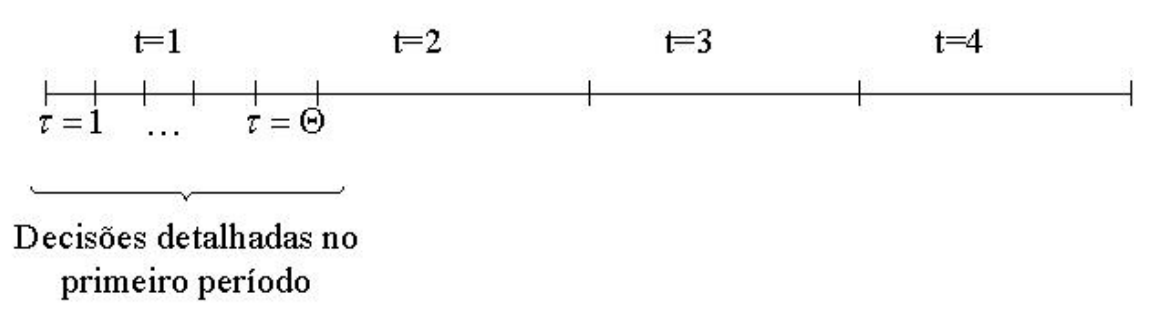

Figura 4.2: Horizonte de Planejamento Rolante.

Inicialmente, o processo de produção da indústria de móveis, utiliza a matéria-prima adquirida, que são placas retangulares de MDF (objetos) de dimensões $L \times W$ (comprimento $L$ e largura $W$ ) e espessura variável. Sem perda de generalidade, consideramos neste trabalho uma dimensão padrão para os painéis, com custo fixo, disponível em quantidade suficiente para atender a demanda dos produtos finais e de espessura fixa. A empresa trabalha com a demanda em carteira dos produtos e ainda considera uma produção extra (representada no modelo como demanda extra), para se ter um nível de estoque de segurança "oportunista" destes produtos ao longo do horizonte de planejamento, caso algum pedido eventual seja feito.

O modelo do problema de otimização integrado foi baseado no processo produtivo simplificado de uma indústria de móveis, em que objetos em estoque devem ser cortados para a produção dos itens, que por sua vez serão furados para então comporem os produtos finais. Isto significa que é necessário resolver um problema de corte de estoque (PCE) e um problema de dimensionamento de lotes multiestagiado (PDL), considerando as capacidades da serra e da furadeira, as quais representam os principais gargalos de produção da empresa.

Os detalhamentos de corte e furação são considerados somente no primeiro período do horizonte de planejamento, em todos os subperíodos. A serra e a furadeira possuem limites de capacidade, os quais não podem ser excedidos.

No problema de corte é necessário preparar a serra para cortar as placas, com diferentes padrões de corte bidimensionais. Cada padrão de corte leva um tempo para ser cortado. Numa primeira abordagem, não consideramos o tempo de preparação das máquinas (associamos para isso uma capacidade mais apertada), apenas o tempo de corte para os padrões de corte. No problema de dimensionamento de lotes há um custo associado à produção e ao estoque de todos os tipos de produtos finais, em todos os períodos do horizonte de planejamento. 
O objetivo do problema de otimização integrado, consiste então em minimizar o custo total do processo produtivo, ou seja, minimizar os custos de produção e estoque e os custos de perda no processo de corte.

\subsection{Modelagem Matemática}

A seguir apresentamos o modelo matemático inteiro do Problema Integrado, baseado em Silva et al. (2007), o qual objetiva minimizar os custos de produção e estoque e os custos de perda no processo de corte, respeitando as capacidades disponíveis em cada período do horizonte de planejamento e atendendo a demanda esperada (parte em carteira e parte prevista).

Os índices, parâmetros e variáveis utilizados no modelo são:

\section{- Índices:}

$t=1, \ldots, T \quad$ (T: número de períodos do horizonte de planejamento).

$\tau=1, \ldots, \Theta \quad(\Theta$ : número de subperíodos do horizonte de planejamento $)$.

$i=1, \ldots, M \quad$ (M: número de tipos de produtos finais).

$p=1, \ldots, P \quad$ (P: número de tipos de peças que compõem os produtos finais).

$j=1, \ldots, N \quad(\mathrm{~N}$ : número de diferentes padrões de corte para a placa $\mathrm{L} \times \mathrm{W})$.

\section{- Parâmetros:}


$c_{i t}: \quad$ custo unitário de produzir o produto $i$ no período $t$;

$h_{i t}$ : $\quad$ custo de estocar uma unidade do produto $i$ no período $t$;

$f_{i t}$ : $\quad$ custo de estoque extra do produto $i$ no período $t$;

$c p_{j \tau}$ : $\quad$ custo por $m m^{2}$ de material perdido no padrão de corte $j$ no subperíodo $\tau$;

$d_{i t}$ : demanda em carteira do produto $i$ no período $t$;

$D_{i}$ : demanda esperada do produto $i$ no horizonte de planejamento;

$r_{p i}$ : número de peças do tipo $p$ necessárias para compor uma unidade do produto final do tipo $i$;

$a_{p j \tau}: \quad$ número de peças do tipo $p$ no padrão de corte $j$ no subperíodo $\tau$;

$t c_{i}$ : $\quad$ tempo (em segundos) gasto para cortar as peças necessárias para compor uma unidade do produto $i$ (estimativa para períodos agregados);

$t f_{i}: \quad$ tempo (em segundos) gasto para furar as peças necessárias para compor uma unidade do produto $i$ (estimativa para períodos agregados);

$v_{j \tau}: \quad$ tempo (em segundos) gasto para cortar uma placa $(L \mathrm{x} W)$ no padrão de corte $j$

$b_{p}: \quad$ tempo (em segundos) gasto para furar uma peça do tipo $p$ (em segundos);

$\operatorname{cap}_{\tau}: \quad$ capacidade da serra no subperíodo $\tau$ (em segundos);

$\operatorname{capF}_{\tau}: \quad$ capacidade da furadeira no subperíodo $\tau$ (em segundos);

$\operatorname{Cap}_{t}$ : capacidade da serra no período $t$ (em segundos, estimativa para períodos agregados);

$C a p F_{t}$ : capacidade da furadeira no período $t$ (em segundos, estimativa para períodos agregados);

\section{- Variáveis:}

$x_{i t}$ : quantidade a ser produzida do produto $i$ no período $t$ para atender a carteira de pedidos, mais a demanda extra;

$E_{i t}$ : demanda extra do produto $i$ no período $t$, também chamada de "variável oportunista";

$I_{i t}$ : quantidade em estoque do produto $i$ no final do período $t$;

$y_{j \tau}: \quad$ quantidade de placas cortadas no padrão de corte $j$ no subperíodo $\tau$;

Assim, o modelo matemático para o Problema Integrado de Dimensionamento de Lotes e Corte de Estoque pode ser descrito como: 
$\begin{aligned} \operatorname{Min} & \sum_{i=1}^{M} \sum_{t=1}^{T}\left(c_{i t} x_{i t}+h_{i t} I_{i t}+f_{i t} E_{i t}\right)+\sum_{j=1}^{N} \sum_{\tau=1}^{\Theta} c p_{j \tau} y_{j \tau} \\ \text { sujeito a: } & \left\{\begin{array}{lll}x_{i t}+I_{i(t-1)}-I_{i t} & =d_{i t}+E_{i t} & i=1, \ldots, M ; \quad t=1, \ldots, T \\ \sum_{t=1}^{T}\left(d_{i t}+E_{i t}\right) & =D_{i} & i=1, \ldots, M \\ \sum_{j=1}^{N} \sum_{\tau=1}^{\Theta} a_{p j \tau} y_{j \tau} & =\sum_{i=1}^{M} r_{p i} x_{i 1} & p=1, \ldots, P \\ \sum_{j=1}^{N} v_{j \tau} y_{j \tau} & \leq c a p S_{\tau} & \tau=1, \ldots, \Theta \\ \sum_{p=1}^{P} b_{p} \sum_{j=1}^{N} a_{p j \tau} y_{j \tau} & \leq c a p F_{\tau} & \tau=1, \ldots, \Theta \\ \sum_{i=1}^{M} t c_{i} x_{i t} & \leq C a p S_{t} & t=2, \ldots, T \\ \sum_{i=1}^{M} t f_{i} x_{i t} & \leq C a p F_{t} & t=2, \ldots, T \\ x_{i t}, I_{i t}, E_{i t} & \geq 0 \text { e inteiros } & i=1, \ldots, M ; \quad t=1, \ldots, T \\ y_{j \tau} & \geq 0 \text { e inteiros } & j=1, \ldots, N ; \quad \tau=1, \ldots, \Theta\end{array}\right.\end{aligned}$

A seguir faremos uma descrição das restrições associadas ao modelo (4.1)-(4.10):

- Função objetivo (4.1): O objetivo do modelo consiste em minimizar os custos com a produção $\left(c_{i t}\right)$, o estoque $\left(h_{i t}\right)$, o estoque da demanda extra $\left(f_{i t}\right)$ e o material perdido $\left(c p_{j \tau}\right)$.

- Restrições de balanço de estoque dos produtos finais (4.2): Esse conjunto de restrições considera a demanda (em carteira e extra) de cada produto $i$ em cada período $t$, assegurando que seja atendida para $i=1, \ldots, M$ e $t=1, \ldots, T$. Sem perda de generalidade, o estoque inicial do produto $i\left(I_{i 0}\right)$ é considerado nulo, para $i=1, \ldots, M$.

- Restrições de atendimento à demanda esperada (4.3): Esse conjunto de restrições garante que toda a demanda esperada do produto $i\left(D_{i}\right)$ seja produzida no horizonte de planejamento.

- Restrições de atendimento à demanda de peças (4.4): Esse conjunto de restrições assegura que a demanda de peças (em carteira e extra) gerada pela produção 
de itens finais no primeiro período seja satisfeita. Como consideramos o horizonte de planejamento rolante, o detalhamento de corte é feito somente no primeiro período, mas em todos os subperíodos. A quantidade de peças do tipo $p$ cortada no período 1 é dada por $\sum_{\tau=1}^{\Theta} \sum_{j=1}^{N} a_{p j} y_{j \tau}$ e considerando que a produção do produto final $i$ é $x_{i 1}$ para o período 1 , a demanda de peças do tipo $p$ neste período é dada por $\sum_{i=1}^{M} r_{p i} x_{i 1}$ para $p=1, \ldots, P$. As restrições (4.4) integram os problemas de dimensionamento de lotes e de corte de estoque, pois incluem ambas as variáveis $x_{i 1}$ e $y_{j \tau}$, que definem o tamanho dos lotes no período 1 e a quantidade de placas cortadas em cada subperíodo do período 1, respectivamente.

- Restrições de capacidade da serra nos subperíodos (4.5): Esse conjunto de restrições assegura que o tempo total gasto para cortar as placas nos diversos padrões de corte é limitado pela capacidade disponível de serra $\left(\operatorname{cap} S_{\tau}\right)$ em cada subperíodo $\tau$, para $\tau=1, \ldots, \Theta$.

- Restrições de capacidade da furadeira nos subperíodos (4.6): A furadeira também possui um limite de capacidade. O tempo gasto para furar uma única peça do tipo $p$ é dado por $b_{p}=5 s$ (a furadeira fura uma peça por vez e estas levam em torno de $5 s$ para serem furadas independente da espessura, que neste caso consideramos fixa). Assim, as restrições (4.6) garantem que o tempo gasto para furar todas as peças do tipo $p$ cortadas no subperíodo $\tau$ não ultrapasse o tempo limite da furadeira $(c a p F \tau)$, em cada subperíodo $\tau$, para $\tau=1, \ldots, \Theta$.

- Restrições de capacidade da serra nos períodos (4.7): Esse conjunto de restrições garantem que o tempo gasto para cortar todas as peças necessárias para compor os produtos finais demandados $\left(\sum_{i=1}^{M} t c_{i} x_{i t}\right)$ não exceda a capacidade da serra $\left(C a p S_{t}\right)$ nos períodos 2 a $t$.

- Restrições de capacidade da furadeira nos períodos (4.8): Esse conjunto de restrições garantem que o tempo gasto para furar as peças necessárias para compor os produtos finais demandados $\left(\sum_{i=1}^{M} t f_{i} x_{i t}\right)$, nos períodos 2 a $T$, não exceda a capacidade da furadeira deste período. O tempo gasto para furar todas as peças que compõem uma unidade do produto $i$ é dado por $t f_{i}=\sum_{p=1}^{P} b_{p} r_{p i}$. 
- Restrições de não-negatividade e integralidade (4.9): Esse conjunto de restrições garantem que as variáveis de produção $\left(x_{i t}\right)$, demanda extra $\left(E_{i t}\right)$ e estoque $\left(I_{i t}\right)$ são valores inteiros e não-negativos.

- Restrições de não-negatividade e integralidade (4.10): Essas restrições garantem que as quantidades de placas cortadas no padrão de corte $j$ no subperíodo $\tau$ são valores inteiros e não-negativos.

A dificuldade de resolução do modelo matemático inteiro (4.1)-(4.10) deve-se principalmente a dois fatores:

1. A integralidade das variáveis $y_{j \tau}$;

2. A grande quantidade de padrões de corte que podem ser gerados.

Geralmente, devido a essas dificuldades, na prática as empresas de móveis optam por resolver o problema integrado decompondo-o em dois subproblemas: o problema de dimensionamento de lotes e o problema de corte de estoque. Mas, ao resolver o problema decomposto pode-se encontrar infactibilidades na produção, pois a quantidade de peças necessárias para a produção do período (obtida pela resolução do problema de dimensionamento de lotes) pode ser maior que a capacidade da serra para cortar todas as peças (restrição do problema de corte de estoque). Entretanto, se os problemas forem resolvidos de forma integrada, pode-se antecipar a produção de certos lotes, a fim de obter uma melhor utilização das máquinas ou evitar períodos em que os limites de capacidade da serra sejam ultrapassados.

\section{- Observações}

1. Note que a restrição (4.4) não considera a variável de estoque para as peças, isso porque na indústria considerada não é possível estocar todas as peças separadamente devido a falta de espaço físico e também pela dificuldade operacional;

2. Na função objetivo o custo de perda de material no processo de corte é contabilizado apenas no primeiro período, assim, somamos uma estimativa do custo de perda de material ao custo de produção para os períodos 2 a $T$;

3. Na restrição (4.5) a serra pode cortar, ao mesmo tempo, uma certa quantidade de placas $(q)$, dependendo da espessura e que chamamos de lote de placas. O tempo gasto para cortar uma placa é dado por $v_{j \tau}=\frac{\bar{v}_{j \tau}}{q}$ (estimado), em que $\bar{v}_{j \tau}$ é o tempo 
médio do ciclo da serra (neste modelo consideramos $v_{j \tau}=v$, ou seja, um parâmetro constante). A experiência prática mostra que a empresa corta em média 50 lotes de placas por subperíodo (ciclos da serra).

4. Na restrição (4.7) o tempo gasto para cortar todas as peças que compõem uma unidade do produto $i\left(t c_{i}\right)$ é dado pelo produto entre o número estimado de placas usadas para compor o produto $i$ e o tempo estimado de cortar uma placa.

5. A demanda esperada do produto $i\left(D_{i}\right)$ durante o horizonte de planejamento dada na restrição (4.3) representa a soma da demanda em carteira $\left(d_{i t}\right)$ mais uma expectativa de vendas extra, a qual chamamos também de "demanda extra" $\left(E_{i t}\right)$. Essa expectativa de venda é determinada pelo gerente de produção da empresa e baseada em sua experiência profissional e bom senso. Podemos entender $E_{i t}$ como uma variável "oportunista" que decidirá em quais períodos e em que quantidades a demanda extra será produzida, de modo que melhor combinem com os produtos já programados referentes à demanda em carteira.

6. A perda inerente à serra é em média $4 m m$ e, sem perda de generalidade, supomos que as dimensões das peças e da placa já tenham sido aumentadas por este valor: $l_{i} \leftarrow l_{i}+\sigma, w_{i} \leftarrow w_{i}+\sigma, L \leftarrow L+\sigma$ e $W \leftarrow W+\sigma$, em que $\sigma$ é a perda da serra (Gilmore \& Gomory (1965)). Em Arenales et al. (2004) é apresentada uma modelagem considerando a perda inerente à serra, para o problema de corte unidimensional.

As estratégias de horizonte rolante e estoque de produtos finais referentes à demanda extra (baseada em expectativas de vendas) são utilizados com frequência para atenuar o componente estocástico da demanda. A demanda extra representada no modelo pela variável $E_{i t}$ gera uma produção extra e conseqüentemente um nível de estoque extra dos produtos finais, motivo pelo qual denominamos $E_{i t}$ como uma variável "oportunista". Porém este estoque "extra" difere do estoque convencinal $I_{i t}$ determinado pela demanda em carteira. Vejamos a seguir porque não consideramos a demanda extra como o estoque convencional.

Suponhamos um horizonte de planejamento com 2 períodos, 1 produto final, as demandas em carteira $d_{11}=10$ e $d_{12}=10$, e a demanda esperada a ser vendida do produto 1, $D_{1}=30$. Assim, denotando $E_{1 t}$ como demanda extra do produto 1 no período $t$, 
teríamos:

$$
\begin{aligned}
& \begin{cases}x_{i t}+I_{i(t-1)}=d_{i t}+E_{i t}+I_{i t} & i=1 ; \quad t=1,2 \\
\sum_{t=1}^{T}\left(d_{i t}+E_{i t}\right)=D_{i} & i=1 \\
x_{i t} \geq 0, E_{i t} \geq 0 & i=1 ; \quad t=1,2\end{cases} \\
& \left\{\begin{array} { l } 
{ x _ { 1 1 } + I _ { 1 0 } = d _ { 1 1 } + E _ { 1 1 } + I _ { 1 1 } } \\
{ x _ { 1 2 } + I _ { 1 1 } = d _ { 1 2 } + E _ { 1 2 } + I _ { 1 2 } } \\
{ d _ { 1 1 } + E _ { 1 1 } + d _ { 1 2 } + E _ { 1 2 } = D _ { 1 } } \\
{ x _ { 1 1 } \geq 0 , x _ { 1 2 } \geq 0 , E _ { 1 1 } \geq 0 , E _ { 1 1 } \geq 0 }
\end{array} \Rightarrow \left\{\begin{array}{l}
20+0=10+10+0 \\
10+0=10+0+0 \\
10+10+10+0=30
\end{array}\right.\right.
\end{aligned}
$$

Observe que a solução (4.2) obtida para o modelo (4.1) atende a demanda esperada do produto 1, sendo que a demanda extra será toda produzida no primeiro período. Rolando o horizonte, o segundo período passa a ser o primeiro, os dados são atualizados e eventualmente a demanda em carteira pode ser atendida pelos produtos em estoque no período correspondente.

Considerando a variável $E_{i t}$ como a própria variável de estoque $I_{i t}$ teríamos:

$$
\begin{gathered}
\begin{cases}x_{i t}+I_{i(t-1)}=d_{i t}+I_{i t} & i=1 ; \quad t=1,2 \\
\sum_{t=1}^{T}\left(d_{i t}+I_{i t}\right)=D_{i} & i=1 \\
x_{i t} \geq 0 & i=1 ; \quad t=1,2\end{cases} \\
\left\{\begin{array} { l } 
{ x _ { 1 1 } + I _ { 1 0 } = d _ { 1 1 } + I _ { 1 1 } } \\
{ x _ { 1 2 } + I _ { 1 1 } = d _ { 1 2 } + I _ { 1 2 } } \\
{ d _ { 1 1 } + I _ { 1 1 } + d _ { 1 2 } + I _ { 1 2 } = D _ { 1 } }
\end{array} \Rightarrow \left\{\begin{array}{l}
20+0=10+10 \\
0+10=10+0 \\
10+10+10+0=30
\end{array}\right.\right.
\end{gathered}
$$

Observamos que ao considerar a variável $E_{i t}$ como uma variável típica de estoque as restrições são satisfeitas, mas por outro lado a solução não atende a meta de produzir 30 unidades do produto 1 no horizonte de planejamento, são produzidos apenas 20. Esse fato mostra que a variável $E_{i t}$ não pode ser entendida simplesmente como uma variável de estoque convencional.

Segue no próximo capítulo uma breve revisão da teoria da relaxação Lagrangina, que pode ser usada na resolução do problema-chave desta dissertação. 


\section{Capítulo 5}

\section{Relaxação Lagrangiana}

\subsection{Introdução}

A relaxação lagrangiana é uma técnica bastante utilizada para resolver problemas de otimização combinatória. De maneira simplificada, a idéia principal desta técnica é relaxar um conjunto de restrições complicadas, eliminando-as do problema e incorporá-las na função objetivo, multiplicadas por penalidades, chamadas multiplicadores de Lagrange. A relaxação de restrições apropriadas procura gerar um problema lagrangiano fácil de resolver, cujo valor da solução ótima é um limite inferior (para problemas de minimização) para o valor ótimo do problema original, possibilitando estimar a proximidade de uma solução viável disponível da solução ótima.

Os precursores do uso eficiente dos métodos de relaxação lagrangiana foram Held \& Karp (1970) e Held \& Karp (1971), com as publicações sobre a resolução do problema do caixeiro viajante. Geoffrion (1974) definiu formalmente o termo "relaxação lagrangiana" para a resolução de problemas de otimização inteira.

\subsection{Relaxação Lagrangiana e o Problema Dual La- grangiano}

Considere o problema de otimização linear inteiro $(P)$ :

$$
\begin{array}{ll}
z(P)=\min & c x \\
\text { sujeito a: } & \left\{\begin{array}{l}
A x=b \\
C x \leq d \\
x \in \mathbb{Z}_{+}^{n}
\end{array}\right.
\end{array}
$$


em que $c^{t} \in R^{n}, x \in R^{n}, A \in R^{m \times n}, b \in R^{m}, C \in R^{p \times n}, d \in R^{p}$. Denotamos por $F(P)$ a região factível do problema $(P)$ e $z(P)$ o valor ótimo da função objetivo do problema $(P)$.

Suponhamos que o conjunto de restrições $A x=b$ sejam restrições complicadas, sem as quais o problema $(P)$ apresente uma estrutura mais simples de se resolver.

Definição 5.2.1 A relaxação lagrangiana de $(P)$ com relação ao conjunto de restrições $A x=b$, com um vetor multiplicador de Lagrange $\lambda^{t} \in R^{m}$ é dada por:

$$
\begin{array}{ll}
z\left(L R_{\lambda}\right)=\min & L(x, \lambda) \\
\text { sujeito } a: & \left\{\begin{array}{l}
C x \leq d \\
x \in \mathbb{Z}_{+}^{n}
\end{array} \quad\left(L R_{\lambda}\right)\right.
\end{array}
$$

em que $L(x, \lambda)=c x+\lambda(A x-b)$ é chamada de função Lagrangiana, $z\left(L R_{\lambda}\right)$ é o valor ótimo do problema relaxado e $F\left(L R_{\lambda}\right)$ denota a região factível do problema $\left(L R_{\lambda}\right)$. Este problema resultante é chamado problema Lagrangiano.

Dizemos que as restrições $A x=b$ do problema $(\mathrm{P})$ foram dualizadas e o problema $\left(L R_{\lambda}\right)$ é uma relaxação de $(\mathrm{P})$, pois:

- $F\left(L R_{\lambda}\right) \supseteq F(P), \mathrm{e}$

- $\forall x \in F(P)$ e qualquer $\lambda, z\left(L R_{\lambda}\right) \leq z(P)$.

Note que para cada $\lambda$ há um problema $\left(L R_{\lambda}\right)$ associado, o qual fornece um limitante inferior para o valor ótimo do problema $(\mathrm{P})$. A importância da relaxação lagrangiana nesse sentido é determinar um limitante inferior mais próximo possível do valor ótimo de $(\mathrm{P})$. No caso de fornecer soluções infactíveis para o problema original, essas soluções podem ser utilizadas como pontos iniciais para heurísticas especializadas (heurísticas lagrangianas).

Um critério para a escolha mais apropriada de $\lambda$ é aquele que fornece o maior limitante inferior lagrangiano, sugerindo o seguinte problema:

$$
z(D)=\max \quad z\left(L R_{\lambda}\right)
$$

o qual é denominado problema dual Lagrangiano do problema primal (P) e $z(D)$ é o valor ótimo do problema. 
As condições suficientes para que uma solução do problema $\left(L R_{\lambda}\right)$ seja solução ótima ou quase-ótima do problema original $(P)$ podem ser encontradas no teorema apresentado por Geoffrion (1974):

Teorema 5.2.1 Se para um dado $\lambda$, um vetor $x$ satisfaz as seguintes condições:

(i) $x$ é ótimo para o problema Lagrangiano $\left(L R_{\lambda}\right)$;

(ii) $A x=b, x$ é factível para o problema original $(P)$;

(iii) $\lambda(A x-b)=0$ (isto é, $(\lambda, x)$ satisfaz as folgas complementares);

então x é solução ótima de $(P)$. Se x satisfazer $(i)$, (ii) mas não (iii), então dizemos que $x$ é uma solução $\epsilon$-ótima de $(P) \operatorname{com} \epsilon=\lambda(A x-b)$

Assim, a importância da relaxação lagrangiana é encontrar limitantes inferiores para $z(P)$, bem como possibilitar a obtenção de uma solução ótima ou quase-ótima de $(\mathrm{P})$. A qualidade da solução factível obtida pela relaxação lagrangiana é dada pelo "gap"dual entre $z(P)$ e $z(D)$, que é a diferença entre os valores das funções objetivos primal e dual $z(P)-z(D)$.

Para a resolução do problema dual, pode ser utilizado o método do subgradiente, que é uma adaptação do método do gradiente, apresentado mais adiante.

\subsection{Método do Subgradiente}

A idéia principal do método do subgradiente é aplicar uma busca na direção de um subgradiente da função $z\left(L R_{\lambda}\right)$, analogamente ao método do gradiente. O método do subgradiente é de fácil implementação e, em geral, fornece boas aproximações à solução dual, mas sua eficiência depende de alguns fatores como do subproblema a ser resolvido em cada iteração, da obtenção de um bom conjunto de multiplicadores para os problemas duais correspondentes, do tamanho do passo e do critério de parada.

Dado um multiplicador inicial $\lambda^{0}$, uma sequência $\left\{\lambda^{k}\right\}$ de multiplicadores lagrangianos é gerada por:

$$
\lambda^{k+1}=\lambda^{k}+t_{k}\left(A x^{k}-b\right)
$$

em que $x^{k}$ é a solução ótima do problema $\left(L R_{\lambda}\right)$ na iteração $\mathrm{k}, t_{k}$ é um escalar positivo que indica o tamanho do passo e $\left(A x^{k}-b\right)^{T}=s^{k}$ é um subgradiente da função $Z\left(L R_{\lambda}\right)$ em $\lambda=\lambda^{k}$. Por ser um método fácil de implementar e ter mostrado bom desempenho para muitos problemas práticos (Fisher (1981)), o método do subgradiente é um boa opção para se obter uma solução para o problema (D). 
A dificuldade dos métodos que utilizam (5.1) decorre do fato que o subgradiente $s^{k}$ nem sempre é uma direção de subida, como ocorre no método do gradiente, o que faz com que a taxa de convergência de tais algoritmos esteja estritamente ligada à determinação do tamanho do passo na direção do subgradiente $s^{k}$ (Florentino (1990)). As propriedades de convergência do método do subgradiente são apresentadas em Held et al. (1974) e o resultado teórico fundamental com relação ao passo $t_{k}$ é que $z\left(L R_{\lambda^{k}}\right) \rightarrow z(D)$ se:

- $t_{k} \rightarrow 0$ e $\sum_{i=0}^{k} t_{i} \rightarrow \infty$ quando $k \rightarrow \infty$;

Existem algumas propostas na literatura que relatam a escolha do tamanho do passo $t_{k}$ com o objetivo de obter uma taxa de convergência mais rápida. A mais usada na prática é:

$$
t_{k}=\sigma_{k} \frac{z(P)^{*}-z\left(L R_{\lambda^{k}}\right)}{\left\|s^{k}\right\|^{2}}
$$

em que $\sigma_{k}$ é um escalar satisfazendo $0<\sigma_{k} \leq 2$ e $z(P)^{*}$ é um limitante superior de $z(D)$, geralmente obtido por heurísticas aplicadas a $(\mathrm{P})$, para obter uma boa solução factível.

Para problemas de minimização da forma $(P)$, o algoritmo do subgradiente é o seguinte:

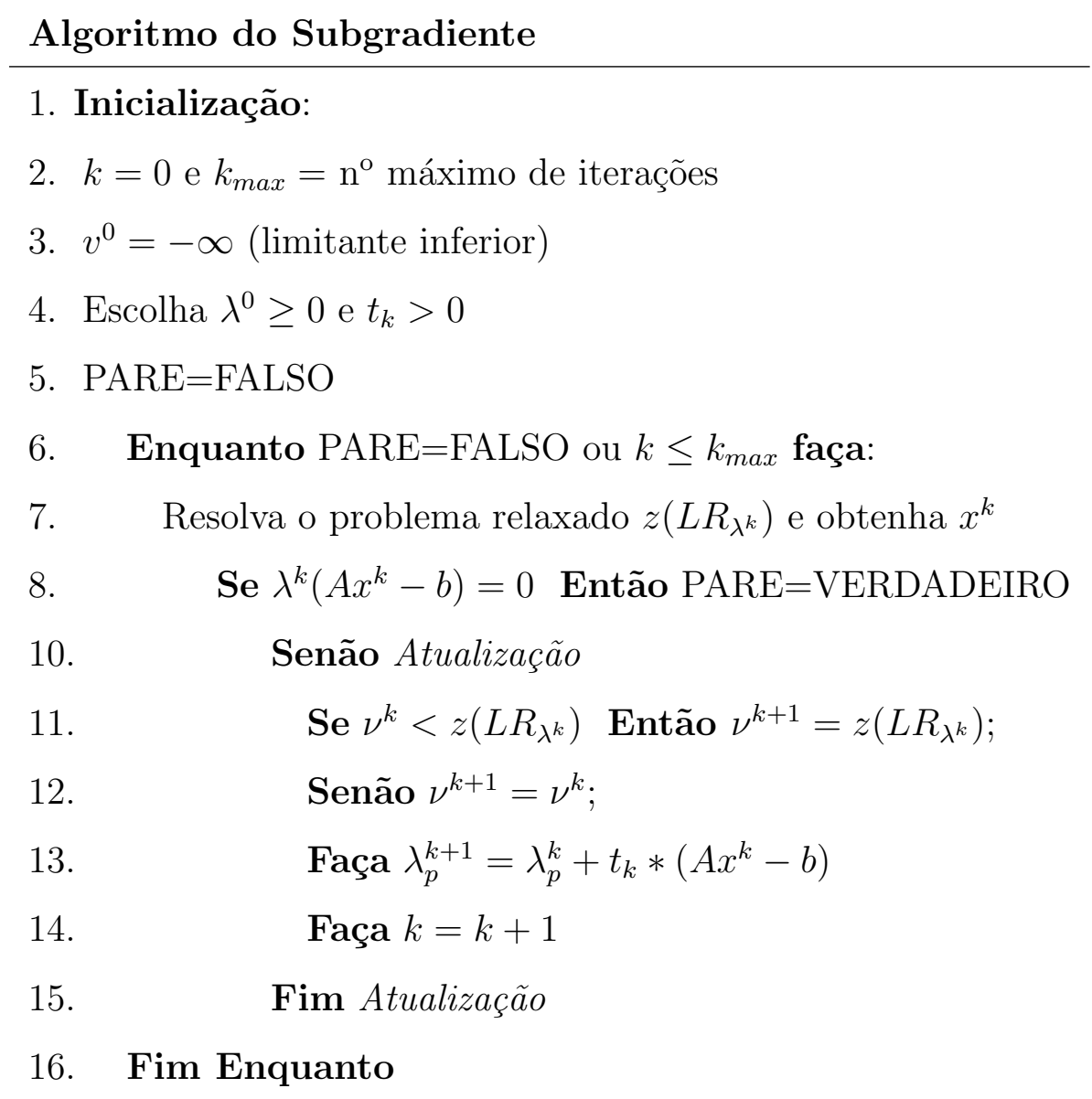




\section{Capítulo 6}

\section{Resolução do Modelo Integrado por Relaxação Lagrangiana}

\subsection{Relaxação Lagrangiana do Modelo Integrado \\ O problema-chave estudado nesta dissertação representado pelo modelo (4.1)-(4.10)}

tem sua dificuldade aumentada devido às restrições (4.4), a qual integra dois problemas de otimização já complexos, o problema de dimensionamento de lotes (PDL) e o problema de corte de estoque (PCE). As condições de integralidade das variáveis de corte $y_{j \tau}$ são relaxadas e os padrões utilizados são os padrões de corte guilhotinados em 2-estágios exatos.

O método de solução proposto é baseado na relaxação lagrangiana. As restrições de acoplamento (4.4) são dualizadas e incorporadas na função objetivo com um multiplicador $\lambda_{p}\left(\lambda_{p}\right.$ irrestrito de sinal pois as restrições que foram dualizadas são restrições de igualdade), $p=1, \ldots, P$, obtendo o problema lagrangiano: 


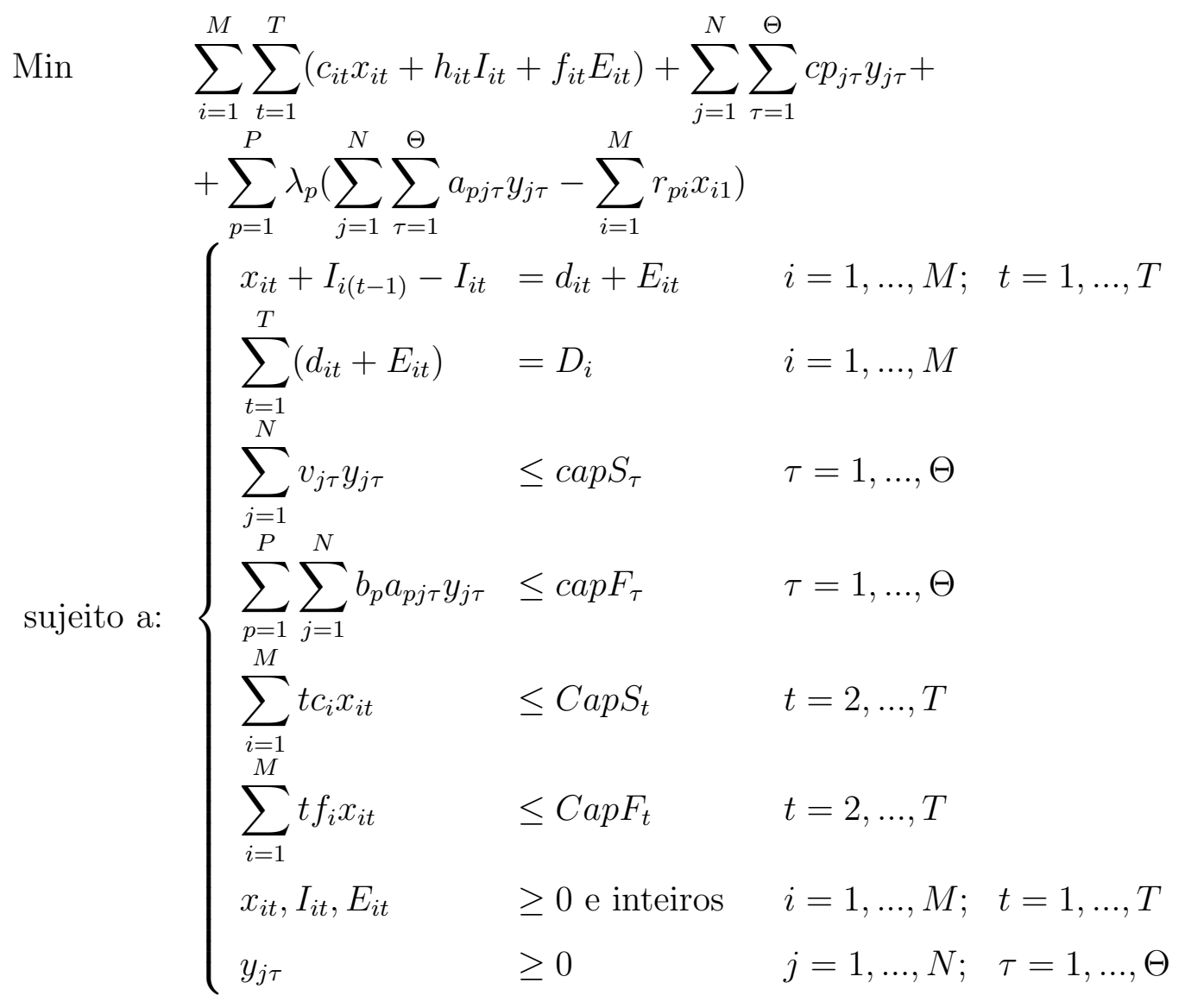

Como visto na seção 5.2, se resolvido otimamente, a solução do problema Lagrangiano fornece um limitante inferior para o problema original, assim para cada $\lambda_{p}, p=1, \ldots, P$, o problema lagrangiano (6.1) forneceria um limitante inferior para a solução ótima do problema integrado (4.1) - (4.10). Procuramos portanto, obter os multiplicadores lagrangianos que forneçam o maior dos limitantes inferiores, para obtermos uma solução mais próxima possível da solução ótima do problema (4.1) - (4.10).

Primeiramente, observamos que o modelo (6.1) pode ser decomposto em dois subproblemas: um problema de dimensionamento de lotes e um problema de corte de estoque, o qual denominaremos subproblema 1 e subproblema 2, nos grupos de variáveis $\left(x_{i t}, I_{i t}\right.$ e $\left.E_{i t}\right)$ e $\left(y_{j \tau}\right)$, respectivamente. A seguir, apresentamos estes subproblemas e seus respectivos métodos de solução.

\subsection{Subproblema 1}

O subproblema 1 é dado a seguir: 


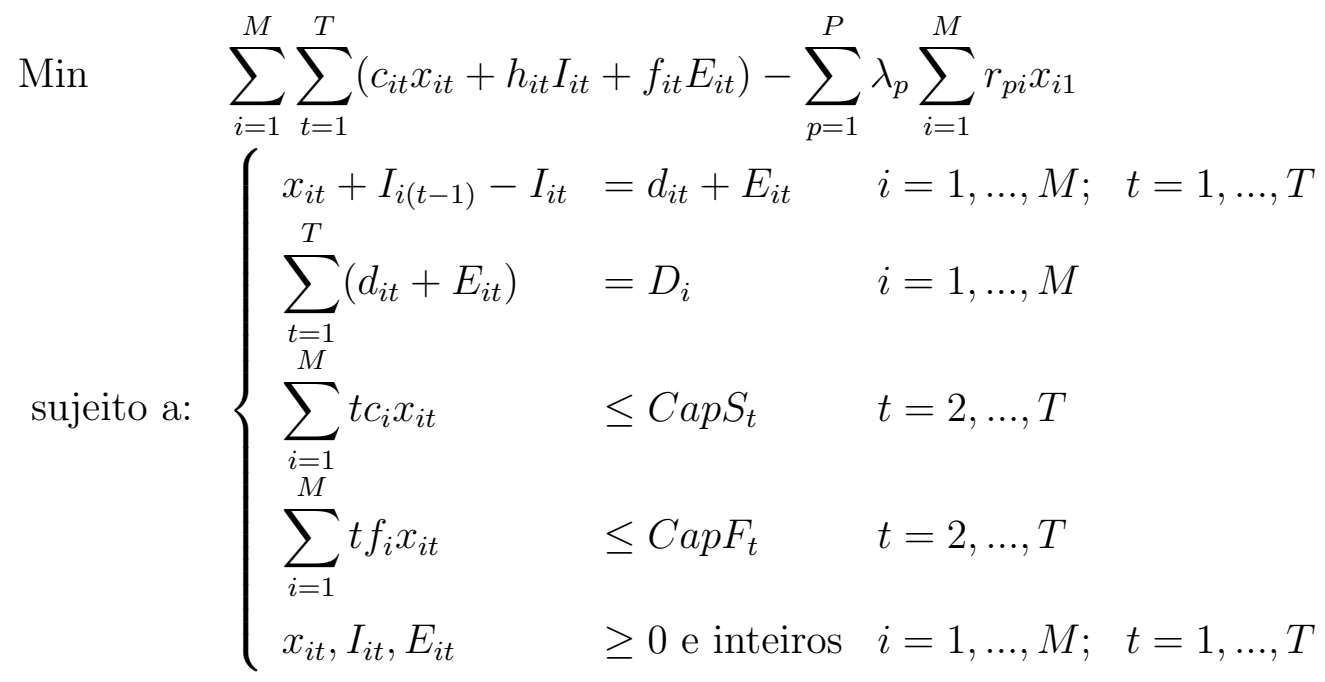

A função objetivo do modelo (6.2) pode ser reescrita como:

$$
\operatorname{Min} \sum_{i=1}^{M}\left[\left(c_{i 1}-\sum_{p=1}^{P} \lambda_{p} r_{p i}\right) x_{i 1}+\sum_{t=2}^{T} c_{i t} x_{i t}+\sum_{t=1}^{T}\left(h_{i t} I_{i t}+f_{i t} E_{i t}\right)\right]
$$

Assim, o subproblema 1 pode ser reescrito como:

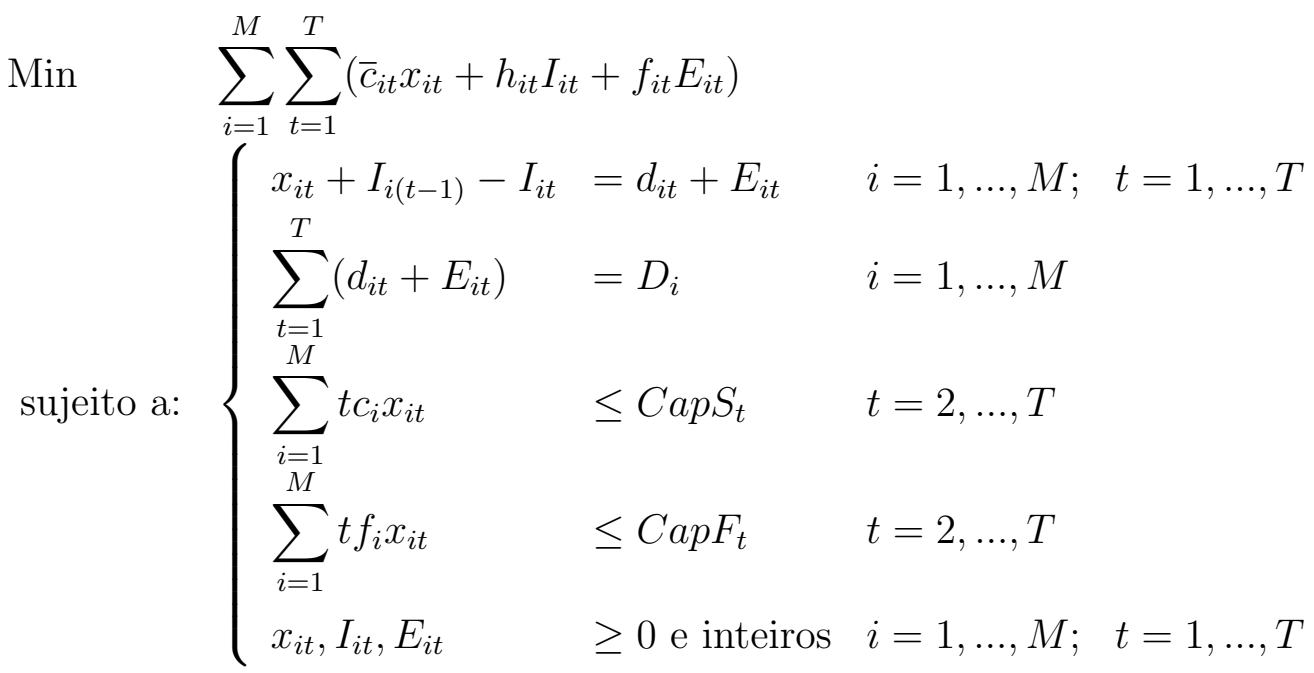

em que

$$
\begin{array}{r}
\bar{c}_{i t}=\left(c_{i 1}-\sum_{p=1}^{P} \lambda_{p} r_{p i}\right) ; \text { para } t=1, i=1, \ldots, M \\
\bar{c}_{i t}=c_{i t} ; \text { para } t=2, \ldots, T, i=1, \ldots, M
\end{array}
$$

Este subproblema de dimensionamento de lotes é linear e pode ser resolvido por algum software de otimização linear. Porém, propomos um método heurístico de busca a ser 
aplicado na resolução deste subproblema. Santos (1996) utiliza uma abordagem similar para a resolução de um problema de dimensionamento de lotes multiestágio.

Inicialmente consideramos o problema primal dado pela função objetivo e pelas restrições do subproblema 1 que representam o balanço de estoque dos produtos finais e o atendimento à demanda esperada ( $1^{\mathrm{a}}$ e $2^{\mathrm{a}}$ restrições), ou seja, relaxamos as restrições de capacidade, obtendo o seguinte modelo:

$$
\begin{aligned}
& \text { Min } \sum_{i=1}^{M} \sum_{t=1}^{T}\left(\bar{c}_{i t} x_{i t}+h_{i t} I_{i t}+f_{i t} E_{i t}\right) \\
& \text { sujeito a: } \begin{cases}x_{i t}+I_{i(t-1)}-I_{i t} & =d_{i t}+E_{i t} \quad i=1, \ldots, M ; \quad t=1, \ldots, T \\
\sum_{t=1}^{T} E_{i t} & =D_{i}-\sum_{t=1}^{T} d_{i t} \quad i=1, \ldots, M \\
x_{i t}, I_{i t}, E_{i t} & \geq 0 \text { e inteiros } \quad i=1, \ldots, M ; \quad t=1, \ldots, T\end{cases}
\end{aligned}
$$

\begin{tabular}{|c|c|c|c|c|c|c|c|c|c|c|c|c|}
\hline \multicolumn{4}{|c|}{$x_{i t}$} & \multicolumn{4}{|c|}{$I_{i t}$} & \multicolumn{4}{|c|}{$E_{i t}$} & Vetor de recursos \\
\hline \multicolumn{4}{|c|}{$t=1, \ldots, T$} & \multicolumn{4}{|c|}{$t=1, \ldots, T$} & \multicolumn{4}{|c|}{$t=1, \ldots, T$} & $\mathrm{t}=1, \ldots, \mathrm{T}$ \\
\hline$i=1$ & $i=2$ & $\ldots$ & $i=M$ & $i=1$ & $i=2$ & $\ldots$ & $i=M$ & $i=1$ & $i=2$ & $\ldots$ & $i=M$ & \\
\hline$x_{1 t}$ & $x_{2 t}$ & $\ldots$ & $x_{M T}$ & $I_{1 t}$ & $I_{2 t}$ & $\ldots$ & $I_{M T}$ & $E_{1 t}$ & $E_{2 t}$ & $\ldots$ & $E_{M T}$ & \\
\hline I & 0 & $\ldots$ & 0 & $-\mathrm{I}$ & 0 & $\ldots$ & 0 & $-\mathrm{I}$ & 0 & $\ldots$ & 0 & {$\left[d_{1 t}\right]_{T \times 1}$} \\
\hline 0 & I & $\ldots$ & 0 & I & $-\mathrm{I}$ & $\ldots$ & 0 & 0 & $-\mathrm{I}$ & $\ldots$ & 0 & {$\left[d_{2 t}\right]_{T \times 1}$} \\
\hline$\ldots$ & $\ldots$ & $\ldots$ & $\cdots$ & $\ldots$ & $\ldots$ & $\ldots$ & ... & $\cdots$ & ... & $\ldots$ & $\ldots$ & $\ldots$ \\
\hline 0 & 0 & $\ldots$ & I & 0 & 0 & $\ldots$ & $-\mathrm{I}$ & 0 & 0 & $\ldots$ & $-\mathrm{I}$ & {$\left[d_{3 t}\right]_{T \times 1}$} \\
\hline 0 & 0 & $\ldots$ & 0 & 0 & 0 & $\ldots$ & 0 & {$[1]_{1 \times T}$} & 0 & $\ldots$ & 0 & $D_{1}-\sum_{t=1}^{T} d_{1 t}$ \\
\hline 0 & 0 & $\ldots$ & 0 & 0 & 0 & $\ldots$ & 0 & 0 & {$[1]_{1 \times T}$} & $\ldots$ & 0 & $D_{2}-\sum_{t=1}^{t} d_{2 t}$ \\
\hline$\cdots$ & $\cdots$ & $\ldots$ & $\cdots$ & $\cdots$ & $\cdots$ & $\ldots$ & $\ldots$ & $\cdots$ & $\ldots$ & $\cdots$ & $\ldots$ & $\cdots$ \\
\hline 0 & 0 & $\ldots$ & 0 & 0 & 0 & $\ldots$ & 0 & 0 & 0 & $\ldots$ & {$[1]_{1 \times T}$} & $D_{i}-\sum_{t=1} d_{M t}$ \\
\hline
\end{tabular}

Na tabela 6.1 apresentamos a estrutura da matriz de restrições do modelo (6.7).

Tabela 6.1: Matriz de restrições do problema primal (6.7)

Para efeito de melhor compreensão, consideremos um modelo em que a matriz de restrições do problema primal (6.7) apresenta 2 produtos finais e o horizonte de planejamento com 3 períodos de tempo $(M=2$ e $T=3)$. Assim, a matriz de restrições tem a estrutura da tabela 6.2.

A resolução do modelo (6.7) é obtida por inspeção usando o problema dual, construído definindo-se as variáveis duais $\pi_{i t}$ e $\beta_{i}$, relacionadas com as restrições de balanço de estoque e de atendimento à demanda, respectivamente. O problema dual é dado por: 


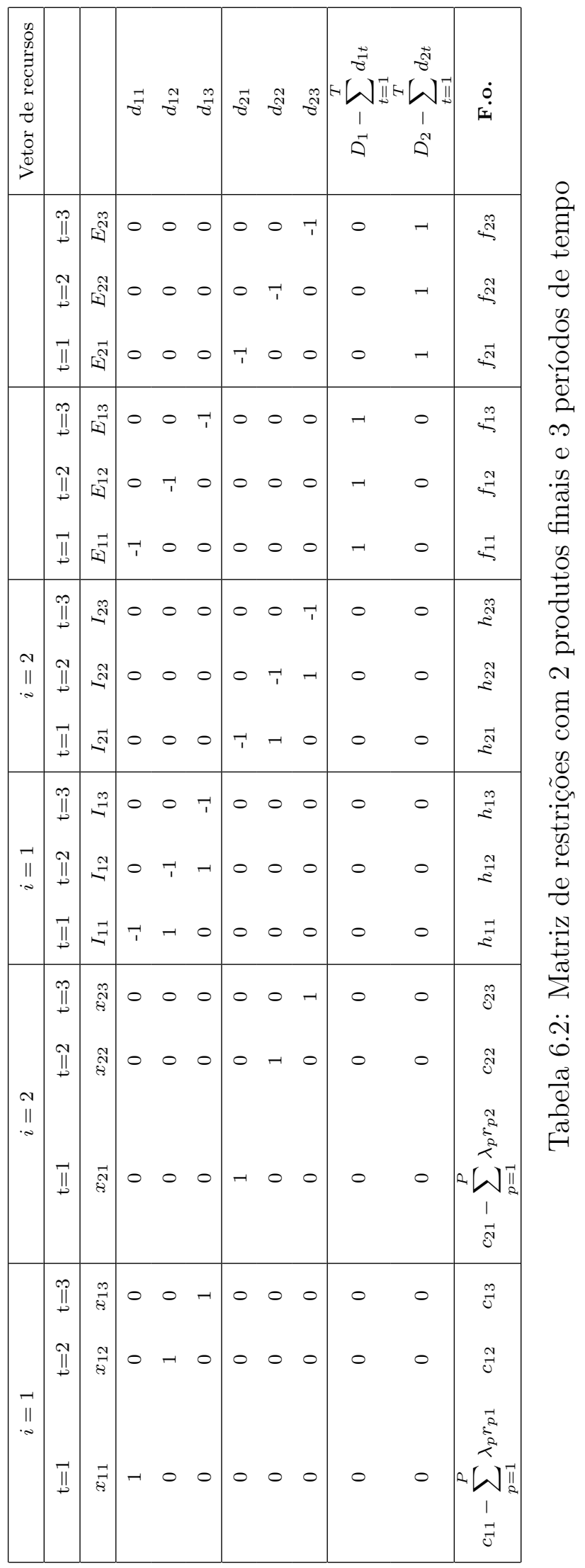


$\begin{aligned} & \operatorname{Max} \sum_{i=1}^{M} \sum_{t=1}^{T} \pi_{i t} d_{i t}+\sum_{i=1}^{M} \beta_{i}\left(D_{i}-\sum_{t=1}^{T} d_{i t}\right) \\ & \text { sujeito a: }\left\{\begin{array}{lr}\pi_{i t} & i=1, \ldots, M ; t=1, \ldots, T \\ -\pi_{i t}+\pi_{i(t+1)} \leq h_{i t} \quad i=1, \ldots, M ; t=1, \ldots, T \\ -\pi_{i t}+\beta_{i} & \leq f_{i t} \quad i=1, \ldots, M ; t=1, \ldots, T \\ \pi_{i t}, \beta_{i} \text { livres } & i=1, \ldots, M ; t=1, \ldots, T\end{array}\right.\end{aligned}$

Vejamos de maneira mais detalhada a resolução do problema dual em (6.8) e a obtenção da solução primal com o auxílio das folgas complementares. Note, por definição, que $\bar{c}_{i t}=c_{i 1}-\sum_{p=1}^{P} \lambda_{p} r_{p i}$ para $t=1$ e $\bar{c}_{i t}=c_{i t}$ para $t=2, \ldots, T, i=1, \ldots, M$.

- Para $\mathrm{i}=1(\mathrm{t}=1, \ldots, \mathrm{T})$

Com relação ao primeiro conjunto de restrições do problema dual temos:

$$
\pi_{1 t} \leq \bar{c}_{1 t} \Rightarrow\left\{\begin{array}{l}
\pi_{11} \leq c_{11}-\sum_{p=1}^{P} \lambda_{p} r_{p 1} \\
\pi_{12} \leq c_{12} \\
\cdots \\
\pi_{1 T} \leq c_{1 T}
\end{array}\right.
$$

O segundo conjunto de restrições duais fornece:

$$
-\pi_{1 t}+\pi_{1(t+1)} \leq h_{1 t} \Rightarrow\left\{\begin{array} { l } 
{ - \pi _ { 1 1 } + \pi _ { 1 2 } } \\
{ - \pi _ { 1 2 } + \pi _ { 1 3 } \leq h _ { 1 1 } } \\
{ \cdots } \\
{ - \pi _ { 1 ( T - 1 ) } + \pi _ { 1 T } \leq h _ { 1 2 } }
\end{array} \Rightarrow \left\{\begin{array}{l}
\pi_{12} \leq \pi_{11}+h_{11} \\
\pi_{13} \leq \pi_{12}+h_{12} \\
\cdots \\
\pi_{1 T} \leq \pi_{1(T-1)}+h_{1(T-1)}
\end{array}\right.\right.
$$

E com relação ao terceiro conjunto de restrições duais temos:

$$
-\pi_{1 t}+\beta_{1} \leq f_{1 t} \Rightarrow\left\{\begin{array} { l } 
{ - \pi _ { 1 1 } + \beta _ { 1 } \leq f _ { 1 1 } } \\
{ - \pi _ { 1 2 } + \beta _ { 1 } \leq f _ { 1 2 } } \\
{ \cdots } \\
{ - \pi _ { 1 ( T ) } + \beta _ { 1 } \leq f _ { 1 T } }
\end{array} \Rightarrow \left\{\begin{array}{l}
\beta_{1} \leq \pi_{11}+f_{11} \\
\beta_{1} \leq \pi_{12}+f_{12} \\
\cdots \\
\beta_{1} \leq \pi_{1 T}+f_{1 T}
\end{array}\right.\right.
$$

Como os coeficientes da função objetivo de (6.8) são todos positivos $\left(d_{i t} \geq 0\right.$ e $D_{i}-$ $\left.\sum_{t=1}^{T} d_{i t} \geq 0\right)$, quanto maior os valores das variáveis $\pi_{i t}$ e $\beta_{i}$ maior o valor da função objetivo. 
Logo, estas variáveis devem ser escolhidas tais que:

$$
\begin{array}{lll}
\pi_{11} & =\bar{c}_{11}=c_{11}-\sum_{p=1}^{P} \lambda_{p} r_{p 1} & \\
\pi_{1 t}=\min _{t}\left\{c_{1 t}, h_{1(t-1)}+\pi_{1(t-1)}\right\} & t=2, \ldots, T \\
\beta_{1}=\min _{t}\left\{\pi_{1 t}+f_{1 t}\right\} & t=1, \ldots, T
\end{array}
$$

- Para $\mathrm{i}=2(\mathrm{t}=1, \ldots, \mathrm{T})$

Com relação ao primeiro conjunto de restrições do problema dual temos:

$$
\pi_{2 t} \leq \bar{c}_{2 t} \Rightarrow\left\{\begin{array}{l}
\pi_{21} \leq c_{21}-\sum_{p=1}^{P} \lambda_{p} r_{p 2} \\
\pi_{22} \leq c_{22} \\
\cdots \\
\pi_{2 T} \leq c_{2 T}
\end{array}\right.
$$

O segundo conjunto de restrições duais fornece:

$$
-\pi_{2 t}+\pi_{2(t+1)} \leq \bar{h}_{2 t} \Rightarrow\left\{\begin{array} { l } 
{ - \pi _ { 2 1 } + \pi _ { 2 2 } } \\
{ - \pi _ { 2 2 } + \pi _ { 2 3 } \leq h _ { 2 1 } } \\
{ \cdots } \\
{ - \pi _ { 2 ( T - 1 ) } + \pi _ { 2 T } \leq h _ { 2 3 } }
\end{array} \Rightarrow \left\{\begin{array}{l}
\pi_{22} \leq \pi_{21}+h_{21} \\
\pi_{23} \leq \pi_{22}+h_{22} \\
\ldots \\
\pi_{2 T} \leq \pi_{2(T-1)}+h_{2(T-1)}
\end{array}\right.\right.
$$

E o terceiro conjunto de restrições duais fornece:

$$
-\pi_{2 t}+\beta_{2} \leq f_{2 t} \Rightarrow\left\{\begin{array} { l } 
{ - \pi _ { 2 1 } + \beta _ { 2 } \leq f _ { 2 1 } } \\
{ - \pi _ { 2 2 } + \beta _ { 2 } \leq f _ { 2 2 } } \\
{ \cdots } \\
{ - \pi _ { 2 ( T ) } + \beta _ { 2 } \leq f _ { 2 T } }
\end{array} \Rightarrow \left\{\begin{array}{l}
\beta_{2} \leq \pi_{21}+f_{21} \\
\beta_{2} \leq \pi_{22}+f_{22} \\
\cdots \\
\beta_{2} \leq \pi_{2 T}+f_{2 T}
\end{array}\right.\right.
$$

Portanto, a melhor escolha para os valores deste grupo de variáveis é dada por:

$$
\begin{array}{lll}
\pi_{21} & =\bar{c}_{21}=c_{21}-\sum_{p=1}^{P} \lambda_{p} r_{p 2} & \\
\pi_{2 t}=\min _{t}\left\{c_{2 t}, h_{2(t-1)}+\pi_{2(t-1)}\right\} & t=2, \ldots, T \\
\beta_{2}=\min _{t}\left\{\pi_{2 t}+f_{2 t}\right\} & t=1, \ldots, T
\end{array}
$$

Generalizando, como os coeficientes da função objetivo do problema (6.8) são todos positivos, $\pi_{i t}$ e $\beta_{i}$ devem ser escolhidos com o maior valor possível e esta escolha deve ser feita de tal maneira que $\pi_{i t}$ e $\beta_{i}$ sejam factíveis, deste modo: 


$$
\begin{gathered}
\pi_{i 1}=\bar{c}_{i 1}=c_{i 1}-\sum_{p=1}^{P} \lambda_{p} r_{p i} \quad i=1, \ldots, M \quad t=1 \\
\pi_{i t}=\min _{t}\left\{c_{i t}, h_{i(t-1)}+\pi_{i(t-1)}\right\} \quad i=1, \ldots, M \quad t=2, \ldots, T \\
\beta_{i}=\min _{t}\left\{\pi_{i t}+f_{i t}\right\} \quad i=1, \ldots, M \quad t=1, \ldots, T
\end{gathered}
$$

Primeiramente, resolve-se o problema dual calculando para cada $i$ e $t$ os valores de $\pi_{i t}$ e $\beta_{i}$ dado pelas relações (6.9), (6.10) e (6.11). Depois, a solução do problema primal (6.7) será construída seqüencialmente, iniciando do último período e trabalhando regressivamente no tempo, para todos os produtos finais e com o auxílio das folgas complementares.

Pela propriedade (A01) sabemos que se $f\left(x^{*}\right)=g\left(\pi^{*}\right)$ então $x^{*}$ e $\pi^{*}$ são soluções ótimas primal e dual, respectivamente (e vice-versa) e pela propriedade (A02) das folgas complementares (ver Apêndice A), uma condição necessária e suficiente para que $x$ seja solução ótima é que exista um $\pi$ dual factível tal que

$$
\left(c^{T}-\pi^{T} A\right) x=0
$$

\section{- Construção de uma solução primal factível}

Apresentamos os passos para a construção de uma solução primal factível, satisfazendo as folgas complementares.

Temos que as variáveis primais $x_{i t}, I_{i t}$ e $E_{i t}$ estão associadas, respectivamente, às seguintes restrições duais:

$$
\left\{\begin{array} { c l } 
{ \pi _ { i t } } & { \leq \overline { c } _ { i t } } \\
{ - \pi _ { i t } + \pi _ { i , t + 1 } } & { \leq h _ { i t } } \\
{ - \pi _ { i t } + \beta _ { i } } & { \leq f _ { i t } }
\end{array} \Rightarrow \left\{\begin{array}{cc}
x_{i t}\left(\bar{c}_{i t}-\pi_{i t}\right) & =0 \\
I_{i, t-1}\left(h_{i, t-1}+\pi_{i, t-1}-\pi_{i t}\right) & =0 \\
E_{i t}\left(f_{i t}+\pi_{i t}-\beta_{i}\right) & =0
\end{array}\right.\right.
$$

Desta maneira, a escolha de $\pi_{i t}$ e $\beta_{i}$ é um indicador se há ou não produção. Observe que se $\pi_{i t}=\bar{c}_{i t}$ na solução dual, então haverá produção do item $i$ no período $t\left(x_{i t} \geq 0\right)$, e o estoque do produto $i$ no período anterior será nulo, isto é,

$$
x_{i t}=d_{i t}+E_{i t}+I_{i t} \quad \text { e } I_{i(t-1)}=0
$$


Caso contrário, se $\pi_{i t}=h_{i(t-1)}+\pi_{i(t-1)}$ na solução dual, não haverá produção do item $i$ no período $t$ e a demanda será atendida pelo estoque do período anterior, isto é,

$$
x_{i t}=0 \quad \text { e } I_{i(t-1)}=d_{i t}+E_{i t}+I_{i t}
$$

Estes resultados podem ser verificados utilizando o teorema das folgas complementares. Vejamos:

- Para o período $t=1$ em (6.9) sempre teremos:

$$
\pi_{i 1}=\bar{c}_{i 1}=\sum_{i=1}^{M}\left(c_{i 1}-\sum_{p=1}^{P} \lambda_{p} r_{p i}\right)
$$

Neste caso, tem-se a restrição (6.8.1) ativa e a restrição (6.8.2) inativa e assim, $x_{i 1}\left(\bar{c}_{i 1}-\pi_{i 1}\right)=0$ será satisfeita com $x_{i 1} \geq 0$ e $I_{i 0}\left(h_{i 0}+\pi_{i 0}-\pi_{i 1}\right)=0$ com $I_{i 0}=0$.

Isto significa que para o primeiro período sempre haverá produção, sendo $x_{i 1}=$ $d_{i 1}+E_{i 1}+I_{i 1}$, para $\mathrm{i}=1, \ldots, \mathrm{M}$. Uma restrição $g_{i}(x) \leq 0$ é chamada "ativa" em um ponto factível $x$ se $g_{i}(x)=0$ e "inativa" em $x$ se $g_{i}(x)<0$, ou seja, é ativa quando um ponto está sobre a fronteira da região factível e inativa quando um ponto está no interior da região factível.

- Para $t=2, \ldots, T$ em $(6.10)$ :

1. Se a escolha for $\pi_{i t}=c_{i t}$, para algum $i$, analogamente ao caso anterior, a restrição (6.8.1) no problema dual é ativa e a restrição (6.8.2) inativa e assim, $x_{i t}\left(\bar{c}_{i t}-\pi_{i t}\right)=0$ será satisfeita com $x_{i t} \geq 0$ e $I_{i(t-1)}\left(h_{i(t-1)}+\pi_{i(t-1)}-\pi_{i t}\right)=0 \operatorname{com} I_{i(t-1)}=0$.

Isso significa que haverá produção do item $i$ no período $t$ e o estoque do período anterior será nulo, ou seja, $x_{i t}=d_{i t}+E_{i t}+I_{i t}$ e $I_{i(t-1)}=0$

2. Se a escolha for $\pi_{i t}=h_{i(t-1)}+\pi_{i(t-1)}$, para algum $i$, então a restrição (6.8.1) no problema dual é inativa e a restrição (6.8.2) ativa e assim, $x_{i t}\left(\bar{c}_{i t}-\pi_{i t}\right)=0$ será satisfeita com $x_{i t}=0$ e $I_{i(t-1)}\left(h_{i(t-1)}+\pi_{i(t-1)}-\pi_{i t}\right)=0 \operatorname{com} I_{i(t-1)} \geq 0$.

Aqui não haverá produção do item $i$ no período $t$ e a demanda neste período será atendida pelo estoque do período anterior, ou seja, $x_{i t}=0$ e $I_{i(t-1)}=$ $d_{i t}+E_{i t}+I_{i t}$ 
- Para $i=1, \ldots, M$ em (6.11) a escolha é dada por:

$$
\beta_{i}=\min _{t}\left\{f_{i t}+\pi_{i t}\right\}=f_{i t_{i}}+\pi_{i t_{i}}
$$

para algum $t_{i}$, então a restrição (6.8.3) do problema dual é ativa, e as folgas complementares $E_{i t}\left(f_{i t}+\pi_{i t}-\beta_{i}\right)=0$ serão satisfeitas com $E_{i t_{i}} \geq 0$, cujo valor será fornecido pela restrição de atendimento a demanda do problema primal:

$$
E_{i t_{i}}=D_{i}-\sum_{t=1}^{T} d_{i t} \text { e } E_{i t}=0 \text { para } t \neq t_{i}
$$

Por exemplo, se $i=1, t=3 \mathrm{e}$

$$
\beta_{1}=\min \left\{f_{11}+\pi_{11}, f_{12}+\pi_{12}, f_{13}+\pi_{13}\right\}=f_{12}+\pi_{12}
$$

Teríamos $t_{1}=2$, e assim, $E_{12}=D_{1}-d_{11}-d_{12}-d_{13}, E_{11}=0$ e $E_{13}=0$.

Depois de obtida a solução do subproblema relaxado (6.7), verificamos a factibilidade das restrições de capacidade do subproblema 1. Note que o primeiro período deve ser incluído às restrições de capacidade, pois no modelo geral as restrições de capacidade do primeiro período estão em termos das variáveis de corte $y_{j \tau}$, as quais não aparecem no subproblema 1. Logo, com as variáveis $x_{i t}$ determinadas, verificamos as seguintes restrições:

$$
\left\{\begin{array}{l}
\sum_{i=1}^{M} t c_{i} x_{i t} \leq \operatorname{CapS}_{t} \quad t=1, \ldots, T \\
\sum_{i=1}^{M} t f_{i} x_{i t} \leq \operatorname{CapF}_{t} \quad t=1, \ldots, T
\end{array}\right.
$$

Se viola $S_{t}>0$ ou viola $F_{t}>0$ aplicamos a heurística de transferência, em que:

$$
\begin{aligned}
& {\text { viola } S_{t}}^{=}=\sum_{i=1}^{M} t c_{i} x_{i t}-\text { Cap }_{t} \quad t=1, \ldots, T \\
& {\text { viola } F_{t}}^{=}=\sum_{i=1}^{M} t f_{i} x_{i t}-C_{a p F_{t}} t=1, \ldots, T
\end{aligned}
$$

Se a solução do problema (6.7) satisfaz as restrições de capacidade, obtemos uma solução factível para o subproblema 1, e a próxima etapa é a resolução do subproblema 2. Caso contrário, se alguma das restrições de capacidade em (6.17) forem violadas, é aplicada uma heurística de transferência entre os lotes, transferindo-os para períodos anteriores ou posteriores, de acordo com a capacidade disponível em cada período.

A heurística de transferência é baseada na seguinte idéia: 


\section{Procedimento Geral}

1. Leia os valores de $x_{i t}()$;

2. Para $t=1,2, \ldots, T$ faça

3. Calcule viola $S_{t}$ e viola $F_{t}$;

4. Para $k=1,2, \ldots$, MaxIterações faça

5. $\quad$ Para $t=1,2, \ldots, T-1$ faça

6. $\quad$ Se viola $S_{t}>0$ ou viola $F_{t}>0$ faça

7. Transferência Progressiva;

8. - calcule variação do custo em transferir usando $E_{i t}$;

9. - calcule variação do custo em transferir usando $I_{i t}$;

10. - transfere produto $i$ que apresentar menor variação de custo;

11. - atualize viola $S_{t}$ e viola $F_{t}$;

12. Fim Para

13. Para $t=T, \ldots, 2$ faça

14. Se viola $S_{t}>0$ ou viola $F_{t}>0$ faça

15. Transferência Regressiva;

16. - calcule variação do custo em transferir usando $E_{i t}$;

17. - calcule variação do custo em transferir usando $I_{i t}$;

18. - transfere produto $i$ que apresentar menor variação de custo;

19. - atualize viola $S_{t}$ e viola $F_{t}$;

20. $\quad$ Fim Para

21. Fim Para

\section{- Exemplo simplificado da resolução do subproblema 1}

Ilustramos a seguir o método proposto, para a obtenção da solução primal por intermédio da solução dual e com o auxílio das folgas complementares.

Suponha um modelo do problema primal com a matriz de restrições apresentada na tabela 6.2 (com 3 períodos de tempo e 2 tipos de produtos finais). Os custos de produção e de estoque, a demanda em carteira e o número de peças do tipo $p$ necessárias para compor uma unidade do produto final $i$ são dados na tabela 6.3. A demanda esperada do produto $i$ no final do horizonte de planejamento é $D_{1}=12$ e $D_{2}=10$ (os multiplicadores lagrangianos nulos na $1^{\mathrm{a}}$ iteração, isto é, $\left.\lambda_{p}=0, p=1, \ldots P\right)$. 


\begin{tabular}{|c|ccc|ccc|ccc|ccc|ccc|}
\hline & \multicolumn{3}{|c|}{$c_{i t}$} & \multicolumn{3}{|c|}{$h_{i t}$} & \multicolumn{3}{c|}{$f_{i t}$} & \multicolumn{3}{c|}{$d_{i t}$} & \multicolumn{3}{c|}{$r_{p i}$} \\
\hline & $\mathrm{t}=1$ & $\mathrm{t}=2$ & $\mathrm{t}=3$ & $\mathrm{t}=1$ & $\mathrm{t}=2$ & $\mathrm{t}=3$ & $\mathrm{t}=1$ & $\mathrm{t}=2$ & $\mathrm{t}=3$ & $\mathrm{t}=1$ & $\mathrm{t}=2$ & $\mathrm{t}=3$ & $\mathrm{p}=1$ & $\mathrm{p}=2$ & $\mathrm{p}=3$ \\
\hline $\mathrm{i}=1$ & 3 & 3 & 3 & 1 & 1 & 1 & 0.3 & 0.3 & 0.3 & 3 & 0 & 3 & 2 & 3 & 2 \\
\hline $\mathrm{i}=2$ & 5 & 5 & 5 & 2 & 2 & 2 & 0.5 & 0.5 & 0.5 & 0 & 4 & 2 & 2 & 2 & 4 \\
\hline
\end{tabular}

Tabela 6.3: Tabela com dados sobre $c_{i t}, h_{i t}, f_{i t}, d_{i t}$ e $r_{p i}$

Logo, o problema primal será:

Min $[3-2(0)-3(0)-2(0)] x_{11}+3 x_{12}+3 x_{13}+[5-2(0)-2(0)-4(0)] x_{21}+5 x_{22}+5 x_{13}$ $+I_{11}+I_{12}+I_{13}+2 I_{21}+2 I_{22}+2 I_{23}+0.3 E_{11}+0.3 E_{12}+0.3 E_{13}+0.5 E_{21}+0.5 E_{22}+0.5 E_{23}$

$=\operatorname{Min} 3 x_{11}+3 x_{12}+3 x_{13}+5 x_{21}+5 x_{22}+5 x_{23}+I_{11}+I_{12}+I_{13}+2 I_{21}+2 I_{22}+2 I_{23}+2 I_{23}$ $+0.3 E_{11}+0.3 E_{12}+0.3 E_{13}+0.5 E_{21}+0.5 E_{22}+0.5 E_{23}$

sujeito a: $\begin{cases}x_{11}-I_{11}-E_{11} & =3 \\ x_{12}+I_{11}-I_{12}-E_{12} & =0 \\ x_{13}+I_{12}-E_{13} & =3 \\ x_{21}-I_{21}-E_{21} & =0 \\ x_{22}+I_{21}-I_{22}-E_{22} & =4 \\ x_{23}+I_{22}-E_{23} & =2 \\ E_{11}+E_{12}+E_{13} & =6 \\ E_{21}+E_{22}+E_{23} & =4 \\ x_{i t}, I_{i t}, E_{i t} & \geq 0 \quad i=1,2 \quad t=1,2,3\end{cases}$

O problema dual de (6.18) é dado por: 


$$
\begin{aligned}
& \operatorname{Max} 3 \pi_{11}+0 \pi_{12}+3 \pi_{13}+0 \pi_{21}+4 \pi_{22}+2 \pi_{23}+6 \beta_{1}+4 \beta_{2} \\
& \text { sujeito a: }\left\{\begin{aligned}
\pi_{11} & \leq 3-2(0)-3(0)-2(0) \\
\pi_{12} & \leq 3 \\
\pi_{13} & \leq 3 \\
\pi_{21} & \leq 5-2(0)-2(0)-4(0) \\
\pi_{22} & \leq 5 \\
\pi_{23} & \leq 5 \\
-\pi_{11}+\pi_{12} & \leq 1 \\
-\pi_{12}+\pi_{13} & \leq 1 \\
-\pi_{21}+\pi_{22} & \leq 2 \\
-\pi_{11}+\beta_{1} & \leq 2 \\
-\pi_{12}+\beta_{1} & \leq 0.3 \\
-\pi_{13}+\beta_{1} & \leq 0.3 \\
-\pi_{21}+\beta_{2} & \leq 0.5 \\
-\pi_{22}+\beta_{2} & \leq 0.5 \\
-\pi_{23}+\beta_{2} & \leq 0.5 \\
\pi_{i t} \text { irrestrito } & i=1,2 ; t=1,2,3 ; \\
\beta_{i} \text { irrestrito } & i=1,2 ;
\end{aligned}\right.
\end{aligned}
$$

A solução dual é calculada usando (6.9), (6.10) e (6.11), resultando:

$$
\begin{array}{lll}
\pi_{11}=\bar{c}_{11}=3 & \Rightarrow \min \{3,1+3\}=3 \\
\pi_{12}=\min \left\{c_{12}, h_{11}+\pi_{11}\right\} & \Rightarrow & \min \{3,1+3\}=3 \\
\pi_{13}=\min \left\{c_{13}, h_{12}+\pi_{12}\right\} & & \\
\pi_{21}=\bar{c}_{21}=5 & \Rightarrow & \min \{5,2+5\}=5 \\
\pi_{22}=\min \left\{c_{22}, h_{21}+\pi_{21}\right\} & \Rightarrow \min \{5,2+5\}=5 \\
\pi_{23}=\min \left\{c_{23}, h_{22}+\pi_{22}\right\} & \Rightarrow \min \{3.3,3.3,3.3\}=3.3 \\
\beta_{1}=\min \left\{\pi_{11}+f_{11}, \pi_{12}+f_{12}, \pi_{13}+f_{13}\right\} & \Rightarrow \min \{5.5,5.5,5.5\}=5.5 \\
\beta_{2}=\min \left\{\pi_{21}+f_{21}, \pi_{22}+f_{22}, \pi_{23}+f_{23}\right\} & \Rightarrow
\end{array}
$$

No caso de empate para a escolha dos valores mínimos, como por exemplo em $\beta_{1}$ e $\beta_{2}$, escolhemos para mínimo o valor da variável com o menor índice $t$ entre as que empataram. Com as variáveis duais $\pi_{i t}$ e $\beta_{i}$ calculadas, obtemos o valor da função objetivo dual:

$$
\text { f.o. }(\text { dual })=3(3)+0(3)+3(3)+0(5)+4(5)+2(5)+6(3.3)+4(5.5)=89.8
$$


A resolução do problema primal é feita regressivamente do último período para o primeiro. Logo, temos:

- $\mathrm{t}=3$ : Para $\beta_{1}$ e $\beta_{2}$, a escolha foi $\pi_{11}+f_{11}$ e $\pi_{21}+f_{21}$, respectivamente. Assim:

$$
\begin{aligned}
& \beta_{1}=\pi_{1 t_{1}}+f_{1 t_{1}}=\pi_{11}+f_{11}\left(t_{1}=1\right) \\
& \beta_{2}=\pi_{2 t_{2}}+f_{2 t_{2}}=\pi_{21}+f_{21}\left(t_{2}=1\right)
\end{aligned}
$$

Temos que $E_{i t}=D_{i}-\sum_{t=1}^{T} d_{i t}$ para $t=t_{i}$ e $E_{i t}=0$ para $t \neq t_{i}$, então:

$$
\begin{aligned}
& E_{11}=D_{1}-\left(d_{11}+d_{12}+d_{13}\right)=12-(6)=6 \\
& E_{21}=D_{2}-\left(d_{21}+d_{22}+d_{23}\right)=10-(6)=4 \\
& E_{12}=E_{13}=E_{22}=E_{23}=0
\end{aligned}
$$

A escolha em (6.10) para $\pi_{13}$ foi a primeira parte $\left(c_{13}\right)$ e em $\pi_{23}$ foi a primeira parte $\left(c_{23}\right)$ também. Assim, temos:

$$
\begin{aligned}
& x_{13}=d_{13}+E_{13}+I_{13}=3+0+0=3 \\
& I_{12}=0 \\
& x_{23}=d_{23}+E_{23}+I_{23}=2+0+0=2 \\
& I_{22}=0
\end{aligned}
$$

- $\mathrm{t}=2$ : a escolha em (6.10) para $\pi_{12}$ foi a primeira parte $\left(c_{12}\right)$ e em $\pi_{22}$ também foi a primeira parte $\left(c_{22}\right)$. Assim:

$$
\begin{aligned}
& x_{12}=d_{12}+E_{12}+I_{12}=0+0+0=0 \\
& I_{11}=0 \\
& x_{22}=d_{22}+E_{22}+I_{22}=4+0+0=4 \\
& I_{21}=0
\end{aligned}
$$

- $\mathrm{t}=1$ : a escolha em (6.9) é sempre $\pi_{11}=\bar{c}_{11}$ e $\pi_{21}=\bar{c}_{21}$. Logo:

$$
\begin{aligned}
& x_{11}=d_{11}+E_{11}+I_{11}=3+6+0=9 \\
& I_{10}=0 \\
& x_{21}=d_{21}+E_{21}+I_{21}=0+4+0=4 \\
& I_{20}=0
\end{aligned}
$$

Desta maneira, com o auxílio das folgas complementares obtemos a solução primal, e calculamos o valor da função objetivo primal, que é dada por: 
f.o. $($ primal $)=3(9)+3(0)+3(3)+5(4)+5(4)+5(2)+1(0)+1(0)+1(0)+2(0)+$ $2(0)+2(0)+0.3(6)+0.3(0)+0.3(0)+0.5(4)+0.5(0)+0.5(0)=89.8$

Note que os valores das funções objetivo primal e dual são iguais e, portanto, $x_{i t}^{*}$ e $\pi_{i t}^{*}$ são soluções ótimas primal e dual, respectivamente.

Portanto, a solução primal é:

$$
\left\{\begin{array}{llllll}
x_{11}=9 & x_{21}=4 & E_{11}=6 & E_{21}=4 & I_{11}=0 & I_{21}=0 \\
x_{12}=0 & x_{22}=4 & E_{12}=0 & E_{22}=0 & I_{12}=0 & I_{22}=0 \\
x_{13}=3 & x_{23}=2 & E_{13}=0 & E_{23}=0 & I_{13}=0 & I_{23}=0
\end{array}\right.
$$

Obtida a solução $x_{i t}, i=1, \ldots, M, t=1, \ldots, T$, verificamos as restrições (6.17) e se necessário aplicamos a heurística de transferência.

Supondo que as capacidades de serra e de furadeira sejam $C_{a p} S_{t}=18, \forall t$ e $C a p F_{t}=$ 20, $\forall t$, e que os tempos para serrar e furar todas as peças que compõe cada produto final $i$ sejam dados por $t c_{1}=2, t c_{2}=3, t f_{1}=1$ e $t f_{2}=2$, temos:

$$
\left\{\begin{array} { l } 
{ 2 x _ { 1 1 } + 3 x _ { 2 1 } \leq 1 8 } \\
{ 2 x _ { 1 2 } + 3 x _ { 2 2 } \leq 1 8 } \\
{ 2 x _ { 1 3 } + 3 x _ { 2 3 } \leq 1 8 } \\
{ 1 x _ { 1 1 } + 2 x _ { 2 1 } \leq 2 0 } \\
{ 1 x _ { 1 2 } + 2 x _ { 2 2 } \leq 2 0 } \\
{ 1 x _ { 1 3 } + 2 x _ { 2 3 } \leq 2 0 }
\end{array} \Rightarrow \left\{\begin{array}{l}
2(9)+3(4)=30>18 \\
2(0)+3(4)=12 \leq 18 \\
2(3)+3(2)=12 \leq 18 \\
1(9)+2(4)=17 \leq 20 \\
1(0)+2(4)=8 \leq 20 \\
1(3)+2(2)=7 \leq 20
\end{array}\right.\right.
$$

Para $t=1, \ldots, T$ verificamos as restrições de capacidade, se viola $S_{t}>0$ ou viola $F_{t}>0$ aplicamos a heurística de transferência, em que:

$$
\begin{aligned}
\text { viola }_{t} & =\sum_{i=1}^{M} t c_{i} x_{i t}-\text { Cap }_{t} \\
\text { viola }_{t} & =\sum_{i=1}^{M} t f_{i} x_{i t}-C a p F_{t}
\end{aligned}
$$

- Passo Progressivo: $t=1 \rightarrow t=2$

Temos que viola $S_{1}=12$ e viola $F_{1}=-3, \log$ analisamos a variação de custo em transferir o produto $i$ em dois casos:

1. Para $\sum_{i=1}^{M} E_{i 1}>0 \quad\left(E_{11}=6\right.$ e $E_{21}=4$, logo podemos fazer a transferência analisando a produção extra $\left.E_{i 1}\right)$. 
O produto $i=1$ pode ser transferido em 6 unidades, respeitando a capacidade da serra no período seguinte e a variação de custo é $\Delta E_{11}=0$.

O produto $i=2$ pode ser transferido em 4 unidades, respeitando a capacidade da serra no período seguinte e a variação de custo é $\Delta E_{21}=0$.

No caso de empate da variação de custo, escolhemos o produto com menor índice $i$ entre os empatados. Assim, transferimos 6 unidades do produto 1 do primeiro para o segundo período.

2. Para $\sum_{i=1}^{M} I_{i 1}>0 \quad\left(I_{11}=0\right.$ e $I_{21}=0$, logo não é possível transferir nenhum produto analisando o estoque $I_{i 1}$ ).

Os cálculos dessa transferência e da variação de custo são feitos da seguinte maneira:

\begin{tabular}{|c|}
\hline $\mathrm{i}=1$ \\
\hline$Q \operatorname{Emin}_{11}=\min \left\{x_{11}, E_{11}\right\}=\min \{9,6\}=6$ \\
\hline$Q C_{11}=\frac{v i o l a S_{1}}{t c_{1}}=\frac{12}{2}=6$ e $Q F_{11}=\frac{\text { viola } F_{1}}{t f_{1}}=\frac{-3}{1}=-3$ \\
\hline$Q E \max _{11}=\max \left\{\left\lceil Q C_{11}\right\rceil,\left\lceil Q F_{11}\right\rceil\right\}=\max \{6,-3\}=6$ \\
\hline$Q T_{11}=\min \left\{Q \operatorname{Emin}_{11}, Q \operatorname{Emax}_{11}\right\}=\min \{6,6\}=6$ \\
\hline$\Delta V_{11}=-c_{11} * Q T_{11}+c_{12} * Q T_{11}=-3(6)+3(6)=0$ \\
\hline$i=2$ \\
\hline$Q \operatorname{Emin}_{21}=\min \left\{x_{21}, E_{21}\right\}=\min \{4,4\}=4$ \\
\hline$Q C_{21}=\frac{v i o l a S_{1}}{t c_{2}}=\frac{12}{3}=4$ e $Q F_{21}=\frac{v i o l a F_{1}}{t f_{2}}=\frac{-3}{2}=-1.5$ \\
\hline$Q E \max _{21}=\max \left\{\left\lceil Q C_{21}\right\rceil,\left\lceil Q F_{21}\right\rceil\right\}=\max \{4,-1\}=4$ \\
\hline$Q T_{21}=\min \left\{Q \operatorname{Emin}_{21}, Q \operatorname{Emax}_{21}\right\}=\min \{4,4\}=4$ \\
\hline$\Delta V_{21}=-c_{21} * Q T_{21}+c_{22} * Q T_{21}=-5(4)+5(4)=0$ \\
\hline
\end{tabular}

em que:

- QEmin $i t$ é a quantidade possível que se pode transferir do produto $i$ no período $t$; 
- $Q C_{i t}$ e $Q F_{i t}$ indicam o quanto se deve transferir do produto $i$ para eliminar a violação das capacidades de serra ou de furadeirante, no período $t$;

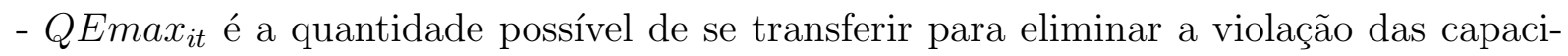
dades de serra e de furadeira no período $t$;

- $Q T_{i t}$ é a quantidade transferida do produto $i$ no período $t$

- $\Delta V_{i t}$ é a variação do custo em transferir $Q T_{i t}$ unidades do produto $i$ do período $t$ para o período $t+1$;

Observação: O passo regressivo nas transferências entre lotes é feito de maneira análoga ao passo pogressivo.

Assim, a nova solução é dada por:

$$
\left\{\begin{array}{llllll}
x_{11}=3 & x_{21}=4 & E_{11}=0 & E_{21}=4 & I_{11}=0 & I_{21}=0 \\
x_{12}=6 & x_{22}=4 & E_{12}=6 & E_{22}=0 & I_{12}=0 & I_{22}=0 \\
x_{13}=3 & x_{23}=2 & E_{13}=0 & E_{23}=0 & I_{13}=0 & I_{23}=0
\end{array}\right.
$$

Verificando as restrições de capacidade temos:

$$
\left\{\begin{array}{l}
2(3)+3(4)=18 \leq 18 \\
2(6)+3(4)=24>18 \\
2(3)+3(2)=12 \leq 18 \\
1(3)+2(4)=11 \leq 20 \\
1(6)+2(4)=14 \leq 20 \\
1(3)+2(2)=7 \leq 20
\end{array}\right.
$$

Obs.: Se a restrição de capacidade da serra no período 1 continuasse violada e $\sum_{i=1}^{M} E_{i 1}>0$, escolheríamos outro produto $i$ para fazer a transferência.

- Passo Progressivo: $t=2 \rightarrow t=3$

Temos que viola $S_{2}=6$ e viola $F_{2}=-6$, novamente analisamos a variação de custo em transferir o produto $i$ em dois casos:

1. Para $\sum_{i=1}^{M} E_{i 2}>0 \quad\left(E_{12}=6\right.$ e $E_{22}=0$, logo podemos fazer a transferência analisando a produção extra $E_{i 2}$ ).

O produto $i=1$ pode ser transferido em 3 unidades, respeitando a capacidade da serra no período seguinte, e a variação de custo é $\Delta E_{12}=0$.

O produto $i=2$ não pode ser transferido pois $E_{22}=0$. 
Assim, transferimos 3 unidades do produto 1 do segundo para o terceiro período.

2. Para $\sum_{i=1}^{M} I_{i 1}>0 \quad\left(I_{21}=0\right.$ e $I_{22}=0$, logo não é possivel transferir nenhum produto analisando o estoque $I_{i 2}$ ).

A nova solução é dada por:

$$
\left\{\begin{array}{llllll}
x_{11}=3 & x_{21}=4 & E_{11}=0 & E_{21}=4 & I_{11}=0 & I_{21}=0 \\
x_{12}=3 & x_{22}=4 & E_{12}=3 & E_{22}=0 & I_{12}=0 & I_{22}=0 \\
x_{13}=6 & x_{23}=2 & E_{13}=3 & E_{23}=0 & I_{13}=0 & I_{23}=0
\end{array}\right.
$$

em que o valor da função objetivo permanece 89.8. Verificando novamente as restrições de capacidade:

$$
\left\{\begin{array}{l}
2(3)+3(4)=18 \leq 18 \\
2(3)+3(4)=18 \leq 18 \\
2(6)+3(2)=18 \leq 18 \\
1(3)+2(4)=11 \leq 20 \\
1(3)+2(4)=11 \leq 20 \\
1(6)+2(2)=10 \leq 20
\end{array}\right.
$$

Portanto, eliminamos as violações nas restrições e obtemos uma solução factível para o subproblema 1. Como o valor da função objetivo é o mesmo da função objetivo relaxada, a solução é ótima.

Resolvendo o modelo (6.18) capacitado pelo software CPLEX 7.5 obtemos a solução ótima alternativa:

$$
\left\{\begin{array}{llllll}
x_{11}=9 & x_{21}=4 & E_{11}=6 & E_{21}=4 & I_{11}=0 & I_{21}=0 \\
x_{12}=0 & x_{22}=4 & E_{12}=0 & E_{22}=0 & I_{12}=0 & I_{22}=0 \\
x_{13}=3 & x_{23}=2 & E_{13}=0 & E_{23}=0 & I_{13}=0 & I_{23}=0
\end{array}\right.
$$

a qual satisfaz as restrições de capacidade e cujo valor da função objetivo é 89.8 .

\section{- Significado da variável oportunista $E_{i t}$}

Para um melhor entendimento do significado da variável oportunista $E_{i t}$, utilizamos o exemplo simplificado descrito anteriormente. Os dados referentes ao exemplo (6.18) e a solução obtida para o primeiro período foram: 


\begin{tabular}{|l|ccc|c|}
\hline$d_{i t}$ & $\mathrm{t}=1$ & $\mathrm{t}=2$ & $\mathrm{t}=3$ & $D_{i}$ \\
\hline $\mathrm{i}=1$ & 3 & 0 & 3 & 12 \\
$\mathrm{i}=2$ & 0 & 4 & 2 & 10 \\
\hline
\end{tabular}

Tabela 6.4: Demanda em carteira $\left(d_{i t}\right)$ e esperada $\left(D_{i}\right)$ do produto $i$ do exemplo $(6.18)$

\begin{tabular}{|c|c|c|}
\hline $\mathrm{t}=1$ & $t=2$ & $\mathrm{t}=3$ \\
\hline$\left\{\begin{array}{l}d_{11}=3 \\
d-0\end{array}\right.$ & & \\
\hline$d_{21}=0$ & & \\
\hline $\int x_{11}=3$ & $E_{11}=0$ & \\
\hline$\left\{x_{21}=4\right.$ & $E_{21}=4$ & \\
\hline
\end{tabular}

Figura 6.1: Solução referente ao primeiro período do exemplo (6.18)

A solução para o primeiro período mostra que a variável oportunista $E_{21}$ antecipou a produção de 4 unidades extras do produto 2 para o $1^{\circ}$ período, aproveitando folgas nas capacidades de serra e de furadeira neste período. Ao rolarmos o horizonte de planejamento o segundo período passa a ser o primeiro período e assim sucessivamente. Logo, os dados são atualizados pois, na prática, a demanda em carteira e a expectativa de vendas podem sofrer alterações.

Suponhamos que a nova demanda em carteira sofreu alterações devido a um cliente que solicitou um pedido urgente de 5 unidades do produto 1 e 2 unidades do produto 2 . Assim, ao rolar o horizonte, $d_{12}=0$ passou a ser $d_{11}=5$ e $d_{22}=4$ passou a ser $d_{21}=6$. Também um novo pedido para a última semana é contabilizado. Assim, a nova demanda em carteira é representada na tabela 6.5:

\begin{tabular}{|l|ccc|}
\hline$d_{i t}$ & $\mathrm{t}=1$ & $\mathrm{t}=2$ & $\mathrm{t}=3$ \\
\hline $\mathrm{i}=1$ & 5 & 3 & 4 \\
$\mathrm{i}=2$ & 6 & 2 & 3 \\
\hline
\end{tabular}

Tabela 6.5: Nova demanda em carteira para o exemplo (6.18)

A utilidade da variável oportunista $E_{i t}$ é proporcionar ao gerente de processos a decisão sobre alterações das demandas em carteira e extra, ou seja, o gerente pode decidir dar baixa ou não na demanda em carteira do produto 2 (já que $E_{21}=4$ ) e além disso, com base em sua experiência profissional e em expectativas de vendas, decidir o quanto determinar de produção extra para atender uma demanda esperada de cada produto final 
$\left(D_{i}\right)$ ao longo do horizonte de planejamento. Suponhamos que o gerente decida dar baixa na demanda do produto $2\left(d_{21}=6-4=2\right)$, manter a expectativa de vendas para o produto 2 mas, aumentar em relação ao produto 1. Logo, a nova demanda em carteira e as expectativas de vendas são dadas pela tabela 6.6:

\begin{tabular}{|l|ccc|c|}
\hline$d_{i t}$ & $\mathrm{t}=1$ & $\mathrm{t}=2$ & $\mathrm{t}=3$ & $D_{i}$ \\
\hline $\mathrm{i}=1$ & 5 & 3 & 4 & 18 \\
$\mathrm{i}=2$ & 2 & 2 & 3 & 10 \\
\hline
\end{tabular}

Tabela 6.6: Nova demanda em carteira e expectativas de vendas do produto $i$ ao longo do horizonte de planejamento para o exemplo (6.18)

Portanto, as variáveis $E_{i t}$ oferecem oportunidades de antecipação da produção, gerando um estoque "oportunista" de segurança ao longo do horizonte de planejamento e dando suporte operacional ao gerente de processos para a tomada de decisões sobre a programação da produção.

\subsection{Subproblema 2}

O subproblema 2, no grupo das variáveis de corte $y_{j \tau}$, é dado por:

$$
\begin{aligned}
& \operatorname{Min} \quad \sum_{j=1}^{N} \sum_{\tau=1}^{\Theta} c p_{j} y_{j \tau}+\sum_{p=1}^{P} \lambda_{p}\left(\sum_{j=1}^{N} \sum_{\tau=1}^{\Theta} a_{p j \tau} y_{j \tau}\right)
\end{aligned}
$$

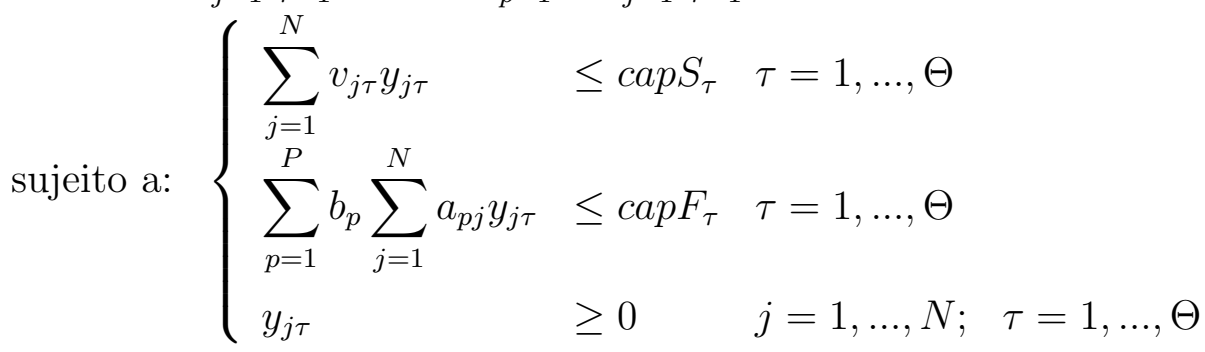

Este problema de corte apresenta-se muito folgado devido à decomposição do modelo em dois subproblemas, além de não apresentar nenhuma ligação com a produção $x_{i t}$, pois a restrição de acoplamento (4.4) foi relaxada. Com as variáveis $x_{i t}$ determinadas no subproblema 1 (em particular as variáveis $x_{i 1}$ são conhecidas), o termo $\sum_{i=1}^{M} r_{p i} x_{i 1}$ fornece o número total de peças necessárias para compor todos os produtos finais, que devem ser produzidos no primeiro período, sendo que o corte destas peças está detalhado nos subperíodos. Assim, o termo do lado direito da restrição de acoplamento

$$
\sum_{j=1}^{N} \sum_{\tau=1}^{\Theta} a_{p j \tau} y_{j \tau}=\sum_{i=1}^{M} r_{p i} x_{i 1}
$$


será uma constante positiva.

A idéia é, portanto, acrescentar essa restrição de acoplamento no subproblema 2 de maneira "suave", a qual levará a informação do número de peças necessárias para a produção do primeiro período. Para isto, introduzimos variáveis artificiais $y_{p}^{a}$ (irrestritas de sinal, $p=1, \ldots, P)$ na restrição de acoplamento. Para as restrições de capacidade da serra e de furadeira, acrescentamos as variáveis de folga $u_{\tau}$ e $q_{\tau}, \tau=1, \ldots, \Theta$, respectivamente. Agrupando as variáveis em função de $y_{j \tau}$ na função objetivo e reescrevendo o subproblema 2, obtemos:

$$
\begin{aligned}
& \operatorname{Min} \sum_{j=1}^{N} \sum_{\tau=1}^{\Theta}\left(c p_{j \tau}+\sum_{p=1}^{P} \lambda_{p} a_{p j \tau}\right) y_{j \tau}+M\left|y_{p}^{a}\right| \\
& \text { sujeito a: }\left\{\begin{array}{lll}
\sum_{j=1}^{N} \sum_{\tau=1}^{\Theta} a_{p j \tau} y_{j \tau}-y_{p}^{a} & =\sum_{i=1}^{M} r_{p i} x_{i 1} & p=1, \ldots, P \\
\sum_{j=1}^{N} v_{j \tau} y_{j \tau}+u_{\tau} & =c a p S_{\tau} & \tau=1, \ldots, \Theta \\
P & & \\
\sum_{p=1}^{P} b_{p} \sum_{j=1}^{N} a_{p j} y_{j \tau}+q_{\tau} & =c a p F_{\tau} & \tau=1, \ldots, \Theta \\
y_{j \tau} & \geq 0 & j=1, \ldots, N ; \quad \tau=1, \ldots, \Theta \\
y_{p}^{a} & \text { irrestrito } & p=1, \ldots, P
\end{array}\right.
\end{aligned}
$$

Observe que a variável irrestrita de sinal $y_{p}^{a}$, pode ser escrita como $y_{p}^{a}=y_{p}^{a^{+}}-y_{p}^{a^{-}}$, $y_{p}^{a^{+}} \geq 0$ e $y_{p}^{a^{-}} \geq 0$. Uma penalidade $\mathrm{M}$ grande deve ser incluída na função objetivo, para que o modelo procure satisfazer a restrição de acoplamento na igualdade. O módulo de $y_{p}^{a}$ que aparece na função objetivo, significa que a penalidade a se pagar por produzir peças em falta ou em excesso é o mesmo. Fazendo a linearização do modelo anterior, obtemos finalmente o modelo a ser utilizado para o procedimento de geração de colunas: 


$$
\begin{aligned}
& \text { Min } \quad \sum_{j=1}^{N} \sum_{\tau=1}^{\Theta}\left(c p_{j \tau}+\sum_{p=1}^{P} \lambda_{p} a_{p j \tau}\right) y_{j \tau}+M y_{p}^{a^{+}}+M y_{p}^{a^{-}} \\
& \text {sujeito a: }\left\{\begin{array}{lll}
\sum_{j=1}^{N} \sum_{\tau=1}^{\Theta} a_{p j \tau} y_{j \tau}-y_{p}^{a^{+}}+y_{p}^{a^{-}} & =\sum_{i=1}^{M} r_{p i} x_{i 1} \quad p=1, \ldots, P \\
\sum_{j=1}^{N} v_{j \tau} y_{j \tau}+u_{\tau} & =\operatorname{cap} S_{\tau} \quad \tau=1, \ldots, \Theta \\
\sum_{p=1}^{P} b_{p} \sum_{j=1}^{N} a_{p j} y_{j \tau}+q_{\tau} & =c a p F_{\tau} & \tau=1, \ldots, \Theta \\
y_{j \tau} & \geq 0 & j=1, \ldots, N ; \quad \tau=1, \ldots, \Theta \\
y_{p}^{a^{+}} \geq 0, y_{p}^{a^{-}} \geq 0 & p=1, \ldots, P
\end{array}\right.
\end{aligned}
$$

A matriz de restrições do modelo (6.26) é dada na tabela 6.7 (consideramos apenas as colunas correspondentes ao primeiro subperíodo, pois para os demais subperíodos elas possuem a mesma estrutura).

Para desenvolver o subproblema gerador que será utilizado no método simplex com geração de colunas, consideramos o problema mestre restrito inicial formado pelas variáveis básicas $y_{p}^{a+}, y_{p}^{a-}, u_{\tau}$ e $q_{\tau}$, ou seja, fixamos em zero as variáveis não-básicas $y_{j \tau}$.

Os coeficientes das variáveis básicas do problema mestre restrito inicial são dados pelo seguinte vetor:

$$
c_{B}=\left[\begin{array}{llllllllllll|llll}
M & M & \ldots & M \mid & M & M & \ldots & M \mid & 0 & 0 & \ldots & 0 \mid & 0 & 0 & \ldots & 0
\end{array}\right]_{1 \mathrm{x}(2 P+2 \Theta)}
$$

Dessa maneira, o método simplex tradicional pode ser aplicado e a solução básica inicial é dada por $y_{B}=B^{-1} b$ e o vetor multiplicador simplex dado por $\pi^{T}=c_{B}^{T} B^{-1}$.

Em seguida, calculamos os custos relativos das variáveis não-básicas, ou seja, o custo relativo de $y_{j \tau}$, usualmente dado por: $c_{k}=\min \left\{c_{j}-\pi^{T} a_{j}, j=1, \ldots, N\right\}$. Para o modelo (6.26) a coluna da variável $y_{j \tau}$ (o que corresponde a $a_{j}$ na equação anterior) é dada por:

$$
\left[\begin{array}{llllllllllllll}
a_{1 j \tau} & a_{2 j \tau} & \ldots & a_{P j \tau} \mid & 0 & \ldots & v_{j \tau} & \ldots & 0 & 0 & \ldots & \sum_{p=1}^{P} b_{p} a_{p j \tau} & \ldots & 0
\end{array}\right]_{(P+2 \Theta) \times 1}^{T}
$$

Observe, que há $\mathrm{P}$ termos $a_{p j \tau}, p=1, \ldots, P$, o termo $v_{j \tau}$ está na posição $P+\tau$ e o termo $\sum_{p=1}^{P} b_{p} a_{p j \tau}$ está na posição $P+\Theta+\tau$. Portanto, o custo relativo da variável $y_{j \tau}$ será: 


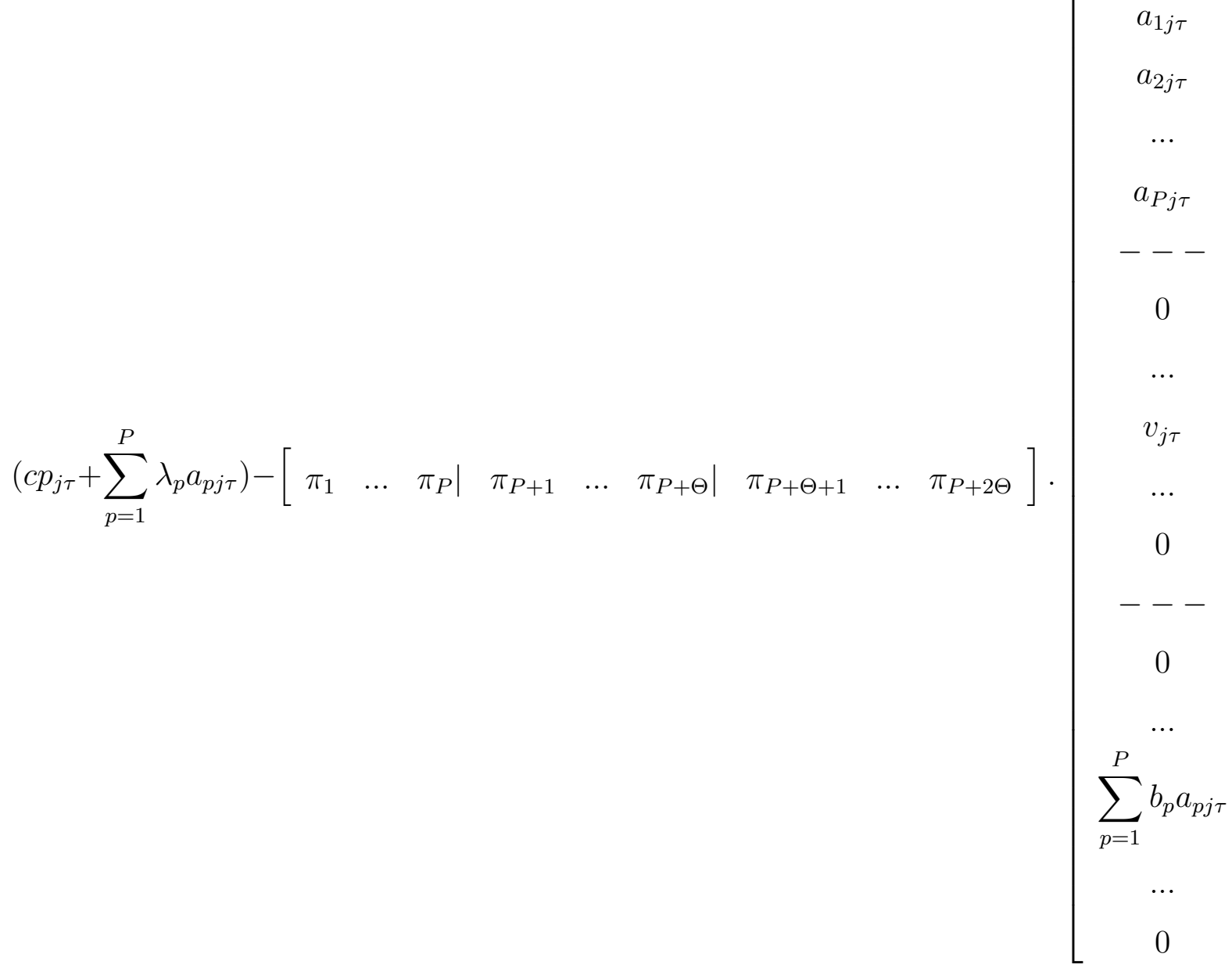

Como $c p_{j \tau}$ é o custo de material perdido por $m m^{2}$ no padrão de corte $j$ no subperíodo $\tau$, isto é,

$$
c p_{j \tau}=\left(L . W-\sum_{p=1}^{P} l_{p} w_{p} a_{p j \tau}\right) . c m a
$$

em que $\mathrm{cma}$ é o custo de material por $\mathrm{mm}^{2}$, obtemos:

$$
\begin{gathered}
\left(L . W-\sum_{p=1}^{P} l_{p} w_{p} a_{p j \tau}\right) c m a+\sum_{p=1}^{P} \lambda_{p} a_{p j \tau}-\sum_{p=1}^{P} \pi_{p} a_{p j \tau}-\pi_{P+\tau} v_{j \tau}-\pi_{P+\Theta+\tau}\left(\sum_{p=1}^{P} b_{p} a_{p j \tau}\right) \\
=\left(\text { L.W.cma }-\pi_{P+\tau} v_{j \tau}\right)-\sum_{p=1}^{P}\left(l_{p} w_{p} c m a-\lambda_{p}+\pi_{p}+\pi_{P+\Theta+\tau} b_{p}\right) a_{p j \tau}
\end{gathered}
$$

Devemos maximizar o segundo termo da expressão acima para obter o menor custo relativo. Ressaltando aqui que consideramos o tempo para cortar uma placa no padrão de corte $j, v_{j \tau}=v$, ou seja, um parâmetro constante, mas sem perda de generalidade, este poderia ser considerado em função da quantidade de peças a serem cortadas no padrão de corte, por exemplo, $v_{j \tau}=\sum_{p=1}^{P} \tilde{v}_{p j} a_{p j \tau}$.

Assim, o subproblema gerador para o problema de corte bidimensional (6.26) deve ser: 
Para $\tau=1, \ldots, \Theta$ faça:

$$
\begin{array}{ll}
z_{\tau}=\operatorname{Max} & \sum_{p=1}^{P}\left(l_{p} w_{p} c m a-\lambda_{p}+\pi_{p}+\pi_{P+\Theta+\tau} b_{p}\right) \alpha_{p} \\
\text { sujeito a: } & \left\{\begin{array}{l}
\left(\alpha_{1}, \alpha_{2}, \ldots, \alpha_{P}\right): \text { Tal que corresponda a um padrão de corte } \\
\text { bidimensional guilhotinado 2-estágios }
\end{array}\right.
\end{array}
$$

A solução do problema de corte bidimensional fornece a coluna com menor custo relativo para o subperíodo $\tau$ :

$$
a_{j \tau}=\left[\begin{array}{llllllllllllll}
a_{1 j \tau} & a_{2 j \tau} & \ldots & a_{P j \tau} & 0 & \ldots & v & \ldots & 0 & 0 & \ldots & \sum_{p=1}^{P} b_{p} a_{p j \tau} & \ldots & 0
\end{array}\right]^{T}
$$

em que

$$
\left[\begin{array}{llll}
a_{1 j \tau} & a_{2 j \tau} & \ldots & a_{P j \tau}
\end{array}\right]^{T}
$$

é o padrão de corte obtido pelo subproblema gerador (6.27), o qual determina o número de itens (peças do tipo $p$ ) neste padrão.

Dessa maneira, o subproblema 2, que é um problema de corte, pode ser resolvido pela técnica de geração de colunas. Lembrando que o termo do lado direito da restrição

$$
\sum_{j=1}^{N} \sum_{\tau=1}^{\Theta} a_{p j \tau} y_{j \tau}-y_{p}^{a}=\sum_{i=1}^{M} r_{p i} x_{i 1} \quad p=1, \ldots, P
$$

fornece o número total de peças necessárias para compor os produtos finais do primeiro período, mas, a solução $x_{i 1}$ determinada pelo subproblema 1 pode fazer com que $y_{p}^{a} \neq 0$ para algum $p$. Ao ocorrer isto, o método do subgradiente será utilizado para atualizar os multiplicadores lagrangianos a cada iteração. O critério de parada será o número máximo de iterações ou até que

$$
y_{p}^{a}=\frac{y_{p}^{a}}{\left\|y_{p}^{a}\right\|_{\infty}} \leq \epsilon(\epsilon \text { pequeno }), p=1, \ldots, P
$$

em que $\left\|y_{p}^{a}\right\|_{\infty}=\max _{1 \leq p \leq P}\left|y_{p}^{a}\right|$. Neste último caso, as peças serão produzidas na quantidade ideal determinada pelo subproblema 1 , sem violar as restrições de capacidade de serra e de furadeira do subproblema 2. Logo, obtemos uma solução factível para o problema de corte. 
Observe que

$$
y_{p}^{a}=\sum_{j=1}^{N} \sum_{\tau=1}^{\Theta} a_{p j \tau} y_{j \tau}-\sum_{i=1}^{M} r_{p i} x_{i 1} \quad p=1, \ldots, P
$$

é o subgradiente do modelo (4.1) - (4.10) e a cada iteração do método do subgradiente um novo plano de produção $\left(x_{i t}\right)$ é obtido, iniciando o processo novamente a fim de encontrar uma solução factível para o problema de corte.

A seguir descrevemos um esquema simplificado do procedimento de resolução por relaxação lagrangiana para o modelo integrado:

\section{Procedimento Geral}

\section{Inicialização:}

2. $k=0$ e $k_{\max }=\mathrm{n}^{\mathrm{o}}$ máximo de iterações

3. Multiplicadores lagrangianos iniciais $\lambda_{p}^{0}=0, p=1, \ldots, P$, e $\nu^{0}=-\infty$

4. Escolha $t_{0}>0$

5. $\mathrm{PARE}=\mathrm{FALSO}$

6. Enquanto PARE $=$ FALSO ou $k<k_{\max }$ faça:

7. Resolva o subproblema 1 e obtenha $x_{i 1}^{k}, i=1, \ldots, M$;

8. Resolva o subproblema 2 e obtenha a solução $y_{j \tau}^{k}$ e $\left(y_{p}^{a}\right)^{k}, p=1, \ldots, P$;

9. $\quad$ Se $y_{p}^{a}=\frac{y_{p}^{a}}{\left\|y_{p}^{a}\right\|_{\infty}} \leq \epsilon(\epsilon$ pequeno $), p=1, \ldots, P$ Então PARE=VERDADE

10. Senão Atualização

11. $\quad$ Se $\nu^{k}<z\left(L R_{\lambda^{k}}\right)$ Então $\nu^{k+1}=z\left(L R_{\lambda^{k}}\right)$;

12. $\quad$ Senão $\nu^{k+1}=\nu^{k}$;

13. $\quad$ Faça $\lambda_{p}^{k+1}=\lambda_{p}^{k}+t_{k} *\left(y_{p}^{a}\right)^{k}, p=1, \ldots, P$

14. $\quad$ Faça $k=k+1$

15. $\quad$ Fim Atualização

16. Fim Enquanto

\section{- Observações}

1. $t_{k}$ é o tamanho do passo dado por $\frac{1}{\mathrm{n}^{\circ} \text { iterações }+1}=\frac{1}{k+1}$;

2. $\left(y_{p}^{a}\right)^{k}$ é o subgradiente dado por

$$
\left(y_{p}^{a}\right)^{k}=\left(y_{p}^{a+}\right)^{k}-\left(y_{p}^{a-}\right)^{k}=\sum_{j=1}^{N} \sum_{\tau=1}^{\Theta} a_{p j \tau} y_{j \tau}^{k}-\sum_{i=1}^{M} r_{p i} x_{i 1}^{k}, \quad p=1, \ldots, P
$$


3. O valor da solução lagrangiana será:

$$
z\left(L R_{\lambda^{k}}\right)=(f o 1)^{k}+(f o 2)^{k}
$$

em que $(f o 1)^{k}$ é o valor da função objetivo do subproblema 1 inteiro na iteração $k$ e $(f o 2)^{k}$ é o valor da função objetivo do subproblema 2 inteiro na iteração $k$. 


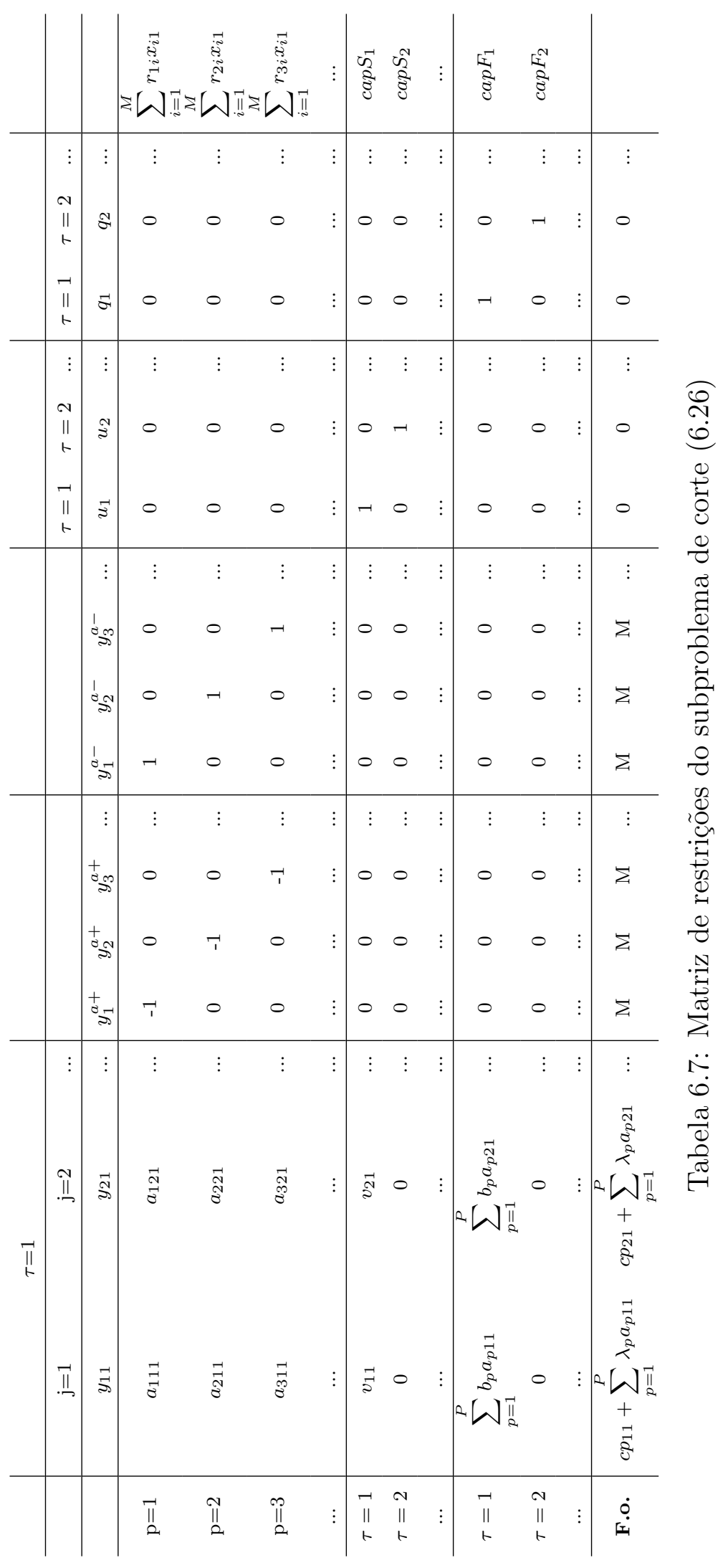




\section{Capítulo 7}

\section{Testes Computacionais}

Neste capítulo avaliamos os resultados obtidos pelo método de solução proposto no capítulo 6 para resolver o problema integrado (4.1)-(4.10). As implementações foram feitas utilizando linguagem programação $\mathrm{C}$ e os testes foram executados em um Pentium IV com 2.0 GB de memória RAM.

O subproblema 1 é primeiramente resolvido pela heurística apresentada na seção 6.2 e o subproblema 2 é resolvido pelo método simplex com geração de colunas (Cplex10), atualizando os multiplicadores lagrangianos pelo método do subgradiente.

\subsection{Conjunto de Dados}

Nesta seção descrevemos os parâmetros utilizados para a geração dos dados. Alguns dados foram baseados no processo produtivo de uma indústria de móveis. Por simplicidade, consideramos apenas os dados referentes à espessura de $15 \mathrm{~mm}$, a qual possui mais peças para a confecção dos móveis.

- dimensões da placa $L \times W: 2750 \mathrm{~mm} \times 1850 \mathrm{~mm}$ (espessura $15 \mathrm{~mm}$ );

- custo da placa $L \times W(c p l): R \$ 68,73$;

- custo de material por $m m^{2}(\mathrm{cmp}): R \$ \frac{68,73}{2750 \times 1850}$;

- número de períodos: $T=4$ semanas;

- número de subperíodos: $\Theta=5$ dias da primeira semana;

- número de tipos de produtos finais: $M=4$ produtos (guarda-roupa de 5 portas, guarda-roupa de 4 portas, cômoda e criado-mudo); 
- número de tipos de peças: $P=18$ peças;

- dimensões das peças: tabela 7.1;

\begin{tabular}{|l|c|}
\hline peças & $l_{p}(m m) \times w_{p}(\mathrm{~mm})$ \\
\hline $\mathrm{p}=1$ & $700 \times 210$ \\
$\mathrm{p}=2$ & $535 \times 1050$ \\
$\mathrm{p}=3$ & $535 \times 430$ \\
$\mathrm{p}=4$ & $535 \times 500$ \\
$\mathrm{p}=5$ & $1050 \times 60$ \\
$\mathrm{p}=6$ & $430 \times 60$ \\
$\mathrm{p}=7$ & $500 \times 60$ \\
$\mathrm{p}=8$ & $450 \times 426$ \\
$\mathrm{p}=9$ & $450 \times 1046$ \\
$\mathrm{p}=10$ & $450 \times 496$ \\
$\mathrm{p}=11$ & $490 \times 60$ \\
$\mathrm{p}=12$ & $450 \times 425$ \\
$\mathrm{p}=13$ & $701 \times 22$ \\
$\mathrm{p}=14$ & $700 \times 75$ \\
$\mathrm{p}=15$ & $700 \times 163$ \\
$\mathrm{p}=16$ & $965 \times 566$ \\
$\mathrm{p}=17$ & $450 \times 130$ \\
$\mathrm{p}=18$ & $600 \times 437$ \\
\hline
\end{tabular}

Tabela 7.1: Dimensões das peças

Observe que apenas as peças com $15 \mathrm{~mm}$ de espessura são consideradas.

- número de peças do tipo $p$ em uma unidade do produto final $i\left(r_{p i}\right)$ : ver tabela 7.2 ;

\begin{tabular}{|c|c|c|c|c|c|c|c|c|c|}
\hline$r_{p i}$ & $\mathrm{i}=1$ & $\mathrm{i}=2$ & $\mathrm{i}=3$ & $\mathrm{i}=4$ & $r_{p i}$ & $\mathrm{i}=1$ & $\mathrm{i}=2$ & $\mathrm{i}=3$ & $\mathrm{i}=4$ \\
\hline $\mathrm{p}=1$ & 4 & 4 & 3 & 0 & $\mathrm{p}=10$ & 4 & 5 & 0 & 0 \\
$\mathrm{p}=2$ & 2 & 2 & 0 & 0 & $\mathrm{p}=11$ & 14 & 9 & 0 & 0 \\
$\mathrm{p}=3$ & 2 & 2 & 0 & 0 & $\mathrm{p}=12$ & 0 & 2 & 0 & 0 \\
$\mathrm{p}=4$ & 2 & 2 & 0 & 0 & $\mathrm{p}=13$ & 0 & 0 & 1 & 0 \\
$\mathrm{p}=5$ & 3 & 6 & 0 & 0 & $\mathrm{p}=14$ & 0 & 0 & 1 & 0 \\
$\mathrm{p}=6$ & 12 & 12 & 0 & 0 & $\mathrm{p}=15$ & 0 & 0 & 2 & 0 \\
$\mathrm{p}=7$ & 3 & 6 & 0 & 0 & $\mathrm{p}=16$ & 0 & 0 & 2 & 0 \\
$\mathrm{p}=8$ & 1 & 0 & 0 & 0 & $\mathrm{p}=17$ & 0 & 0 & 0 & 3 \\
$\mathrm{p}=9$ & 4 & 5 & 0 & 0 & $\mathrm{p}=18$ & 0 & 0 & 0 & 2 \\
\hline
\end{tabular}

Tabela 7.2: Peças necessárias para compor uma unidade de cada produto final 
- custo de produção: dado em função da área de material necessária para formar o produto $i$ (aproximadamente $54 \%$ do custo de produção é de matéria-prima). Assim:

$A_{i}=\sum_{p=1}^{P} r_{p i} l_{p} w_{p}$ (área de material necessário para compor uma unidade produto final $i)$;

$c_{i 1}=\frac{1}{0.54} * \frac{A_{i}}{L \times W} * c p l$

$c_{i t}=c_{i 1}+\frac{A_{i}}{L \times W} * c p l * 0.05$ (contabilizado uma estimativa de $5 \%$ de perda de material nos períodos 2 a $T$ );

- custo de estoque convencional $\left(h_{i t}\right)$ : $2 \%$ do custo de produção;

- custo de estoque da demanda extra $\left(f_{i t}\right): 50 \%$ do custo de estoque convencional;

- demanda esperada do produto final $i\left(D_{i}\right)$ : ver tabela 7.3;

\begin{tabular}{|c|c|}
\hline & $D_{i}$ \\
\hline $\mathrm{i}=1$ & 40 \\
$\mathrm{i}=2$ & 40 \\
$\mathrm{i}=3$ & 50 \\
$\mathrm{i}=4$ & 30 \\
\hline
\end{tabular}

Tabela 7.3: Demanda extra do produto $i$

- demanda em carteira $\left(d_{i t}\right)$ : ver tabelas 7.4 e 7.5 ;

- as demandas do tipo (A) e (B) são referentes ao mês de dezembro e abril, respectivamente (fornecidas pela empresa);

- a demanda do tipo (C) é a média entre os meses de dezembro e abril;

- as demandas do tipo (D) e (E) foram geradas aleatoriamente no intervalo [0 100]

e [0 50], respectivamente.

\begin{tabular}{|l|cccc|cccc|cccc|}
\hline & \multicolumn{5}{|c|}{$(\mathrm{A})$} & \multicolumn{5}{|c|}{$(\mathrm{B})$} & \multicolumn{4}{c|}{$(\mathrm{C})$} \\
\hline$d_{i t}$ & $\mathrm{t}=1$ & $\mathrm{t}=2$ & $\mathrm{t}=3$ & $\mathrm{t}=4$ & $\mathrm{t}=1$ & $\mathrm{t}=2$ & $\mathrm{t}=3$ & $\mathrm{t}=4$ & $\mathrm{t}=1$ & $\mathrm{t}=2$ & $\mathrm{t}=3$ & $\mathrm{t}=4$ \\
\hline $\mathrm{i}=1$ & 27 & 98 & 19 & 7 & 8 & 31 & 28 & 40 & 18 & 65 & 24 & 24 \\
$\mathrm{i}=2$ & 82 & 100 & 32 & 4 & 13 & 38 & 43 & 65 & 48 & 77 & 38 & 35 \\
$\mathrm{i}=3$ & 80 & 32 & 5 & 1 & 2 & 3 & 19 & 13 & 41 & 18 & 12 & 7 \\
$\mathrm{i}=4$ & 85 & 71 & 19 & 7 & 2 & 0 & 0 & 0 & 44 & 36 & 10 & 4 \\
\hline
\end{tabular}

Tabela 7.4: Demanda em carteira do tipo A, B e C do produto $i$ no período $t$ 


\begin{tabular}{|l|cccc|cccc|}
\hline & \multicolumn{5}{|c|}{$(\mathrm{D})$} & \multicolumn{4}{|c|}{$(\mathrm{E})$} \\
\hline$d_{i t}$ & $\mathrm{t}=1$ & $\mathrm{t}=2$ & $\mathrm{t}=3$ & $\mathrm{t}=4$ & $\mathrm{t}=1$ & $\mathrm{t}=2$ & $\mathrm{t}=3$ & $\mathrm{t}=4$ \\
\hline $\mathrm{i}=1$ & 55 & 80 & 39 & 27 & 16 & 40 & 47 & 31 \\
$\mathrm{i}=2$ & 78 & 74 & 87 & 70 & 32 & 12 & 42 & 22 \\
$\mathrm{i}=3$ & 40 & 94 & 68 & 23 & 46 & 43 & 17 & 46 \\
$\mathrm{i}=4$ & 90 & 98 & 6 & 75 & 35 & 45 & 41 & 3 \\
\hline
\end{tabular}

Tabela 7.5: Demanda em carteira do tipo D e E do produto $i$ no período $t$

- capacidade da serra no subperíodo $\tau\left(\operatorname{cap} S_{\tau}\right)$ : estimada em $8 h=28800 s$. Porém, como a indústria trabalha com 372 peças (total necessário para compor uma unidade do produto final $i, i=1,2,3,4$ ) e neste trabalho consideramos apenas 120 peças (as de espessura $15 \mathrm{~mm}$ ), fazemos uma estimativa da capacidade usando a proporção de peças. Assim:

$\operatorname{cap}_{\tau}=40 \%$ de $28800 \mathrm{~s}=11520 \mathrm{~s}$

- capacidade da furadeira no subperíodo $\tau\left(c a p F_{\tau}\right)$ : análogo ao caso anterior, $c a p F_{\tau}=$ $40 \%$ de $28800 s=11520 s ;$

- capacidade da serra no período $t\left(C a p S_{t}\right)$ : dada por $\sum_{\tau=1}^{\Theta} \operatorname{cap} S_{\tau}$;

- capacidade da furadeira no período $t\left(\operatorname{CapF}_{t}\right)$ : dada por $\sum_{\tau=1}^{\Theta} c a p F_{\tau}$;

- tempo de cortar uma placa no padrão de corte $j\left(v_{j \tau}\right)$ : o tempo médio do ciclo da serra é dado pela capacidade do subperíodo dividido pelo $\mathrm{n}^{\mathrm{O}}$ de ciclos utizados no subperíodo, isto fornece uma estimativa de $540 \mathrm{~s}(\approx 9 \mathrm{~min})$ para cada ciclo. $\mathrm{O}$ tempo para cortar uma placa é estimado pelo tempo de cada ciclo dividido pelo lote de placas cortadas simultaneamente (para espessura de $15 \mathrm{~mm}$ pode ser cortado um lote de 4 placas);

- tempo de furar uma peça do tipo $p\left(b_{p}\right)$ : média de $5 s$ para todas as peças;

\subsection{Resultados da Heurística de Decomposição}

Apresentamos nesta seção, um resumo dos resultados obtidos pela decomposição do modelo integrado (4.1)-(4.10). Esse procedimento decompõe o modelo integrado em dois problemas, o problema de dimensionamento de lotes (PDL) e o problema de corte de 
estoque (PCE), procurando imitar o procedimento que as indústrias utilizam na prática, pois usualmente o PDL e o PCE são resolvidos separadamente. A resolução destes problemas foi feita da seguinte maneira:

1. Inicialmente resolvemos o PDL (Cplex10), determinando as quantidades de cada produto final a serem produzidos no primeiro período. Utilizando esta informação convertemos a demanda de produtos finais em demanda de peças, ou seja, a quantidade de peças de cada tipo a serem cortadas. O PDL a ser resolvido é dado pelo primeiro termo da função objetivo do problema (4.1)-(4.10) e pelas restrições (4.2)-(4.3) e (4.7)-(4.9), relaxando as variáveis de integralidade. Acresentamos ao PDL restrições para o primeiro período, para as capacidades de serra e de furadeira, já que as capacidades de corte e furação para o primeiro período são dados nos subperíodos, os quais aparecem no problema de corte.

$$
\begin{aligned}
& \operatorname{Min} \quad \sum_{i=1}^{M} \sum_{t=1}^{T}\left(c_{i t} x_{i t}+h_{i t} I_{i t}+f_{i t} E_{i t}\right) \\
& \text { sujeito a: }\left\{\begin{array}{lll}
x_{i t}+I_{i(t-1)}-I_{i t} & =d_{i t}+E_{i t} & i=1, \ldots, M ; \quad t=1, \ldots, T \\
\sum_{t=1}^{T}\left(d_{i t}+E_{i t}\right) & =D_{i} & i=1, \ldots, M \\
\sum_{i=1}^{M} t c_{i} x_{i t} & \leq \operatorname{Cap}_{t} & t=1, \ldots, T \\
\sum_{i=1}^{M} t f_{i} x_{i t} & \leq C a p F_{t} & t=1, \ldots, T \\
x_{i t}, I_{i t}, E_{i t} & \geq 0 & i=1, \ldots, M ; \quad t=1, \ldots, T
\end{array}\right.
\end{aligned}
$$

2. Em seguida, resolvemos a relaxação linear do PCE, dado pelo segundo termo da função objetivo (4.1) e pelas restrições (4.4)-(4.6) e (4.10), usando o método simplex com geração de colunas (Cplex10), determinando as quantidade de placas a serem cortadas conforme um conjunto de padrões de corte em cada subperíodo, obtendo as peças necessárias para compor os produtos do primeiro período, determinados pela programação da produção. Note que o termo do lado direito de (4.4) será um parâmetro e, portanto, não acopla mais os problemas de dimensionamento de lote e corte de estoque. 


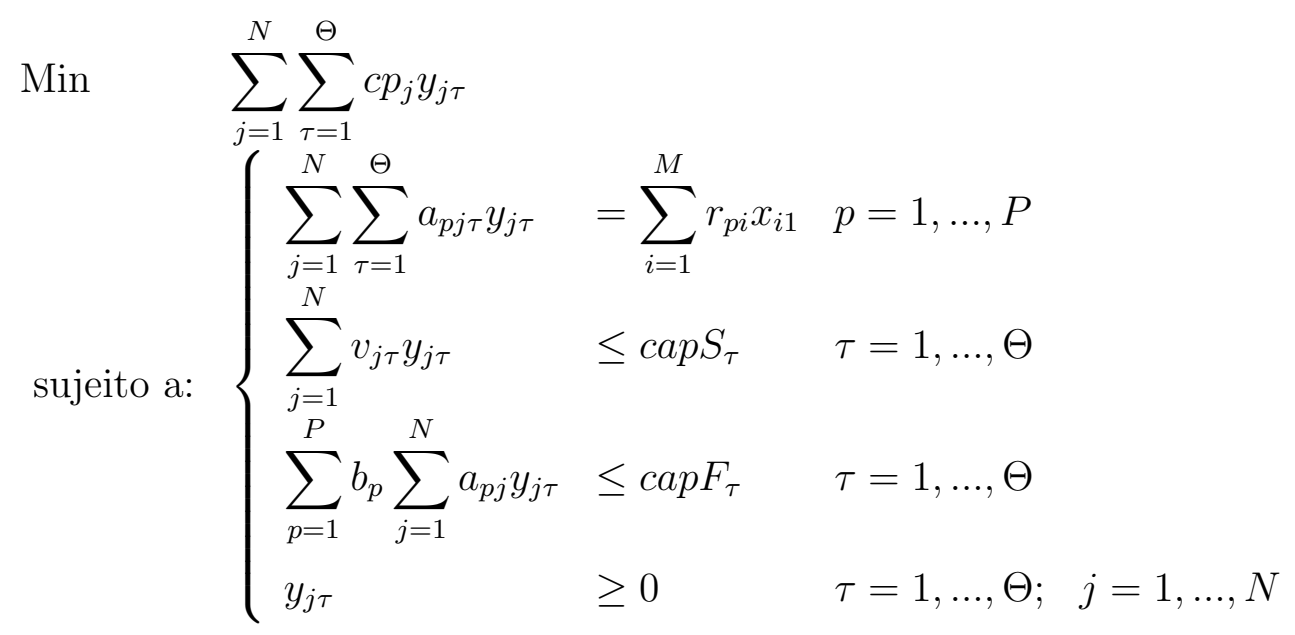

Sabemos da dificuldade de resolução destes modelos, devido principalmente a dois fatores: a integralidade das variáveis em ambos os problemas e a grande quantidade de padrões de corte. Para contornar estas dificuldades, em todas as resoluções do problema de corte (presente nas heurísticas de decomposição, no modelo integrado e na relaxação lagrangiana), relaxamos as variáveis de integralidade, que representam as quantidades de placas a serem cortadas de acordo com os padrões de corte. Utilizamos o método simplex com geração de colunas (Cplex10) para obter os melhores padrões de corte, e no final do processo resolvemos o PCE inteiro com estas colunas inseridas. Contudo, nem sempre é possível obter uma solução inteira com as colunas geradas. Baseado em Silva et al. (2007) relaxamos parcialmente a condição de integralidade, mantendo as demais inteiras e, ao final, arredondamos a solução para o inteiro superior para as frequências com parte decimal superior a 0.01 .

Para obter o custo global do modelo integrado inteiro, somamos os custos obtidos pelos problemas (7.1) e (7.2) inteiros. Usualmente, em aplicações práticas, as indústrias resolvem o problema integrado utilizando o procedimento de decomposição descrito anteriormente. Porém, a resolução dos modelos decompostos, pode fornecer uma solução infactível para o problema de corte de estoque, e então, na prática, são feitos ajustes nas quantidades de lotes, podendo acarretar aumento nos custos. Devemos observar também que, na prática, ambos os problemas são resolvidos de forma empírica.

A tabela 7.6 apresenta os resultados obtidos utilizando duas heurísticas de decomposição para a resolução do modelo integrado (4.1)-(4.10). Para cada tipo de demanda foram testados 5 exemplos, em que os exemplos 1,6,11,16 e 21 utilizam 100\% das capacidades de serra e de furadeira nos subperíodos, os exemplos 2,7,12,17 e 22 utilizam 90\%, 
os exemplos 3,8,13,18 e 23 utilizam 80\%, os exemplos 4,9,14,19 e 24 utilizam $70 \%$ e os exemplos 5,10,15,20 e 25 utilizam $60 \%$.

1. Heurística de Decomposição 01 (HD01) : as capacidades de serra e de furadeira para o primeiro período do modelo (7.1) são consideradas como a somatória das capacidades de serra e de furadeira dos subperíodos, respectivamente. Por exemplo, os exemplos 2,7,12,17 e 22 consideram $90 \%$ das capacidades de serra e de furadeira para os subperíodos, ou seja, 90\% de 11520s $=10368 \mathrm{~s}\left(\operatorname{cap}_{\tau}=\operatorname{cap}_{\tau}=10368 \mathrm{~s}, \tau=\right.$ $1, \ldots, \Theta)$. Assim, as capacidades de serra e de furadeira para $t=1$ são dadas por:

$$
\begin{aligned}
& \operatorname{Cap}_{1}=\sum_{\tau=1}^{\Theta} \operatorname{cap}_{\tau}=51840 \mathrm{~s} \\
& \text { CapF }_{1}=\sum_{\tau=1}^{\Theta} \operatorname{capF}_{\tau}=51840 \mathrm{~s}
\end{aligned}
$$

2. Heurística de Decomposição 02 (HD02) : as capacidades de serra e furadeira para o primeiro período do modelo (7.1) são consideradas como em t=2,3,4. Nos exemplos 2,7,12,17 e 22, independente das capacidades dos subperíodos terem sido apertadas, as capacidades de serra e de furadeira para o primeiro período, e também para os demais, são dadas por:

$$
\begin{aligned}
& C a p S_{1}=\operatorname{cap} S_{\tau} * \Theta=11520 * 5=57600 s \\
& C a p F_{1}=c a p F_{\tau} * \Theta=11520 * 5=57600 s
\end{aligned}
$$

A coluna "fo total" apresenta o custo global para o modelo integrado, dado pela soma dos valores das funções objetivo dos problemas (7.1) e (7.2), representados na tabela por "fo lote"e "fo corte", respectivamente. A coluna "t" dá o tempo (em segundos) de resolução de cada exemplo e a coluna "placas" fornece o número total de placas utilizadas no PCE. 


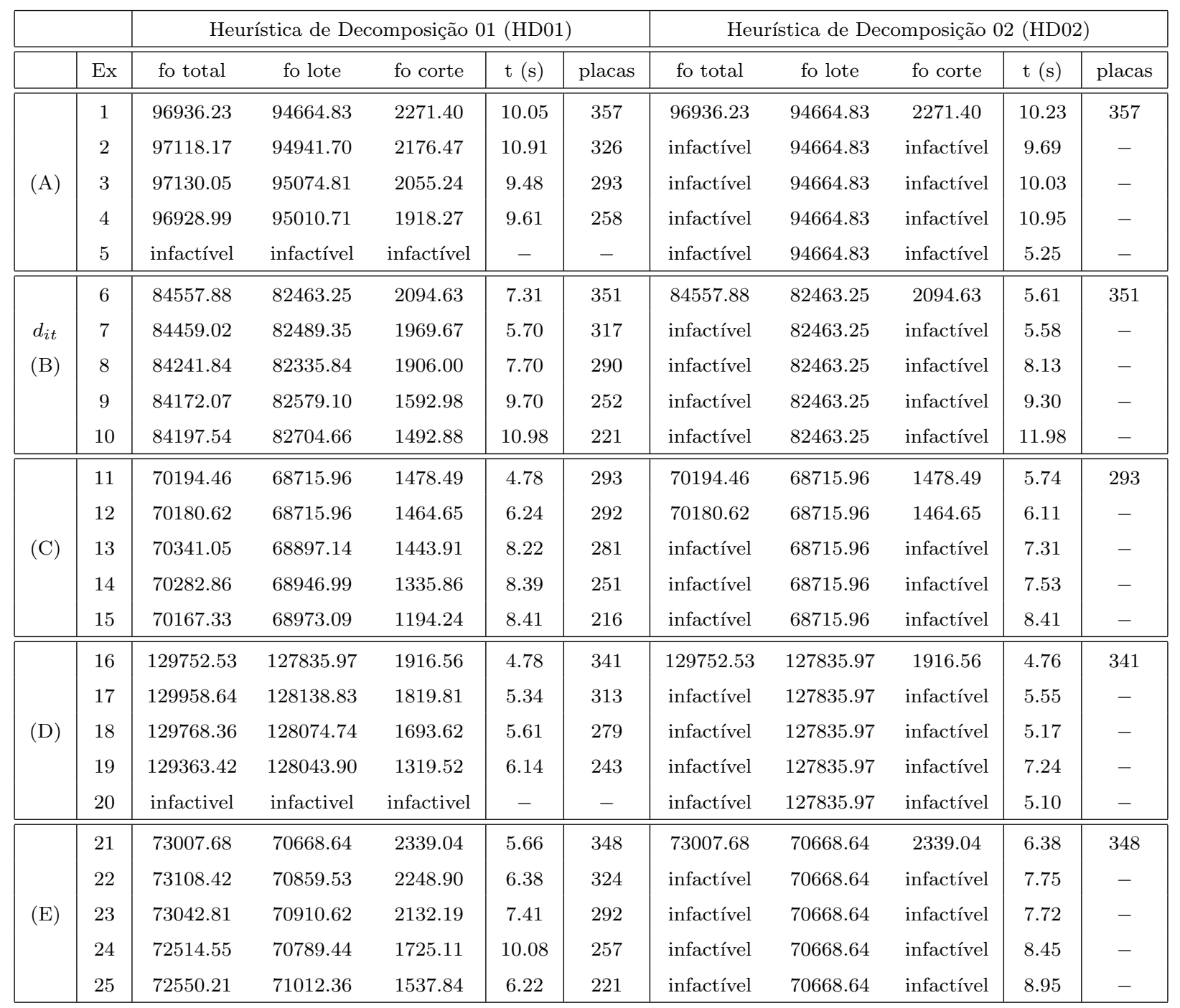

Tabela 7.6: Resultados computacionais das heurísticas de decomposição para o modelo integrado (4.1)-(4.10).

As tabelas 7.7, 7.8 e 7.9 apresentam a programação da produção para o primeiro período. 


\begin{tabular}{|c|cc|c|c|c|c|cc|c|c|c|c|}
\hline & \multicolumn{2}{|c|}{ ex01 } & ex02 & ex03 & ex04 & ex05 & \multicolumn{2}{|c|}{ ex06 } & ex07 & ex08 & ex09 & ex10 \\
\hline & HD01 & HD02 & HD01 & HD01 & HD01 & HD01 & HD01 & HD02 & HD01 & HD01 & HD01 & HD01 \\
\hline$x_{11}$ & 61 & 61 & 38 & 27 & 27 & - & 58 & 58 & 58 & 58 & 40 & 18 \\
$x_{21}$ & 122 & 122 & 122 & 111 & 90 & - & 128 & 128 & 107 & 88 & 88 & 88 \\
$x_{31}$ & 130 & 130 & 130 & 130 & 130 & - & 109 & 109 & 109 & 109 & 91 & 91 \\
$x_{41}$ & 115 & 115 & 115 & 115 & 115 & - & 110 & 110 & 110 & 88 & 74 & 74 \\
\hline$E_{11}$ & 34 & 34 & 11 & 0 & 0 & - & 40 & 40 & 40 & 40 & 22 & 0 \\
$E_{21}$ & 40 & 40 & 40 & 29 & 8 & - & 40 & 40 & 40 & 40 & 40 & 40 \\
$E_{31}$ & 50 & 50 & 50 & 50 & 50 & - & 50 & 50 & 50 & 50 & 50 & 50 \\
$E_{41}$ & 30 & 30 & 30 & 30 & 30 & - & 30 & 30 & 30 & 30 & 30 & 30 \\
\hline$I_{11}$ & 0 & 0 & 0 & 0 & 0 & - & 0 & 0 & 0 & 0 & 0 & 0 \\
$I_{21}$ & 0 & 0 & 0 & 0 & 0 & - & 40 & 40 & 19 & 0 & 0 & 0 \\
$I_{31}$ & 0 & 0 & 0 & 0 & 0 & - & 18 & 18 & 18 & 18 & 0 & 0 \\
$I_{41}$ & 0 & 0 & 0 & 0 & 0 & - & 36 & 36 & 36 & 14 & 0 & 0 \\
\hline
\end{tabular}

Tabela 7.7: Programação da produção no primeiro período para as heurísticas de decomposição, para os exemplos 1 a 10.

\begin{tabular}{|c|cc|c|c|c|c|cc|c|c|c|c|}
\hline & \multicolumn{2}{|c|}{ ex11 } & ex12 & ex13 & ex14 & ex15 & \multicolumn{2}{|c|}{ ex16 } & ex17 & ex18 & ex19 & ex20 \\
\hline & HD01 & HD02 & HD01 & HD01 & HD01 & HD01 & HD01 & HD02 & HD01 & HD01 & HD01 & HD01 \\
\hline$x_{11}$ & 79 & 79 & 79 & 70 & 48 & 48 & 71 & 71 & 55 & 55 & 55 & - \\
$x_{21}$ & 91 & 91 & 91 & 91 & 91 & 70 & 118 & 118 & 112 & 91 & 78 & - \\
$x_{31}$ & 55 & 55 & 55 & 55 & 55 & 55 & 90 & 90 & 90 & 90 & 58 & - \\
$x_{41}$ & 32 & 32 & 32 & 32 & 32 & 32 & 120 & 120 & 120 & 120 & 90 & - \\
\hline$E_{11}$ & 40 & 40 & 40 & 40 & 40 & 40 & 16 & 16 & 0 & 0 & 0 & - \\
$E_{21}$ & 40 & 40 & 40 & 40 & 40 & 40 & 40 & 40 & 34 & 13 & 0 & - \\
$E_{31}$ & 50 & 50 & 50 & 50 & 50 & 50 & 50 & 50 & 50 & 50 & 18 & - \\
$E_{41}$ & 30 & 30 & 30 & 30 & 30 & 30 & 30 & 30 & 30 & 30 & 0 & - \\
\hline$I_{11}$ & 31 & 31 & 31 & 22 & 0 & 0 & 0 & 0 & 0 & 0 & 0 & - \\
$I_{21}$ & 38 & 38 & 38 & 38 & 38 & 17 & 0 & 0 & 0 & 0 & 0 & - \\
$I_{31}$ & 3 & 3 & 3 & 3 & 3 & 3 & 0 & 0 & 0 & 0 & 0 & - \\
$I_{41}$ & 0 & 0 & 0 & 0 & 0 & 0 & 0 & 0 & 0 & 0 & 0 & - \\
\hline
\end{tabular}

Tabela 7.8: Programação da produção no primeiro período para as heurísticas de decomposição, para os exemplos 11 a 20. 


\begin{tabular}{|c|cc|c|c|c|c|}
\hline & \multicolumn{2}{|c|}{ ex21 } & ex22 & ex23 & ex24 & ex25 \\
\hline & HD01 & HD02 & HD01 & HD01 & HD01 & HD01 \\
\hline$x_{11}$ & 96 & 96 & 78 & 56 & 56 & 35 \\
$x_{21}$ & 84 & 84 & 84 & 83 & 72 & 72 \\
$x_{31}$ & 139 & 139 & 139 & 139 & 103 & 96 \\
$x_{41}$ & 110 & 110 & 110 & 110 & 65 & 65 \\
\hline$E_{11}$ & 40 & 40 & 40 & 40 & 40 & 19 \\
$E_{21}$ & 40 & 40 & 40 & 40 & 40 & 40 \\
$E_{31}$ & 50 & 50 & 50 & 50 & 50 & 50 \\
$E_{41}$ & 30 & 30 & 30 & 30 & 30 & 30 \\
\hline$I_{11}$ & 40 & 40 & 22 & 0 & 0 & 0 \\
$I_{21}$ & 12 & 12 & 12 & 11 & 0 & 0 \\
$I_{31}$ & 43 & 43 & 43 & 43 & 7 & 0 \\
$I_{41}$ & 45 & 45 & 45 & 45 & 0 & 0 \\
\hline
\end{tabular}

Tabela 7.9: Programação da produção no primeiro período para as heurísticas de decomposição, para os exemplos 21 a 25.

Observamos que na HD02, exceto para os exemplos considerando 100\% da capacidade de serra e de furadeira nos subperíodos, os demais apresentaram solução infactível para o problema de corte. Essa infactibilidade no problema de corte ocorre devido a uma produção elevada no primeiro período, fornecida pelo PDL, pois na HD02 o primeiro período referente às capacidades de serra e furadeira está relaxado (folgado) e conforme apertamos as capacidades nos subperíodos, os limites de serra e furadeira são excedidos.

Observamos assim, a importância de construir o problema de dimensionamento de lotes com as capacidades de serra e de furadeira no primeiro período compatíveis com as capacidades que estão detalhadas nos subperíodos.

\subsection{Resultados do Modelo Integrado}

O modelo integrado inteiro (4.1)-(4.10) apresenta grandes dificuldades, devido a alguns fatores, tais como a integralidade de suas variáveis e a grande quantidade de padrões de corte. A complexidade computacional pode ser agravada se parâmetros como número de produtos finais, número de peças entre outros, forem muito grandes.

Ao contrário do modelo decomposto, o modelo integrado possibilita antecipar a produção de certos lotes de produtos para o primeiro período, sem que os limites de serra e furadeira nos subperíodos sejam ultrapassados. Essa antecipação se baseia no equilíbrio entre fatores como aumentar os custos de estoque e produção, mas por outro lado diminuir os custos no processo de corte (pois permite um melhor arranjo nos padrões de corte). Neste 
caso, as decisões de produção e estoque são concomitantes com o corte das placas, podendo levar a uma redução de custos.

A resolução do modelo integrado (relaxando as variáveis de integralidade) é feita pelo método simplex com geração de colunas (Cplex10), em que os padrões iniciais são dados pelos padrões homogêneos. As variáveis de produção fracionárias são arredondadas para o inteiro superior e o PCE inteiro é resolvido de maneira análoga à heurística de decomposição.

A tabela 7.10 mostra os resultados computacionais para o modelo integrado (4.1)(4.10). A coluna "fo total" fornece o custo global do modelo integrado, dado pela soma das colunas "fo lote" e "fo corte" que consistem dos custos do PDL e PCE inteiros, respectivamente. A coluna "t"fornece o tempo (em segundos) de resolução de cada exemplo e a coluna "placas" o número total de placas utilizadas no modelo integrado. 


\begin{tabular}{|c|c|c|c|c|c|c|}
\hline \multicolumn{7}{|c|}{ Solução Modelo Integrado (4.1)-(4.10) (SMI) } \\
\hline & Ex & fo total & fo lote & fo corte & $\mathrm{t}(\mathrm{s})$ & placas \\
\hline \multirow{5}{*}{$\begin{array}{c}\text { Demanda } \\
\text { (A) }\end{array}$} & $1(100 \%)$ & 96344.65 & 94928.67 & 1415.97 & 9.20 & 221 \\
\hline & $2(90 \%)$ & 96341.26 & 94928.67 & 1412.58 & 10.08 & 221 \\
\hline & $3(80 \%)$ & 96342.01 & 94928.67 & 1413.33 & 10.34 & 221 \\
\hline & $4(70 \%)$ & 96353.55 & 94928.67 & 1424.87 & 10.16 & 221 \\
\hline & $5(60 \%)$ & infactível & infactível & infactível & - & - \\
\hline \multirow{5}{*}{$\begin{array}{c}\text { Demanda } \\
\text { (B) }\end{array}$} & $6(100 \%)$ & 83586.79 & 82788.85 & 797.94 & 5.13 & 131 \\
\hline & $7(90 \%)$ & 83580.50 & 82788.85 & 791.65 & 5.91 & 131 \\
\hline & $8(80 \%)$ & 83580.50 & 82788.85 & 791.65 & 6.48 & 131 \\
\hline & $9(70 \%)$ & 83586.79 & 82788.85 & 797.94 & 8.53 & 131 \\
\hline & $10(60 \%)$ & 83585.47 & 82788.85 & 796.63 & 9.69 & 131 \\
\hline \multirow{5}{*}{$\begin{array}{c}\text { Demanda } \\
\text { (C) }\end{array}$} & $11(100 \%)$ & 69432.55 & 69259.71 & 172.84 & 4.97 & 41 \\
\hline & $12(90 \%)$ & 69432.55 & 69259.71 & 172.84 & 5.08 & 41 \\
\hline & $13(80 \%)$ & 69432.55 & 69259.71 & 172.84 & 6.88 & 41 \\
\hline & $14(70 \%)$ & 69432.55 & 69259.71 & 172.84 & 7.34 & 41 \\
\hline & $15(60 \%)$ & 69432.55 & 69259.71 & 172.84 & 7.89 & 41 \\
\hline \multirow{5}{*}{$\begin{array}{c}\text { Demanda } \\
\text { (D) }\end{array}$} & $16(100 \%)$ & 129188.81 & 128018.67 & 1170.14 & 5.64 & 234 \\
\hline & $17(90 \%)$ & 129188.81 & 128018.67 & 1170.14 & 5.81 & 234 \\
\hline & $18(80 \%)$ & 129193.12 & 128018.67 & 1174.45 & 5.92 & 234 \\
\hline & $19(70 \%)$ & 129187.05 & 128018.67 & 1168.38 & 7.44 & 234 \\
\hline & $20(60 \%)$ & infactível & infactível & infactível & - & - \\
\hline \multirow{5}{*}{$\begin{array}{c}\text { Demanda } \\
\text { (E) }\end{array}$} & $21(100 \%)$ & 71964.75 & 71187.81 & 776.94 & 7.44 & 113 \\
\hline & $22(90 \%)$ & 71964.75 & 71187.81 & 776.94 & 6.86 & 113 \\
\hline & $23(80 \%)$ & 71967.43 & 71187.81 & 779.62 & 7.78 & 113 \\
\hline & $24(70 \%)$ & 71949.27 & 71187.81 & 761.46 & 10.91 & 110 \\
\hline & $25(60 \%)$ & 71949.27 & 71187.81 & 761.46 & 8.03 & 108 \\
\hline
\end{tabular}

Tabela 7.10: Resultados computacionais para o modelo integrado (4.1)-(4.10).

As tabelas 7.11 e 7.12 mostram a programação da produção para o primeiro período obtida pela resolução do modelo integrado (4.1)-(4.10). 


\begin{tabular}{|c|c|c|c|c|c|c|c|c|c|c|c|c|c|c|c|}
\hline & ex01 & ex02 & ex03 & ex04 & ex05 & ex06 & ex07 & ex08 & ex09 & ex10 & ex11 & ex12 & ex13 & ex14 & ex15 \\
\hline$x_{11}$ & 27 & 27 & 27 & 27 & - & 18 & 18 & 18 & 18 & 18 & 8 & 8 & 8 & 8 & 8 \\
$x_{21}$ & 82 & 82 & 82 & 82 & - & 48 & 48 & 48 & 48 & 48 & 13 & 13 & 13 & 13 & 13 \\
$x_{31}$ & 80 & 80 & 80 & 80 & - & 41 & 41 & 41 & 41 & 41 & 2 & 2 & 2 & 2 & 2 \\
$x_{41}$ & 85 & 85 & 85 & 85 & - & 44 & 44 & 44 & 44 & 44 & 6 & 6 & 6 & 6 & 6 \\
\hline$E_{11}$ & 0 & 0 & 0 & 0 & - & 0 & 0 & 0 & 0 & 0 & 0 & 0 & 0 & 0 & 0 \\
$E_{21}$ & 0 & 0 & 0 & 0 & - & 0 & 0 & 0 & 0 & 0 & 0 & 0 & 0 & 0 & 0 \\
$E_{31}$ & 0 & 0 & 0 & 0 & - & 0 & 0 & 0 & 0 & 0 & 0 & 0 & 0 & 0 & 0 \\
$E_{41}$ & 0 & 0 & 0 & 0 & - & 0 & 0 & 0 & 0 & 0 & 4 & 4 & 4 & 4 & 4 \\
\hline$I_{11}$ & 0 & 0 & 0 & 0 & - & 0 & 0 & 0 & 0 & 0 & 0 & 0 & 0 & 0 & 0 \\
$I_{21}$ & 0 & 0 & 0 & 0 & - & 0 & 0 & 0 & 0 & 0 & 0 & 0 & 0 & 0 & 0 \\
$I_{31}$ & 0 & 0 & 0 & 0 & - & 0 & 0 & 0 & 0 & 0 & 0 & 0 & 0 & 0 & 0 \\
$I_{41}$ & 0 & 0 & 0 & 0 & - & 0 & 0 & 0 & 0 & 0 & 0 & 0 & 0 & 0 & 0 \\
\hline
\end{tabular}

Tabela 7.11: Programação da produção no primeiro período para o modelo integrado (4.1)-(4.10), exemplos 1 a 15.

\begin{tabular}{|c|c|c|c|c|c|c|c|c|c|c|}
\hline & ex16 & ex17 & ex18 & ex19 & ex20 & ex21 & ex22 & ex23 & ex24 & ex25 \\
\hline$x_{11}$ & 55 & 55 & 55 & 55 & - & 16 & 16 & 16 & 16 & 16 \\
$x_{21}$ & 78 & 78 & 78 & 78 & - & 36 & 36 & 36 & 36 & 36 \\
$x_{31}$ & 40 & 40 & 40 & 40 & - & 46 & 46 & 46 & 46 & 46 \\
$x_{41}$ & 90 & 90 & 90 & 90 & - & 35 & 35 & 35 & 35 & 35 \\
\hline$E_{11}$ & 0 & 0 & 0 & 0 & - & 0 & 0 & 0 & 0 & 0 \\
$E_{21}$ & 0 & 0 & 0 & 0 & - & 4 & 4 & 4 & 4 & 4 \\
$E_{31}$ & 0 & 0 & 0 & 0 & - & 0 & 0 & 0 & 0 & 0 \\
$E_{41}$ & 0 & 0 & 0 & 0 & - & 0 & 0 & 0 & 0 & 0 \\
\hline$I_{11}$ & 0 & 0 & 0 & 0 & - & 0 & 0 & 0 & 0 & 0 \\
$I_{21}$ & 0 & 0 & 0 & 0 & - & 0 & 0 & 0 & 0 & 0 \\
$I_{31}$ & 0 & 0 & 0 & 0 & - & 0 & 0 & 0 & 0 & 0 \\
$I_{41}$ & 0 & 0 & 0 & 0 & - & 0 & 0 & 0 & 0 & 0 \\
\hline
\end{tabular}

Tabela 7.12: Programação da produção no primeiro período para o modelo integrado (4.1)-(4.10), exemplos 16 a 25.

As soluções do modelo integrado mostram um pequeno aumento nos custos de produção, quando comparadas com as soluções do PDL fornecidas pela HD01, mas em contrapartida uma considerável redução nos custos de perda de material. Podemos notar que o modelo decide não produzir a demanda extra " $E_{i t}$ " para o primeiro período, mesmo com capacidades folgadas. Isto indica que os custos de estocagem ainda são altos quando comparados com os custos devido às perdas. O decisor deve ajustar estes parâmetros e analisar as soluções obtidas.

Para as demandas do tipo A e D que são relativamente altas, um aperto de $60 \%$ nas capacidades de serra e de furadeira nos subperíodos torna o problema infactível, mostrando que nesses exemplos a capacidade do primeiro período é apertada, no limite de atender a 
demanda em carteira.

\subsection{Resultados da Relaxação Lagrangiana}

A resolução do modelo integrado por relaxação lagrangiana foi feita como descrito no capítulo 6. A restrição (4.4) que integra os problemas de dimensionamento de lotes e corte de estoque foi dualizada e os multiplicadores lagrangianos atualizados pelo método do subgradiente. De maneira simplificada a resolução deste modelo é feita da seguinte forma:

1. O subproblema 1 que representa o PDL é resolvido em dois passos e fornece uma solução inteira. Primeiramente, o problema primal (6.7) é resolvido heuristicamente usando o problema dual e o auxílio das folgas complementares. Em seguida, depois de obtida a solução primal, as restrições de capacidade de serra e de furadeira em (6.17) são verificadas e caso sejam violadas, aplicamos uma heurística de transferência da produção entre períodos na tentativa de obter uma solução factível. Observamos que duas restrições para o primeiro período foram acrescentadas, referentes aos limites de capacidade de serra e furadeira, sendo que as capacidades nesse período foram dadas como em $t=2,3,4$.

2. Para a resolução do subproblema 2 que representa o PCE, dado em (6.24), a restrição de acoplamento (4.4) é adicionada ao modelo, levando a informação de peças necessárias para compor os produtos finais no período 1. O problema relaxado resultante dado em (6.26) é resolvido pelo método simplex com geração de colunas (Cplex10). Os multiplicadores lagrangianos são atualizados pelo método do subgradiente e o PCE inteiro é resolvido de maneira análoga à heurística de decomposição, isto é, assim que $y_{p}^{a}<\epsilon, \forall p$ ( $\epsilon$ suficientemente pequeno), uma solução factível para a relaxação linear do PCE é obtida e as colunas geradas durante o processo são usadas na resolução do problema de corte inteiro.

A tabela 7.13 mostra os resultados computacionais deste método de solução para o modelo integrado (4.1)-(4.10). A coluna "fo total"é a solução inteira obtida pelo método proposto, dada pela soma dos custos obtidos nos subproblemas 1 e 2, dados nas colunas "fo lote"e "fo corte", respectivamente. A coluna "Gap"é dada pela diferença entre a "fo 
total" da solução lagrangiana e da solução do modelo integrado, ou seja:

$$
\frac{\text { fo total }(S L)-\text { fo } \operatorname{total}(S M I)}{\text { fo total }(S M I)} * 100 \%
$$

\begin{tabular}{|c|c|c|c|c|c|c|c|c|}
\hline \multicolumn{9}{|c|}{ Solução Lagrangiana (SL) } \\
\hline & Ex & fo total & fo lote & fo corte & $\mathrm{t}(\mathrm{s})$ & ite & placas & $\operatorname{Gap}(\%)$ \\
\hline \multirow{5}{*}{$\begin{array}{c}\text { Demanda } \\
\text { (A) }\end{array}$} & $1(100 \%)$ & 96415.26 & 94535.59 & 1879.67 & 33.83 & 1 & 356 & 0.07 \\
\hline & $2(90 \%)$ & 96621.56 & 94720.89 & 1900.67 & 83.61 & 3 & 294 & 0.29 \\
\hline & $3(80 \%)$ & 96771.91 & 94914.49 & 1857.41 & 57.06 & 2 & 234 & 0.45 \\
\hline & $4(70 \%)$ & 96777.04 & 94914.49 & 1862.55 & 54.38 & 2 & 238 & 0.44 \\
\hline & $5(60 \%)$ & infactível & 94928.67 & infactível & - & 100 & - & - \\
\hline \multirow{5}{*}{$\begin{array}{c}\text { Demanda } \\
\text { (B) }\end{array}$} & $6(100 \%)$ & 83869.90 & 82331.14 & 1538.76 & 22.81 & 1 & 347 & 0.34 \\
\hline & $7(90 \%)$ & 84421.10 & 82386.55 & 2034.55 & 55.72 & 2 & 264 & 1.01 \\
\hline & $8(80 \%)$ & 83850.32 & 82774.67 & 1075.66 & 39.59 & 2 & 142 & 0.32 \\
\hline & $9(70 \%)$ & 83859.18 & 82774.67 & 1084.51 & 57.25 & 2 & 144 & 0.33 \\
\hline & $10(60 \%)$ & 83634.73 & 82774.67 & 860.06 & 57.11 & 2 & 142 & 0.06 \\
\hline \multirow{5}{*}{$\begin{array}{c}\text { Demanda } \\
\text { (C) }\end{array}$} & $11(100 \%)$ & 70185.65 & 68715.96 & 1469.69 & 25.16 & 1 & 297 & 1.08 \\
\hline & $12(90 \%)$ & 70193.43 & 68715.96 & 1477.46 & 23.78 & 1 & 298 & 1.09 \\
\hline & $13(80 \%)$ & 70243.04 & 68859.31 & 1383.74 & 47.81 & 2 & 166 & 1.17 \\
\hline & $14(70 \%)$ & 69475.71 & 69247.42 & 228.30 & 49.16 & 2 & 47 & 0.06 \\
\hline & $15(60 \%)$ & 69504.96 & 69247.42 & 257.54 & 46.20 & 2 & 45 & 0.10 \\
\hline \multirow{5}{*}{$\begin{array}{c}\text { Demanda } \\
\text { (D) }\end{array}$} & $16(100 \%)$ & 129240.81 & 127689.16 & 1551.64 & 27.11 & 1 & 347 & 0.04 \\
\hline & $17(90 \%)$ & 129629.12 & 128018.67 & 1610.45 & 58.78 & 3 & 244 & 0.34 \\
\hline & $18(80 \%)$ & 129712.68 & 128004.49 & 1708.19 & 38.19 & 2 & 250 & 0.40 \\
\hline & $19(70 \%)$ & 129714.04 & 128004.49 & 1709.55 & 36.34 & 2 & 253 & 0.41 \\
\hline & $20(60 \%)$ & infactível & 128018.67 & infactível & - & - & - & - \\
\hline \multirow{5}{*}{$\begin{array}{c}\text { Demanda } \\
\text { (E) }\end{array}$} & $21(100 \%)$ & 73048.09 & 70668.64 & 2379.45 & 28.73 & 1 & 369 & 1.50 \\
\hline & $22(90 \%)$ & 72604.09 & 70801.21 & 1802.88 & 48.16 & 2 & 240 & 0.89 \\
\hline & $23(80 \%)$ & 72776.72 & 70806.30 & 1970.42 & 38.61 & 2 & 236 & 1.12 \\
\hline & $24(70 \%)$ & 72119.10 & 71194.41 & 924.69 & 62.11 & 2 & 115 & 0.24 \\
\hline & $25(60 \%)$ & 72108.69 & 71194.41 & 914.29 & 43.69 & 2 & 116 & 0.22 \\
\hline
\end{tabular}

Tabela 7.13: Resultados computacionais para a relaxação lagrangiana (6.1).

As tabelas 7.14 e 7.15 apresentam a programação da produção para o primeiro período. 


\begin{tabular}{|c|c|c|c|c|c|c|c|c|c|c|c|c|c|c|c|}
\hline & ex01 & ex02 & ex03 & ex04 & ex05 & ex06 & ex07 & ex08 & ex09 & ex10 & ex11 & ex12 & ex13 & ex14 & ex15 \\
\hline$x_{11}$ & 67 & 27 & 27 & 27 & 27 & 58 & 58 & 18 & 18 & 18 & 79 & 79 & 48 & 8 & 8 \\
$x_{21}$ & 126 & 122 & 82 & 82 & 82 & 144 & 88 & 48 & 48 & 48 & 91 & 91 & 53 & 13 & 13 \\
$x_{31}$ & 80 & 80 & 80 & 80 & 80 & 41 & 41 & 41 & 41 & 41 & 55 & 55 & 2 & 2 & 2 \\
$x_{41}$ & 85 & 85 & 115 & 115 & 85 & 44 & 74 & 74 & 74 & 74 & 32 & 32 & 32 & 32 & 32 \\
\hline$E_{11}$ & 40 & 0 & 0 & 0 & 0 & 40 & 40 & 0 & 0 & 0 & 40 & 40 & 40 & 0 & 0 \\
$E_{21}$ & 40 & 40 & 0 & 0 & 0 & 40 & 40 & 0 & 0 & 0 & 40 & 40 & 40 & 0 & 0 \\
$E_{31}$ & 0 & 0 & 0 & 0 & 0 & 0 & 0 & 0 & 0 & 0 & 50 & 50 & 0 & 0 & 0 \\
$E_{41}$ & 0 & 0 & 30 & 30 & 0 & 0 & 30 & 30 & 30 & 30 & 30 & 30 & 30 & 30 & 30 \\
\hline$I_{11}$ & 0 & 0 & 0 & 0 & 0 & 0 & 0 & 0 & 0 & 0 & 31 & 31 & 0 & 0 & 0 \\
$I_{21}$ & 4 & 0 & 0 & 0 & 0 & 56 & 0 & 0 & 0 & 0 & 38 & 38 & 0 & 0 & 0 \\
$I_{31}$ & 0 & 0 & 0 & 0 & 0 & 0 & 0 & 0 & 0 & 0 & 3 & 3 & 0 & 0 & 0 \\
$I_{41}$ & 0 & 0 & 0 & 0 & 0 & 0 & 0 & 0 & 0 & 0 & 0 & 0 & 0 & 0 & 0 \\
\hline
\end{tabular}

Tabela 7.14: Programação da produção no primeiro período para a relaxação lagrangiana (6.1), exemplos 1 a 15.

\begin{tabular}{|c|c|c|c|c|c|c|c|c|c|c|}
\hline & ex16 & ex17 & ex18 & ex19 & ex20 & ex21 & ex22 & ex23 & ex24 & ex25 \\
\hline$x_{11}$ & 82 & 55 & 55 & 55 & 55 & 96 & 56 & 56 & 16 & 16 \\
$x_{21}$ & 118 & 78 & 78 & 78 & 78 & 84 & 72 & 72 & 32 & 32 \\
$x_{31}$ & 40 & 40 & 40 & 40 & 40 & 139 & 46 & 46 & 46 & 46 \\
$x_{41}$ & 90 & 90 & 120 & 120 & 90 & 110 & 110 & 65 & 65 & 65 \\
\hline$E_{11}$ & 27 & 0 & 0 & 0 & 0 & 40 & 40 & 40 & 0 & 0 \\
$E_{21}$ & 40 & 0 & 0 & 0 & 0 & 40 & 40 & 40 & 0 & 0 \\
$E_{31}$ & 0 & 0 & 0 & 0 & 0 & 50 & 0 & 0 & 0 & 0 \\
$E_{41}$ & 0 & 0 & 30 & 30 & 0 & 30 & 30 & 30 & 30 & 30 \\
\hline$I_{11}$ & 0 & 0 & 0 & 0 & 0 & 40 & 0 & 0 & 0 & 0 \\
$I_{21}$ & 0 & 0 & 0 & 0 & 0 & 12 & 0 & 0 & 0 & 0 \\
$I_{31}$ & 0 & 0 & 0 & 0 & 0 & 43 & 0 & 0 & 0 & 0 \\
$I_{41}$ & 0 & 0 & 0 & 0 & 0 & 45 & 45 & 0 & 0 & 0 \\
\hline
\end{tabular}

Tabela 7.15: Programação da produção no primeiro período para a relaxação lagrangiana (6.1), exemplos 16 a 25.

Observamos que em grande parte dos exemplos a variável "oportunista" $E_{i 1}$ faz com que o modelo decida produzir parte da demanda extra no primeiro período, para produtos que forem mais convenientes a serem combinados.

Observe no exemplo 1 que com o aumento da produção no primeiro período, o número de placas cortadas cresceu de 221 em relação à solução integrada para 356, ou seja, $62 \%$ para uma produção maior. Contudo, o custo devido às perdas em relação à solução integrada cresceu de $\mathrm{R} \$ 1415,97$ para $\mathrm{R} \$ 1879,67$, ou seja, $33 \%$. Note que o custo devido às perdas na solução lagrangiana não cresceu proporcionalmente ao número de placas utilizadas, pois neste caso um aumento de $62 \%$ forneceria o custo de $\mathrm{R} \$ 2293,87$ no processo de corte. Analisando portanto, o custo médio devido à perda de material por 
placa, a solução integrada apresentou em média $\mathrm{R} \$ 6,41\left(\frac{R \$ 1415,97}{221}\right)$, enquanto o custo médio na solução da relaxação lagrangiana foi de $\mathrm{R} \$ 5,28\left(\frac{R \$ 1879,67}{356}\right)$. Isto mostra que a antecipação da produção fez reduzir o custo médio de perda por placa, uma redução de aproximadamente 18\%. Essa redução do custo médio de perda por placa ocorreu em $35 \%$ dos exemplos.

Os tempos de resolução dos exemplos são altos se comparados com os tempos referentes à resolução do modelo integrado e da heurística de decomposição. A melhoria da implementação é tópico para futuras investigações.

Podemos ver que em termos de proximidade com a solução do modelo integrado, a solução lagrangiana está em torno de $1 \%$ para os exemplos testados. 


\section{Capítulo 8}

\section{Conclusões e Passos Futuros}

Neste trabalho abordamos um importante problema de planejamento e programação da produção que surge comumente em indústrias de manufatura. Nas indústrias de móveis, em particular, surgem dois importantes problemas de otimização, muito estudados na literatura, o problema de dimensionamento de lotes (PDL) e o problema de corte de estoque (PCE).

O PDL consiste em determinar um plano de produção de custo mínimo, de forma a atender uma certa demanda e satisfazer os limites de capacidades da produção, e o PCE consiste em otimizar o processo de corte da matéria-prima (neste caso placas de madeira), em peças menores em quantidades e dimensões demandadas para compor os produtos finais, que são os móveis solicitados pelos clientes. Tipicamente, estes problemas são tratados separadamente na prática. Inicialmente o PDL é resolvido, determinando a programação da produção para cada período do horizonte de planejamento, em seguida é determinada a demanda de peças a serem cortadas e os melhores padrões de corte são então gerados. Porém, esse processo pode elevar os custos globais e gerar infactibilidades na produção, de modo que ajustes na programação da produção devem ser feitos por um gerente experiente.

Focalizamos neste trabalho a tendência atual de tratar esses problemas de forma integrada, ou seja, tratamos os problemas de dimensionamento de lotes (PDL) e corte de estoque (PCE) de forma integrada, de maneira a obter uma solução que equilibre e minimize os custos envolvidos nos dois problemas. Apresentamos um modelo matemático inteiro, que integra as decisões de produção e estoque com as decisões do processo de corte. Este modelo apresenta várias dificuldades, principalmente devido à integralidade de suas variáveis. Uma abordagem também utilizada é a técnica de horizonte de planejamento 
rolante, muito utilizada na prática para trabalhar com alterações de demandas dentro do horizonte de planejamento.

Enfatizamos a resolução do modelo integrado (4.1)-(4.10) pela relaxação lagrangiana, em que a restrição (4.4) que integra o PDL e o PCE foi dualizada. Essa relaxação decompõe o modelo em dois subproblemas, um no grupo das variáveis de produção e outro no grupo das variáveis de corte. A resolução destes subproblemas foi apresentada no capítulo 6.

A HD02 relaxa as capacidades de serra e furadeira no PDL, o que causa antecipação da produção para o $1^{\circ}$ período, porém ao converter a demanda de produtos finais em demanda de peças, os limites de capacidades nos subperídos do PCE são excedidos. Observamos assim, que as capacidades para o $1^{\circ}$ período devem ser compatíveis com as capacidades detalhadas nos subperíodos, pois como visto, o problema de dimensionamento de lotes com o primeiro período relaxado (HD02) leva a infactibilidades no problema de corte.

Os testes computacionais mostraram que até o momento a resolução do modelo integrado (seção 7.3) apresentou os melhores resultados. Nos exemplares 5 e 20 a solução é infactível, devido a uma demanda alta e aperto nos limites de capacidade em relação ao primeiro período. Comparando a coluna "fo corte" observamos que os custos no processo de corte são consideravelmente reduzidos, em relação à HD01 mostrando a importância de tomar as decisões de produção e corte de forma integrada.

A coluna "fo total" que representa os custos globais fornecidos pela solução lagrangiana, mostra uma pequena melhora em relação aos custos globais da heurística de decomposição 01. Como ocorreu com a solução integrada, os exemplares 5 e 20 apresentaram soluções infactíveis. Os tempos de resolução ainda são altos e a implementação requer revisão. Mesmo os resultados da solução integrada sendo superiores aos outros procedimentos testados, a proximidade da solução lagrangiana da solução integrada está razoável, em torno de $1 \%$.

Adotamos a resolução heurística do subproblema 1 pelo fato de fornecer uma solução rápida e não necessitar o uso do pacote Cplex10 (apesar de utilizá-lo para resolução do problema de corte, mas em trabalhos futuros pode ser substituído facilmente). Contudo, um aspecto relevante a ser insvestigado é o impacto de se obter uma solução ótima para o subproblema 1. Seria conveniente incluir ou não as restrições referentes às capacidades de serra e de furadeira no primeiro período (que aparecem somente no problema de corte) e como determinar esses limites? Essas questões indicam que a solução heurística do subproblema 1 merece investigação e melhoramentos. 
Vemos pela coluna "ite" da solução lagrangiana que aparentemente o método do subgradiente tem uma convergência precoce, fornecendo soluções próximas às da HD01. Isto indica a necessidade de uma revisão mais criteriosa na teoria da relaxação lagrangiana, em particular no método do subgradiente, revendo parâmetros tais como o tamanho do passo, visando corrigir problemas de convergência e melhoramento da solução.

Podemos considerar portanto, esses resultados como preliminares, pois ainda é necessário revisar esses dois aspectos citados anteriormente, os quais são sugeridos como trabalhos futuros.

Os padrões de corte utilizados neste trabalho foram padrões de corte guilhotinados 2estágios e outros como padrões tabuleiro e variações podem ser usados (Figueiredo (2006)). Neste trabalho consideramos somente a minimização da perda no processo de corte, mas também outra sugestão poderia ser considerar a minimização dos custos de preparação para a troca de diferentes padrões de corte.

Em resumo, a contribuição desta dissertação foi resolver os problemas de dimensionamento de lotes e corte de estoque que surgem nos processos produtivos das indústria de móveis, porém tratando-os de forma integrada. Esse procedimento, ao contrário da resolução do PDL e PCE separadamente, permite uma troca de informações entre estes modelos, tomando uma decisão conjunta na minimização dos custos globais. Mesmo com testes ainda preliminares, a investigação em alguns parâmetros na solução lagrangiana pode melhorar os resultados e fornecer soluções de boa qualidade para o modelo integrado original. 


\section{Apêndice A}

\section{Relações Primais-Duais em}

\section{Otimização Linear}

Consideremos o problema primal e o seu dual, bem como seus respectivos conjuntos de soluções factíveis dados por (Arenales et al. (2007)):

$$
\begin{array}{cc}
\text { Minimizar } f(x)=c^{T} x & \text { Maximizar } g(\lambda)=c^{T} \lambda \\
\text { s.a }\{A x=b, x \geq 0 & \text { s.a }\left\{A^{T} \lambda \leq c\right.
\end{array}
$$

em que $P=\left\{x \in R^{n}\right.$ tal que $\left.A x=b, x \geq 0\right\}$ e $D=\left\{\lambda \in R^{m}\right.$ tal que $\left.A^{T} \lambda \leq c\right\}$ são os conjuntos de soluções factíveis para o problema primal e dual, respectivamente, e as matrizes $A, b, c, x$ e $\lambda$ são matrizes de dimensões apropriadas para as operações.

A propriedade seguinte fornece uma condição de otimalidade para as soluções primais e duais.

Propriedade A.0.1 Sejam $x^{*} \in P$ uma solução factível primal e $\lambda^{*} \in D$ uma solução factível dual. $x^{*}$ e $\lambda^{*}$ são soluções ótimas primal e dual, respectivamente, se, e somente se, $f\left(x^{*}\right)=g\left(\lambda^{*}\right)$.

Uma relação importante entre soluções ótimas primais e duais é chamada de folgas complementares e é dada pelo próximo teorema:

Propriedade A.0.2 As soluções $x \in R^{n}$ e $\lambda \in R^{m}$ são soluções ótimas primais e duais respectivamente, se e somente se,

$$
\left\{\begin{array}{ccc}
A x=b, & x \geq 0 & (x \text { é factivel primal }) \\
A^{T} \lambda+\mu=c, \quad \mu \geq 0 & (\lambda \text { é factivel dual }) \\
\mu^{T} x=0, & & (\text { folgas complementares })
\end{array}\right.
$$




\section{Bibliografia}

Araujo, S. A. (1999). Estudos de problemas de dimenionamento de lotes monoestágio com restrição de capacidade. Tese de mestrado, ICMC - USP.

Araujo, S. A. \& Arenales, M. N. (2000). Problema de dimensionamento de lotes monoestágio com restrição de capacidade: Modelagem de resolução e resultados computacionais. Pesquisa Operacional, 20(2), 455-464.

Arenales, M. N., Morabito, R. \& Yanasse, H. (2004). Problemas de Corte e Empacotamento. Livro-texto de Mini curso, XXXVI SBPO - Simpósio Brasileiro de Pesquisa Operacional, São João Del Rei - MG.

Arenales, M. N., Armentano, V. A., Morabito, R. \& Yanasse, H. (2007). Pesquisa Operacional. Ed. Campus.

Bahl, H. C., Ritzman, L. P. \& Gupta, J. N. D. (1987). Determining lot sizes and resources requirements: a review. Operations Research, 35(3), 329-345.

Billington, P. J., McClain, J. O. \& Thomas, L. J. (1983). Mathematical programming approaches to capacity mrp systems: Review, formulation and problem reduction. Management Science, 29(10), 1126-1141.

Brahimi, N., Dauzere-Peres, S., Najid, N. \& Nordli, A. (2006). Single item lot sizing problems. European Journal of Operational Research, 168, 1-16.

Evans, J. R. (1985). An efficient implementation of the Wagner-Whitin algorithm for dynamic lot-sizing. Journal of Operations Mangament, 5(2), 229-235.

Figueiredo, A. G. (2006). Análise de produtividade de padrões de corte na indústria de móveis. Tese de mestrado, IBILCE - UNESP.

Fisher, M. (1981). The lagrangian relaxation method for solving integer programming problems. Management Science, 27, 1-18. 
Florentino, H. O. (1990). Relaxação Lagrangeana em programação inteira. Tese de mestrado, ICMC - USP.

Geoffrion, A. (1974). Lagrangian relaxation of integer programming. Mathematical Programming Study, 2, 82-114.

Gilmore, P. C. \& Gomory, R. E. (1961). A linear programming approach to the cutting stock problem. Operations Research, 9, 848-859.

Gilmore, P. C. \& Gomory, R. E. (1963). A linear programming approach to the cutting stock problem - part ii. Operations Research, 11, 863-888.

Gilmore, P. C. \& Gomory, R. E. (1965). Multi-stage cutting stock problems of two and more dimensions. Operations Research, 13, 94-120.

Gramani, M. (2001). Otimização do processo de cortagem acoplado ao planejamento da produção. Tese de doutorado, DENSIS-UNICAMP.

Gramani, M. \& França, P. M. (2006). The combined cutting stock and lot-sizing problem in industrial processo. European Journal of Operational Research, 174, 509-521.

Haessler, R. (1971). A heuristic programming solution to a nonlinear cutting stock problem. Management Science, 17, 793-802.

Held, M. \& Karp, R. (1970). The traveling salesman problem and minimum spanning trees. Operations Research, 18, 1138-1162.

Held, M. \& Karp, R. (1971). The traveling salesman problem and minimum spanning trees: Parte ii. Mathematical Programming, 1, 6-25.

Held, M., Wolfe, P. \& Crowder, H. (1974). Validation of subgradient optimization. Mathematical Programming, 6, 62-68.

Hendry, L., Fok, K. \& Shek, K. (1996). A cutting stock scheduling problem in the copper industry. Operational Research Society, 47, 38-47.

Justina, M. (2004). Restrições e estratégias na determinação do preço no mercado moveleiro de São Bento do Sul (SC). Tese de doutorado, UFSC.

Karimi, B., Fatemi Ghomi, S. \& Wilson, J. (2003). The capacitated lot sizing problem: a review of models and algorithms. OMEGA, 31, 365-378. 
Maes, J., McClain, J. O. \& Van Wassenhove, L. N. (1991). Multilevel capacitated lotsizing complexity and lp based heuristic. European Journal of Operational Research, 53, 131148.

Morabito, R. (1992). Uma abordagem em grafo-e-ou para o problema de empacotamento: Aplicação ao carregamento de paletes e contêineres. Tese de doutorado, EESC-USP.

Morabito, R. \& Arenales, M. (1995). Performance of two heuristics for solving large scale two-dimensional guillotine cutting problems. INFOR, 33(2), 145-155.

Morabito, R. \& Arenales, M. (1996). Staged and constrained two-dimensional guillotine cutting problems - an and/or-graph approach. European Journal of Operational Research, 94, 548-560.

Nonas, S. \& Thorstenson, A. (2000). A combined cutting-stock and lot-sizing problem. European Journal of Operational Research, 120, 327-342.

Nonas, S. \& Thorstenson, A. (2007). Solving a combined cutting-stock and lot-sizing problem with a column generating procedure. Computers and Operations Research, doi:10.1016/j.cor.2007.03.005, 1-22.

Poldi, K. C. (2003). Algumas extensões do problema de corte de estoque. Tese de mestrado, ICMC - USP.

Poltroniere, S., Poldi, K., Arenales, M. \& Toledo, F. (2007). A coupling cutting stock-lot sizing problem in the paper industry. Operations Research, 157, 91-104.

Reinders, M. (1992). Cutting stock optimization and integral production planning for centralized wood processing. Mathematical Computer Modeling, 16, 37-55.

Santos, M. O. (1996). Dimensionamento de lotes multiestágios com restrições de capacidade: um novo modelo e proposta de solução. Tese de mestrado, ICMC-USP.

Santos, M. O. (2000). Problemas de dimensionamento de lotes: Modelos e Métodos. Tese de doutorado, ICMC-USP.

Silva, C., Alem, D. \& Arenales, M. N. (2007). A combined cutting stock and lot-sizing problem in the small furniture industry. In: International Conference on Operation Research for Development - Anais do ICORD VI. 
Trigeiro, W. W., J., T. L. \& O., M. J. (1989). Capacitated lot sizing with setup times. Management Science, 35(3), 353-366.

Vianna, A. (2000). Problemas de corte e empacotamento: uma abordagem em grafo E/OU. Tese de doutorado, ICMC-USP.

Wagner, H. M. \& Whitin, T. M. (1958). Dynamic version of the economic lot size model. Management Science, 5(1), 89-96.

Wascher, G. \& Gau, T. (1996). Heuristics for the integer one-dimensional cutting stock problem: a computational study. OR Spektrum, 18, 131-144. 